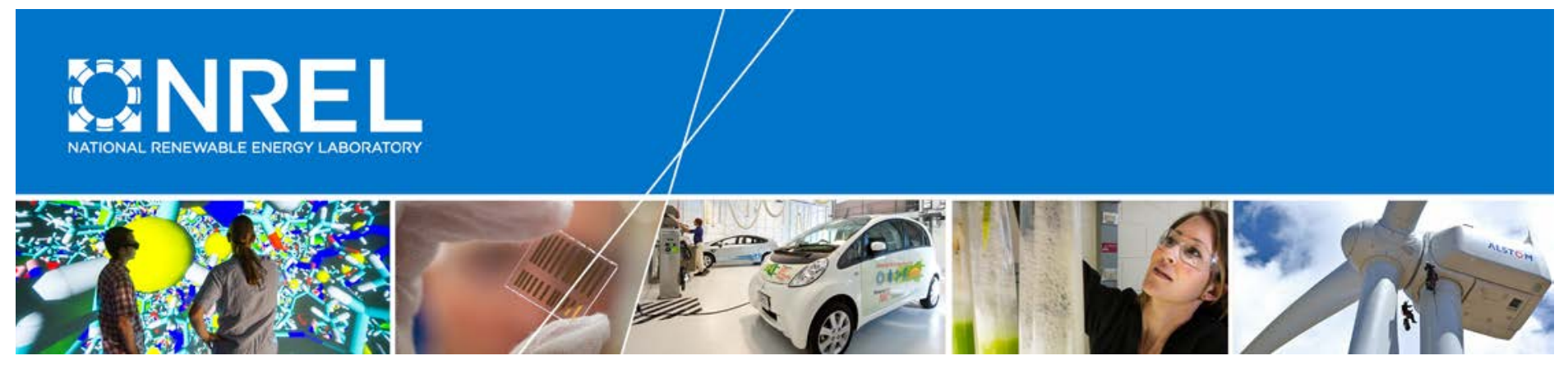

\title{
Renewable Energy Deployment in Colorado and the West: Extended Policy Sensitivities
}

Clayton Barrows, Brady Stoll, and Meghan Mooney National Renewable Energy Laboratory

\section{NATIONAL SYSTEM OF PUBLIC LANDS}

U.S. DEPARTMENT OF THE INTERIOR BUREAU OF LAND MANAGEMENT

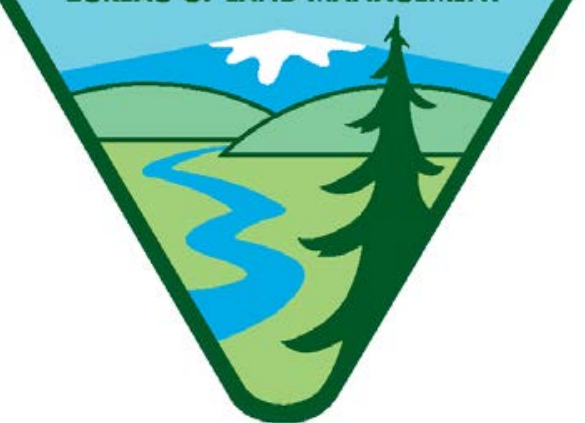

NREL is a national laboratory of the U.S. Department of Energy Office of Energy Efficiency \& Renewable Energy Operated by the Alliance for Sustainable Energy, LLC

This report is available at no cost from the National Renewable Energy Laboratory (NREL) at www.nrel.gov/publications.

Technical Report

NREL/TP-6A20-68662

October 2017 


\section{Renewable Energy Deployment in Colorado and the West: Extended Policy Sensitivities}

Clayton Barrows, Brady Stoll, and Meghan Mooney

National Renewable Energy Laboratory

Prepared under Task No. WFGN.1001

NREL is a national laboratory of the U.S. Department of Energy Office of Energy Efficiency \& Renewable Energy Operated by the Alliance for Sustainable Energy, LLC

This report is available at no cost from the National Renewable Energy Laboratory (NREL) at www.nrel.gov/publications.

National Renewable Energy Laboratory 15013 Denver West Parkway Golden, CO 80401

303-275-3000 • www.nrel.gov

\section{Technical Report}

NREL/TP-6A20-68662

October 2017

Contract No. DE-AC36-08GO28308 


\section{NOTICE}

This report was prepared as an account of work sponsored by an agency of the United States government. Neither the United States government nor any agency thereof, nor any of their employees, makes any warranty, express or implied, or assumes any legal liability or responsibility for the accuracy, completeness, or usefulness of any information, apparatus, product, or process disclosed, or represents that its use would not infringe privately owned rights. Reference herein to any specific commercial product, process, or service by trade name, trademark, manufacturer, or otherwise does not necessarily constitute or imply its endorsement, recommendation, or favoring by the United States government or any agency thereof. The views and opinions of authors expressed herein do not necessarily state or reflect those of the United States government or any agency thereof.

This report is available at no cost from the National Renewable Energy Laboratory (NREL) at www.nrel.gov/publications.

Available electronically at SciTech Connect http:/www.osti.gov/scitech

Available for a processing fee to U.S. Department of Energy and its contractors, in paper, from:

U.S. Department of Energy

Office of Scientific and Technical Information

P.O. Box 62

Oak Ridge, TN 37831-0062

OSTI http://www.osti.gov

Phone: 865.576.8401

Fax: 865.576.5728

Email: reports@osti.gov

Available for sale to the public, in paper, from:

U.S. Department of Commerce

National Technical Information Service

5301 Shawnee Road

Alexandria, VA 22312

NTIS http://www.ntis.gov

Phone: 800.553 .6847 or 703.605 .6000

Fax: 703.605.6900

Email: orders@ntis.gov 


\section{Acknowledgments}

For their valuable contributions, the authors would like to thank Nancy Keohane and Joe Vieira from the Colorado BLM, and Trieu Mai, David Beilen, and Daniel Steinberg from the National Renewable Energy Laboratory for their valuable input and comments in the completion of this report. The authors would also like to thank ABB for permission to include GIS layers from "The Velocity Suite" in the maps displayed in this report. 


\section{List of Acronyms}

$\begin{array}{ll}\text { AEO } & \text { Annual Energy Outlook } \\ \text { BA } & \text { balancing area } \\ \text { BLM } & \text { U.S. Bureau of Land Management } \\ \text { CSP } & \text { Concentrating Solar Power } \\ \text { CPP } & \text { U.S. EPA's Clean Power Plan } \\ \text { DOE } & \text { U.S. Department of Energy } \\ \text { EPA } & \text { Environmental Protection Agency } \\ \text { ECRMP } & \text { BLM Eastern Colorado Resource Management Plan } \\ \text { ERC } & \text { Emissions Rate Credit } \\ \text { GAMS } & \text { General Algebraic Modeling System } \\ \text { GIS } & \text { Geographic Information System } \\ \text { NERC } & \text { North American Electric Reliability Corporation } \\ \text { NG } & \text { natural gas } \\ \text { NREL } & \text { National Renewable Energy Laboratory } \\ \text { PSCO } & \text { Public Service Company of Colorado } \\ \text { PV } & \text { photovoltaic } \\ \text { RGFO } & \text { Royal Gorge Field Office } \\ \text { RMP } & \text { Resource Management Plan } \\ \text { RPM } & \text { Resource Planning Model } \\ \text { RPS } & \text { Renewable Portfolio Standard } \\ \text { TEPPC } & \text { Transmission Expansion Planning Policy } \\ \text { TES } & \text { Committee } \\ \text { VG } & \text { Thermal Energy Storage } \\ \text { WACM } & \text { variable generation } \\ \text { WECC } & \text { Western Area Power Administration, Colorado, and } \\ \text { WWSIS } & \text { Missouri BA } \\ & \text { Western Electricity Coordinating Council } \\ \text { NREL Western Wind and Solar Integration Study }\end{array}$




\section{Glossary}

Alternating Current (AC)

Balancing Area

Balancing Authority

Boundary interactions

Buses

Capacity

Capacity Credit

Capacity Expansion Model

Clean Power Plan

Combined Cycle (CC, NG-CC)

Combustion Turbine (CT, NG-CT)

Curtailment

Cycling

Direct Current (DC)

Dispatch modeling

Electrical buses

Electric infrastructure

Electric network

Fixed tilt photovoltaic
The standard for electricity transmission, where the flow of electric charge periodically reverses direction

Regional grouping of generators, loads and transmission lines whereby aggregate generation and load are balanced (also referred to as Balancing Authority Area)

Responsible party for balancing load and generation within a balancing area

see Interregional Flows

see Electrical Buses

The maximum generating capability of a generating unit

The fraction of a generating unit's nameplate capacity counted towards meeting system reliability reserves

Computational tool used to simulate electric system deployment

The U.S. EPA's regulation that limits $\mathrm{CO}_{2}$ emissions from electric power generating facilities.

A power plant where a combustion turbine and steam turbine are combined and fueled by natural gas

A natural gas fired power plant driven by an internal combustion engine with an upstream rotating compressor and a downstream turbine

Unused energy, usually from variable generation sources

An electrical generator's transition between online and offline status

The unidirectional flow of electric charge. Direct current is produced by photovoltaic and battery devices

see Operations Modeling

Electric network node, representing transmission line connections, generator connection point, or substation

Physical electric system components (transmission lines, generators, transformers, substations, etc.)

The electric grid, composed of transmission lines, transformers, and substations that transport electricity between generators and loads

Solar photovoltaic generators mounted on a tilted, non-tracking structure 
GIS analysis

Grid

Load

Megawatt (MW)

Operating reserve requirements

Operational constraints

Operations modeling

Photovoltaic (PV)

Power system

Reliability (electric)

Renewable capacity expansions

Renewable generation

Renewable resources

Renewable interconnection cost

Single-axis tracking photovoltaic

Transmission congestion

Utility service territory

Utility-scale generation

Variable generation
Geographic Information System analysis to enhance location-based result description

see Electric Network

Electricity demand

The standard unit of measure of power (e.g., for a power plant output)

Generation scheduling requirements to maintain reliable system operations

Constraints that govern electric system operation (e.g., generator and transmission line operating parameters, security constraints, physical laws)

Simulation of generator scheduling for hourly operation to maintain balanced generation and load and system reliability

Semiconductor-based technology that converts solar energy into electricity

The system, comprised of electrical infrastructure components, that serves to convert and deliver energy in the form of electrical power

The ability of the electric system to continue uninterrupted service

Renewable generation capacity deployment

Electricity generation from resources that are naturally replenished on human timescales

The location-dependent energy resources that could potentially be utilized to generate electricity through renewable generation technologies

The cost associated with connecting a renewable generating facility with existing infrastructure (based on distance between renewable generation site and interconnection bus)

Solar photovoltaic generators mounted on a structure that rotates along one axis designed to track the daily relative motion of the sun and the earth

The inability of the electrical grid to facilitate additional electricity transmission due to transmission line flow limits

The load buses served by an electrical utility or load serving entity

Ground mounted generation connected directly to the electrical transmission system (not connected through a distribution feeder).

Electrical generation that depends upon variable energy sources (e.g. wind and solar generation) 
Western Electric Coordinating Council WECC - the regional entity that exists to assure a reliable electric system for the Western

Interconnection power system 


\section{Executive Summary}

Future renewable power plant development in Colorado will be determined by a combination of market and policy demands, including the economic competitiveness of renewable technologies relative to other generation options, such as natural gas. Renewable development, in particular, is dependent upon the availability and quality of local energy resources and their relative location to transmission infrastructure or areas with high electricity consumption. An informed outlook of the future electricity system in Colorado requires detailed considerations of these dynamics. Such an outlook can be useful for utility and land planners in assessing investment and policy decisions over various time horizons.

The Royal Gorge Field Office of the U.S. Department of Interior's Bureau of Land Management (BLM) commissioned the National Renewable Energy Laboratory (NREL) to conduct an assessment of potential trends in future renewable energy technology development within the state of Colorado to help the BLM and the general public understand the locations of potential solar and wind energy developments over a 15-year horizon in Colorado. The analysis uses a combination of electric system capacity expansion modeling and geographic information system (GIS) tools to assess these potentials and is intended to help inform the BLM during the multiyear development of a new Eastern Colorado Resource Management Plan (ECRMP). ${ }^{1}$ Our results highlight trends in Colorado that will help BLM identify areas to consider for renewable energy development allocations in resource management plans. Two sets of analysis have been conducted to capture the sensitivity of renewable energy development trends to several uncertain inputs. The first analysis is presented in a report titled "Renewable Energy Deployment in Colorado and the West: A Modeling Sensitivity and GIS Analysis" (Barrows et al. 2016); this report presents the second analysis.

More specifically, this analysis appends the 2016 report with an updated version of the model and additional sensitivity scenarios. The analysis focuses on regions within Colorado where future utility-scale wind and solar generation development might take place based on scenarios developed using NREL's Resource Planning Model (RPM). The version of RPM used for this analysis has been updated since the 2016 report to include updated energy policy representations and generation technology cost assumptions. We use RPM to model multiple scenarios of the future power system in Colorado and the U.S. West through 2030. These scenarios include a Reference scenario and an alternate natural gas price projection developed by the U.S. Energy Information Administration (EIA) that captures a future where delivered natural gas prices remain below \$4/MMBtu for all years through 2030 . $^{2}$ We also model four scenarios that include the Clean Power Plan (CPP), promulgated by the U.S. Environmental Protection Agency (EPA) to regulate carbon dioxide $\left(\mathrm{CO}_{2}\right)$ emissions from the power sector. The future of the CPP is uncertain due to a stay on its implementation issued by the Supreme Court on February 9, 2016, and a review of the policy ordered by the EPA on April 4, 2017. Despite the uncertain future of the CPP, this analysis presents potential impacts of select policies aimed at reducing $\mathrm{CO}_{2}$ emissions from the power sector. Each of the four scenarios where CPP implementation is modeled represents a different compliance strategy; our results suggest that the choice of CPP

\footnotetext{
${ }^{1}$ The ECRMP region consists of land areas in Colorado east of the continental divide.

${ }^{2}$ Unless otherwise noted, we use real 2010 dollars throughout.
} 
compliance strategy by Colorado and other western states has important implications for the impacts of the policy. These scenarios do not imply any policy recommendations, but are modeled to assess - as is common in utility portfolio planning - how alternative policy and fuel price futures might impact renewable development. ${ }^{3}$ More generally, none of the scenarios should be interpreted as predictions or forecasts from NREL or the U.S. Department of Energy.

The RPM power sector tool used for this analysis is designed to represent multiple complicated factors (e.g., load growth, plant retirements, policy demands, renewable grid integration, etc.) that would likely affect electric infrastructure investments. However, it does not consider economic interactions with other sectors, nor does it estimate impacts on local employment, productivity, health, or ecology. Additionally, RPM does not capture differences in development preferences of certain land types (e.g., public, private, BLM). Therefore, the results presented in this report do not represent forecasts or predictions.

We supplement the RPM scenarios with a GIS analysis that enables visual inspection of model results and development opportunities on lands categorized under four distinct ownership types: BLM-administered, non-BLM federal, private, and other. ${ }^{4}$ To this end we analyze RPMgenerated future portfolios in the context of three different land development preference assumptions:

- Proportional preference. Assumes that new generation capacity simulated in the RPM scenarios is built on each of the four categories of land ownership proportional to the distribution of suitable land area of each ownership type within each model region.

- BLM preference. Assumes that development takes place with the following priority order: BLM-administered land, non-BLM federal, other, and private land.

- Private preference. Assumes that development takes place with the following priority order: private land, other, non-BLM federal, and BLM-administered lands.

The purpose of these land development preference assumptions is to provide a reasonable range of BLM-administered land areas that could be used for future renewable development.

Application of the land development preference assumptions provides bounding estimates of the possible land area requirements for renewable development within each of the four land

ownership categories across all modeled scenarios. In addition to the GIS assessment of the RPM scenario results, we also present high-resolution GIS-based data of suitable land areas for wind and solar development and their proximity to existing transmission infrastructure for multiple regions within Colorado.

\section{Key findings:}

The new scenarios and modeling updates in this analysis highlight several of the key findings from the 2016 report and provide additional insights.

\footnotetext{
${ }^{3}$ The modeling analysis included energy policies and regulations as of April 1, 2016.

4 "Other" land ownership includes jointly owned, non-governmental organization, regional/local, state, tribal, and unknown.
} 
- In the scenarios simulated with RPM, the results show that new capacity additions are dominated by renewable technologies across the Western Interconnection and in Colorado.

- The policy representations and technology cost updates that are included in the RPM version used for this analysis generally increase the simulated utility-scale solar deployments through 2030, relative to the reference case in the 2016 report. For example, the updated reference case simulates 1,280 MW of solar capacity compared to $118 \mathrm{MW}$ simulated in the reference case in the 2016 report.

- Across all modeled scenarios, the geographic distribution of new renewable capacity additions in Colorado is limited to a relatively few resource regions within the state where the resource quality is high.

- New utility-scale solar capacity additions are estimated to take place predominantly in the southern and western parts of the state, in the areas the San Luis Valley and near the city of Grand Junction.

- Across all simulation scenarios, between $78 \%$ and $92 \%$ of Colorado wind capacity deployments are located in the northeastern portion of the state. Due to the scarcity of BLM-administered lands in northeastern Colorado if wind development occurs in this region, the vast majority of Colorado wind developments are likely to occur on private and other federally held lands.

- The amount of Colorado land area needed to accommodate new renewable capacity additions through 2030 range from 250,000 to 640,000 acres across all six modeled scenarios.

- The greatest opportunities for renewable energy development appear to exist on private lands. BLM-administered lands are not necessarily needed to accommodate new renewable capacity additions across any of the scenarios in any of the regions.

- The limited need for BLM-administered lands to be used for renewable capacity additions can be explained by the relatively greater amount and closer proximity to existing transmission infrastructure of renewable-suitable, privately-owned land areas.

- If ultimately implemented, the Clean Power Plan, or other policies supporting low-carbon generation, have the potential to spur increased wind and solar development in western states.

○ Western Interconnection renewable energy deployments increase by 9-14 GW, relative to reference scenario levels in scenarios where CPP requirements are met without interstate emissions trading.

- The likely impacts of Clean Power Plan implementation for utility-scale renewable energy development opportunities on BLM-administered lands in Colorado are minimal. 
- The scenarios that represent different CPP compliance pathways generate little to no increase in Colorado solar capacity expansion over the reference scenario.

While some CPP compliance scenarios generate significant increases in simulated Colorado wind deployment, the suitability of BLM-administered lands for wind development is limited.

These findings are derived using the methodologies and assumptions presented the report. Our methods do not attempt to comprehensively consider the siting or permitting steps undertaken to develop renewable or other power generation capacity. In addition, energy policies and markets often evolve rapidly and are unknowable over the full study horizon. Because of these limitations and uncertainties, as well as other caveats associated with the methods, the local development estimates should not be considered prescriptive or predictive. Nonetheless, the analyses presented here and in the 2016 report identify some general trends that could help inform electric infrastructure and land planning in and around the state of Colorado. 


\section{Table of Contents}

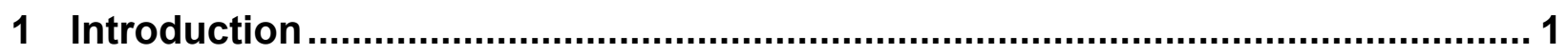

2 Resource Planning Model (RPM) Updates............................................................ 3

2.1 Investment Decision Assumptions and Drivers …………................................................. 3

2.2 Clean Power Plan Representation ..................................................................................... 6

2.3 Renewable Portfolio Standard Updates............................................................................ 8

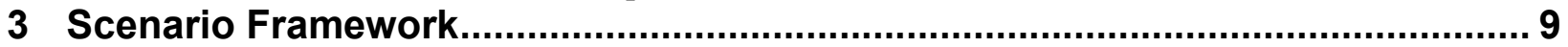

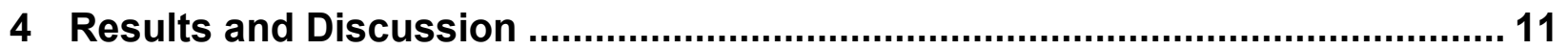

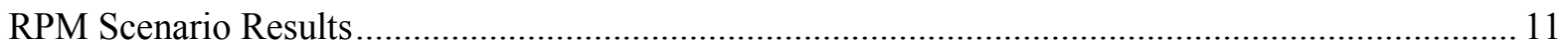

Resource Potential Analysis ..................................................................................................... 14

Statewide and ECRMP Results ………………………………………………………. 14

Resource Region Specific Results...................................................................................... 17

Implications for BLM Resource Management Planning in Colorado ……......................................... 23

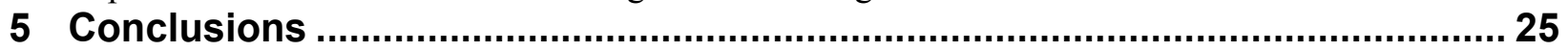

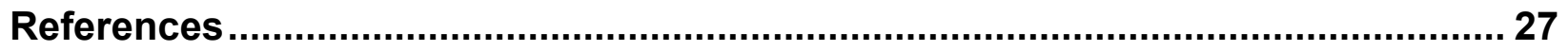

Appendix

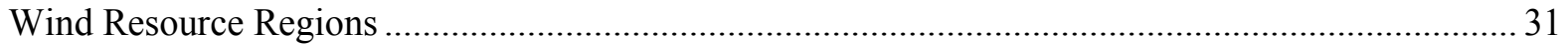

Colorado Wind Resource Regions ……………………………………………………..... 31

ECRMP Wind Resource Regions.................................................................................... 32

PSC01 Wind Resource Region............................................................................................ 33

PSC03 Wind Resource Region.......................................................................................... 35

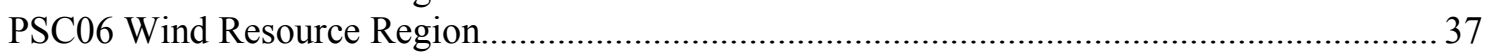

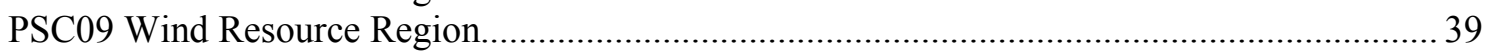

PSC10 Wind Resource Region.......................................................................................... 41

PSC13 Wind Resource Region...................................................................................... 43

PSC14 Wind Resource Region........................................................................................... 45

PSC15 Wind Resource Region....................................................................................... 47

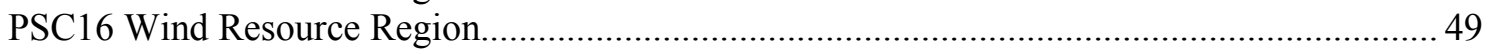

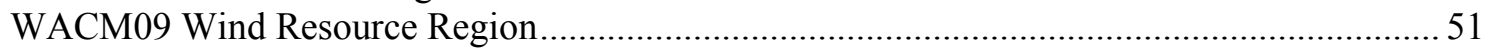

WACM10 Wind Resource Region..................................................................................... 53

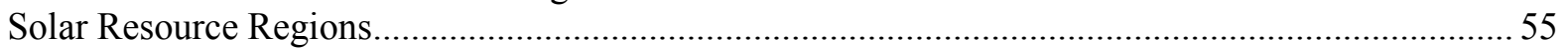

Colorado Solar Resource Regions.................................................................................... 55

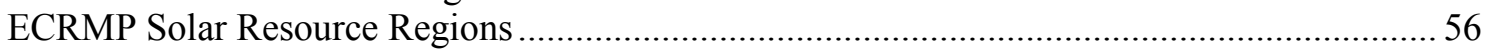

PSC10 Solar Resource Region ......................................................................................5

PSC11 Solar Resource Region ............................................................................................ 59

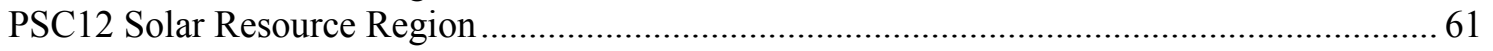

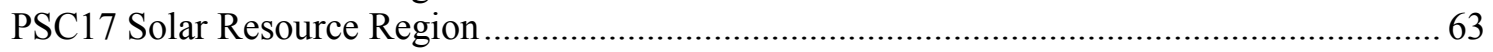

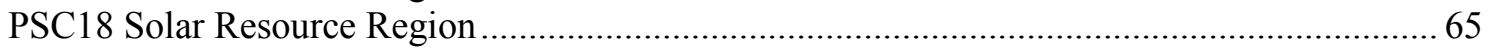

PSC19 Solar Resource Region ........................................................................................ 67

PSC21 Solar Resource Region............................................................................................ 69

PSC22 Solar Resource Region .................................................................................... 71

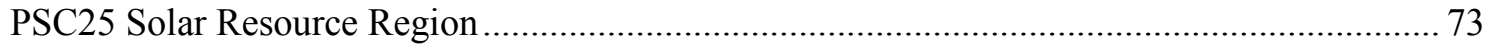

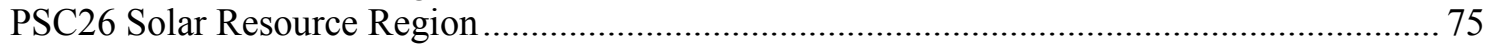




\section{List of Figures}

Figure 1. Assumed delivered natural gas, coal, and uranium AEO 2015 price trajectories from 2010 to 2030 (EIA 2015)

Figure 2. Assumed reference, and low AEO 2015 delivered natural gas price trajectories (EIA 2015) ...... 9

Figure 3. Installed generation capacity in the Western Interconnection for the reference scenario ........... 11

Figure 4. Installed generation capacity in the Colorado-centric focus region for the reference scenario... 12

Figure 5. Differences in 2030 capacity in the Western Interconnection with respect to the reference scenario

Figure 6. Differences in 2030 capacity in the Western Interconnection with respect to the reference

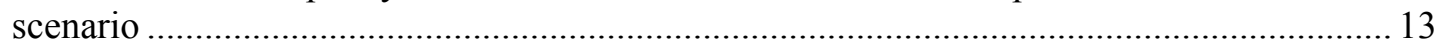

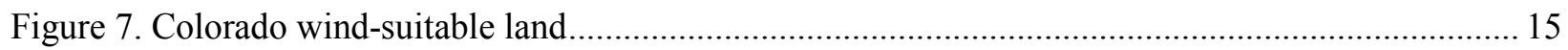

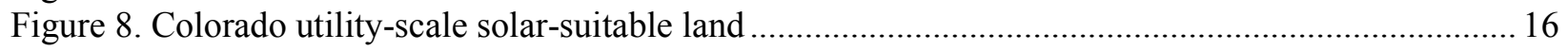

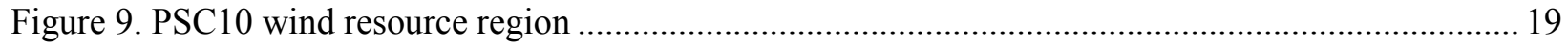

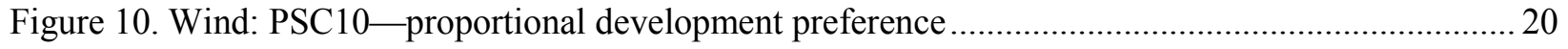

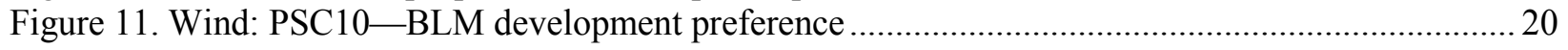

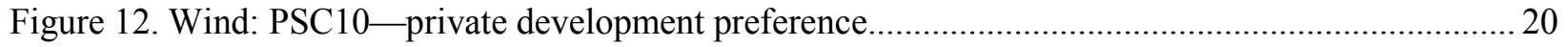

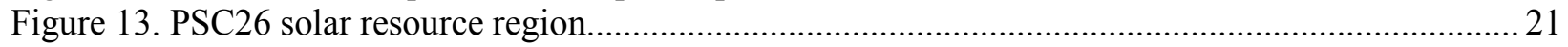

Figure 14. Solar: PSC26 - proportional development preference …............................................. 22

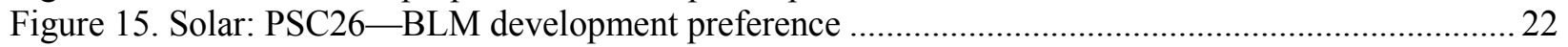

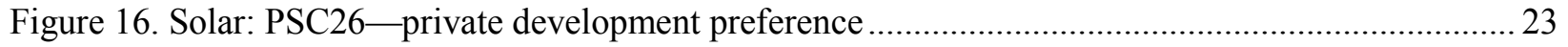

\section{List of Tables}

Table 1. Technology Cost and Performance Assumptions for New Generation Capacity ......................... 4

Table 2. Technology Cost and Performance Assumptions for New Generation Capacity ......................... 10

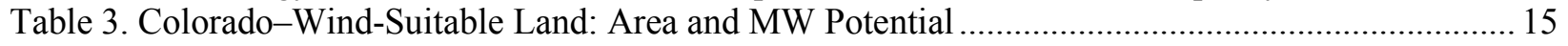

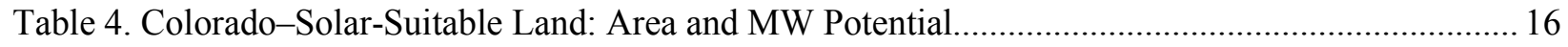

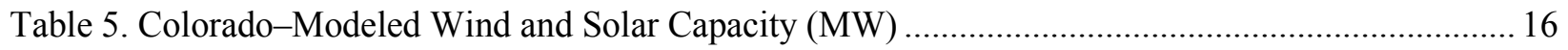

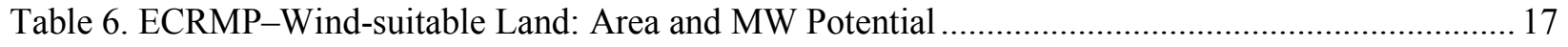

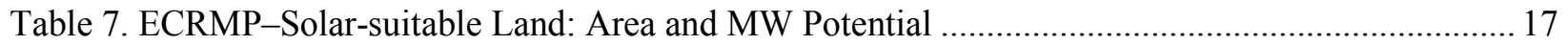

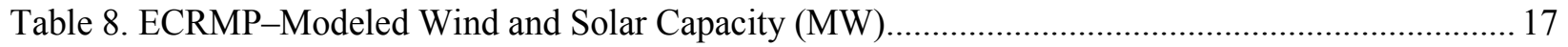

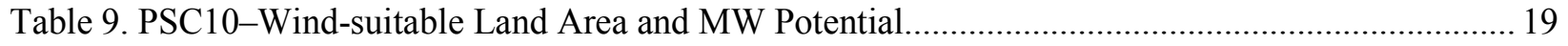

Table 10. PSC10-Modeled Wind Capacity (MW) .............................................................................. 19

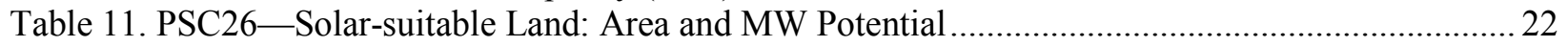

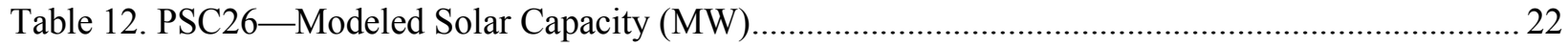




\section{Introduction}

To help inform the United States Bureau of Land Management (BLM) of opportunities to accommodate potential renewable energy developments, the BLM Royal Gorge Field Office commissioned the National Renewable Energy Laboratory (NREL) to study potential demand for renewable energy in Colorado. This study presents an extension of an initial analysis of land suitability and ownership for renewable energy deployment in Colorado (Barrows et al. 2016). Both studies utilize the Resource Planning Model (RPM) to simulate electric sector capacity expansions in Colorado and throughout the Western United States under a variety of assumptions surrounding natural gas price trajectories, and renewable energy and climate policies. The results aim to help the BLM Royal Gorge Field Office develop a new Eastern Colorado Resource Management Plan (ECRMP) that will address the full range of activities that occur on public lands, including the renewable energy development. In particular, the study provides the ECRMP staff with a better understanding of the following:

- Potential demand for utility-scale renewable energy in Colorado between 2015 and 2030, and the geographic regions of the state where future renewable energy and transmission corridor enhancement is likely to take place based on a number of factors including resource potential, access to load, access to existing transmission and corridors, and overall costs of production

- The suitability and potential likelihood that some of those future renewable energy and/or transmission projects might be sited on BLM surface lands within Colorado in general and the ECRMP planning region in particular

- How modifying various policy scenarios and assumptions (e.g., the level of Colorado's Renewable Portfolio Standard (RPS), a range of environmental policies, and a range of natural gas prices) impacts the potential need for renewables and transmission.

Initial study results are summarized in the report, titled "Renewable Energy Deployment in Colorado and the West: A Modeling Sensitivity and GIS Analysis". The modeling assumptions and scenarios result in several key findings:

- In the modeled scenarios, we find that new capacity additions are dominated by renewable technologies across the Western Interconnection. In Colorado, the geographic distribution of new renewable capacity additions is limited to a relatively few areas within the state where the resource quality is high.

- The amount of Colorado land area needed to accommodate new renewable capacity additions through 2030 ranges from 336,000 to 824,000 acres across all five modeled scenarios.

- The greatest opportunities for renewable energy development appear to exist on private lands. The abundance and locations of privately held lands that are suitable for renewable energy development creates a limited need for renewable energy development on BLMadministered lands. 
Several key renewable energy policy developments have taken place in the time since modeling scenarios were analyzed for the previous study. In particular, the U.S. Environmental Protection Agency (EPA) issued the Clean Power Plan (CPP) rule to limit $\mathrm{CO}_{2}$ emissions from power plants (US EPA 2015). Since issuance, the Supreme Court has issued a stay on CPP implementation pending judicial review. Additionally, on April 4, 2017, the EPA announced a pending review of the CPP ("Review of the Clean Power Plan" 2017). Despite the uncertainty around the future of the rulemaking, the CPP provides the opportunity for each state to tailor their own compliance pathway within a set of $\mathrm{CO}_{2}$ reduction, target setting, and interstate coordination options. In the context of BLM resource management planning, and in particular the ECRMP, the particular compliance pathways chosen by Colorado and other western states could have wide ranging impacts on renewable energy development and the associated land requirements.

This study extends the previous analysis by utilizing several model updates that enable representation of CPP, and improve the representation of state Renewable Portfolio Standards (RPS) and interstate renewable energy credit (REC) trading rules. The results presented here include updates to cost data, including several renewable energy tax credit extensions and the most recent fuel and technology cost projections from the EIA and NREL. For this study, we focus on new modeling scenarios surrounding the Clean Power Plan. The modeling scenarios are designed to simulate a range of possible state CPP compliance pathways and highlight the associated land use impacts. With reference to the version used in previous analysis for the ECRMP, the updates included for this version of RPM are described in Section 2. Simulation scenarios that highlight a range of CPP compliance pathways are outlined in Section 3. The analysis, summarized in Section 4, focuses on 2015-2030 planning scenarios for renewable technology deployment on BLM lands within Colorado; additional regional detail is provided in the Appendix. We conclude in Section 5. 


\section{Resource Planning Model (RPM) Updates}

NREL's RPM is a capacity expansion model designed to simulate the evolution of a regional electric power system. With RPM, we simulate investment and operation decisions to minimize overall system cost, including capital costs, fixed and variable operation and maintenance (O\&M) costs, fuel costs, and start-up costs. This section summarizes several RPM updates to represent new policy, fuel and technology cost, and performance projections. For more details about model framework, assumptions and initial conditions, see our previous report (Barrows et al. 2016).

\subsection{Investment Decision Assumptions and Drivers}

Investment decisions in RPM are made simultaneously with the scheduling decision modeling. In this section, we briefly describe the model treatment of certain topics that directly influence investment decisions, and we provide the key assumptions used in our analysis for technologies relevant to our analysis, including natural gas-fired, wind, and solar PV technologies. ${ }^{5}$ The restriction to this small set of technologies is motivated by deployment trends in recent years. We acknowledge that this is a model limitation and that deployment of new capacity from other technologies is expected, at least to limited amounts.

Table 3 shows the assumed technology costs and performance used in our analysis. Data for technologies are drawn from NREL's Annual Technology Baseline (Blair et al. 2015), which relies on data from the Annual Energy Outlook 2015 Reference scenario (EIA 2015) for natural gas-fired technologies, DOE reports (Margolis, Coggeshall, and Zuboy 2012) for solar technologies, and the DOE Wind Vision Study (DOE 2015) for wind technologies. The overnight capital costs shown in Table 3 include costs of all equipment and do not include the spur line and financing costs, which are included separately in the model. ${ }^{6}$ Spur line or interconnection costs for new renewable capacity vary between resource regions and depend on the distance between the wind or solar resource and the connected bus. RPM also includes financing costs (Cole et al. 2016) that vary between technologies to account for differences in construction periods, accelerated tax depreciation rules, and investment tax credits. ${ }^{7}$

Other plant parameters, particularly for natural gas (NG) fired plants, are also used in RPM and are described in (Mai et al. 2015). Reference scenario assumed fuel costs are shown in Figure 1 and are based on national fuel projections from the Annual Energy Outlook 2015 Reference scenario (EIA 2015). Additional fuel cost trajectories for scenario analysis are described in Section 3. Fuel costs are assumed to be uniform across regions and without seasonal or diurnal variations within each solve year ${ }^{8}$.

\footnotetext{
${ }^{5}$ RPM includes many other technologies (see Table 2), some of which may play important roles in the future. Nonetheless, our analysis is restricted to new natural gas-fired, wind, and solar PV technologies.

${ }^{6}$ Real 2010 dollars are used throughout this report unless otherwise noted.

${ }^{7}$ RPM uses technology-specific fixed charge rates. Fixed charge rates for NG-CC, NG-CT, wind, and solar PV are $0.117,0.111,0.098$, and 0.084 , respectively, for all years with the exception of a fixed charge rate of 0.062 for solar $\mathrm{PV}$ in 2015 to represent the $30 \%$ investment tax credit available before 2017 (the analysis was completed before tax credit extensions were passed in December 2015). These fixed charge rates are used to calculate amortized capital over 20 years using a nominal weighted average cost of capital of $8.1 \%$.

${ }^{8} \mathrm{We}$ do not include foresight, such as for fuel price forecasts, in RPM.
} 


\section{Table 1. Technology Cost and Performance Assumptions for New Generation Capacity}

\begin{tabular}{|c|c|c|c|c|}
\hline & 2015 & 2020 & 2025 & 2030 \\
\hline \multicolumn{5}{|c|}{ Overnight Capital Costs $(2010 \$ / k W)$} \\
\hline Natural Gas-Combined Cycle & 900 & 890 & 880 & 860 \\
\hline Natural Gas-Combustion Turbine & 770 & 750 & 740 & 720 \\
\hline Wind (resource class dependent) & $1,530-1,650$ & $1,480-1,630$ & $1,440-1,620$ & $1,430-1,620$ \\
\hline PV Fixed-Tilt ${ }^{*}$ & 1,740 & 1,410 & 1,160 & 910 \\
\hline PV Single-Axis Tracking ${ }^{*}$ & 1,830 & 1,510 & 1,260 & 1,010 \\
\hline \multicolumn{5}{|l|}{ Fixed O\&M (2010\$/kW-yr) } \\
\hline Natural Gas-Combined Cycle & 13 & 13 & 13 & 13 \\
\hline Natural Gas-Combustion Turbine & 7 & 7 & 7 & 7 \\
\hline Wind (all) & 47 & 46 & 45 & 44 \\
\hline PV (all) & 15 & 8 & 8 & 8 \\
\hline \multicolumn{5}{|l|}{ Variable O\&M (2010\$/MWh) } \\
\hline Natural Gas-Combined Cycle & 3 & 3 & 3 & 3 \\
\hline Natural Gas-Combustion Turbine & 12 & 12 & 12 & 12 \\
\hline Wind (all) & 0 & 0 & 0 & 0 \\
\hline PV (all) & 0 & 0 & 0 & 0 \\
\hline \multicolumn{5}{|l|}{ Heat Rate (MMBtu/MWh) } \\
\hline Natural Gas-Combined Cycle & 6.68 & 6.62 & 6.57 & 6.57 \\
\hline Natural Gas-Combustion Turbine & 10.0 & 9.76 & 9.50 & 9.50 \\
\hline \multicolumn{5}{|l|}{ Fuel Cost (2010\$/MMBtu) } \\
\hline Natural Gas & 4.38 & 5.43 & 6.91 & 8.20 \\
\hline \multicolumn{5}{|l|}{ Capacity Factor (\%) } \\
\hline Wind (resource class dependent) & $52 \%-33 \%$ & $54 \%-35 \%$ & $55 \%-36 \%$ & $56 \%-37 \%$ \\
\hline PV Fixed-Tilt & $12-22 \%$ & $12-22 \%$ & $12-22 \%$ & $12-22 \%$ \\
\hline PV Single-Axis Tracking & $14-28 \%$ & $14-28 \%$ & $14-28 \%$ & $14-28 \%$ \\
\hline
\end{tabular}




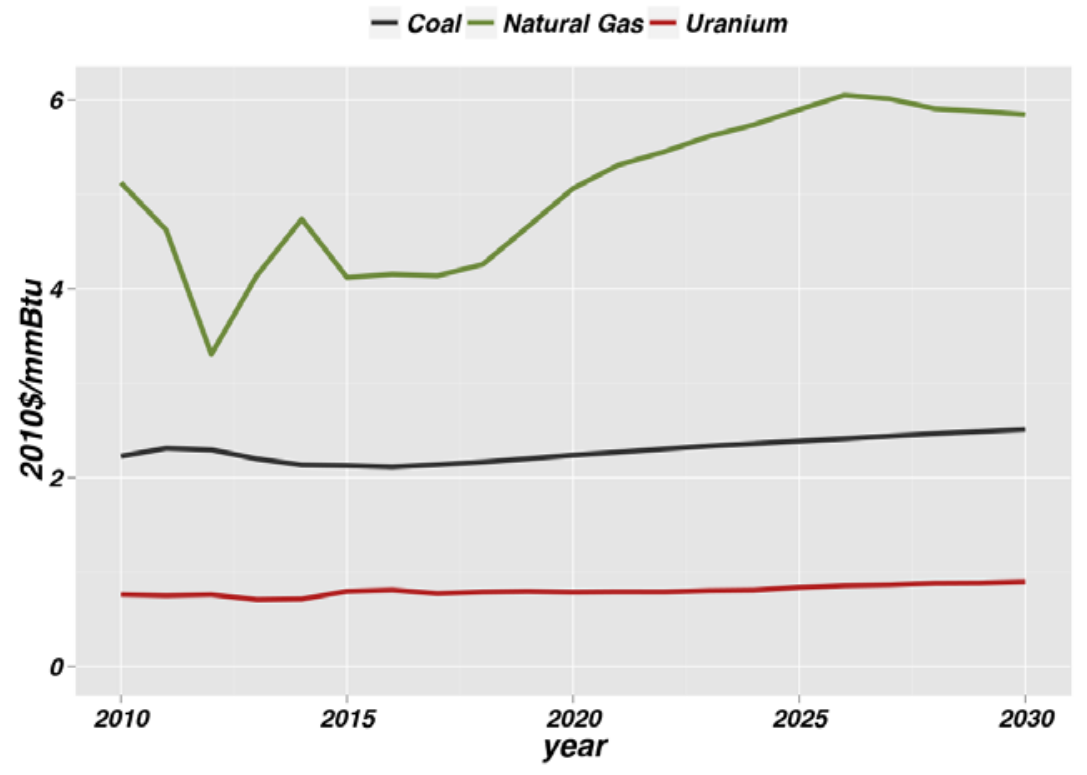

Figure 1. Assumed delivered natural gas, coal, and uranium AEO 2015 price trajectories from 2010 to 2030 (EIA 2015)

The primary factors, beyond fuel and technology costs, that drive RPM's investment decisions relate to demand growth, planning reserves, and policy requirements, including: state renewable portfolio standard (RPS), and investment/production tax credits (ITC/PTC). Planning reserve constraints are applied to ensure North American Electric Reliability Corporation (NERC) resource adequacy reference margins (NERC 2013) are met. We set a planning reserve requirement for each of four NERC sub-regions ${ }^{9}$ in the Western Interconnection to be the peak demand in that region plus a reserve margin (NERC 2013). ${ }^{10}$ All non-variable generators are assumed to contribute their full nameplate capacity to the planning reserve requirement. For variable generation, including wind, solar PV, and CSP without TES, we endogenously estimate the capacity credit using a capacity factor-based approximation.

New wind and solar capacity deployment is restricted by the technical potential of the resource in each resource region. The technical potential assessment uses the same methodology and exclusions as in (Lopez et al. 2012). Wind and solar suitable land exclusions include: slopes greater than $3 \%$ (solar) and $20 \%$ (wind), contiguous areas less than $1 \mathrm{~km}^{2}$ (solar), lands within 1 $\mathrm{km}$ distance to other exclusions (wind), water, wetlands, urban areas, BLM areas of critical environmental concern, National Parks, Fish and Wildlife lands, Federal Parks, wilderness, National Monuments, National Battlefields, Federal Wildlife Areas and other federally identified protected lands. Rooftop PV capacity adoption is defined exogenously and updated after each solve year using NRELs dSolar model (Sigrin et al. 2016).

\footnotetext{
${ }^{9}$ The regions are WECC-CAMX, WECC-NWPP, WECC-RMRG, and WECC-SRSG.

${ }^{10}$ For the WECC-CAMX region, we assume 11,000 MW and 5,000 MW of capacity are available from the NWPP and SRSG sub-regions, respectively, to meet planning reserve requirements for all years. We assume that the deductions from NWPP and SRSG are not available to supply capacity reserves in their respective regions. This representation follows the Maximum Import Capacity considered by the California Independent System Operator. Planning reserve requirements are met by local resources only for the other three sub-regions.
} 
The modeling analysis was completed using data and assumptions available in mid-2016. For energy policies, this includes state renewable portfolio standards (RPSs) at that time and as reflected in DSIRE. ${ }^{11}$ Unlike the model used for the previous study (Barrows et al. 2016), the current model and analysis includes the recently extended RPS requirements for California and Oregon. In addition, the current model reflects the state and generator technology specific rules governing renewable energy credit (REC) trading to satisfy state level RPS requirements. We also include the recently extended federal tax credit legislation for wind and solar: $2.3 \notin$ wind production tax credit for 2015, reducing each year through 2020, and an investment tax credit for commercial and utility-scale solar of $30 \%$ through 2020 , reducing to $10 \%$ by 2022 . The present version of RPM does not include a representation of state carbon cap and trade systems (e.g. California Assembly Bill 32). ${ }^{12}$ Finally, we do not model any changes to policies surrounding public land administration. Future work will address these shortcomings in RPM's policy representations.

Recent (2010-2014) and expected new transmission and generation capacity additions and retirements are exogenously included in RPM based on data from Ventyx (2010) and SolarPaces $(2014)^{13}$. The optimization in RPM does not explicitly consider any other retirements, such as economic retirements.

\subsection{Clean Power Plan Representation}

The Clean Power Plan is a ruling by the EPA that limits $\mathrm{CO}_{2}$ emissions from electric power plants. The CPP defines emission rate standards for fossil steam and combined cycle power plants; in turn, the standards are used to derive goals for states to reduce $\mathrm{CO}_{2}$ pollution. The CPP specifies requirements that increase in stringency from 2022 to 2030. Currently, the CPP is under litigation and the Supreme Court has issued a stay of its implementation. Additionally, the EPA has initiated a review of the CPP ("Review of the Clean Power Plan" 2017). If enacted, these regulations could lead to important changes for states' capacity expansion plans. Impacts of the CPP on both costs and capacity expansion plans are not straightforward. Furthermore, impacts can depend on the compliance pathway used by each state.

There are several manners in which states can implement the CPP. First, states have the freedom to choose between mass- or rate-based goals:

- Mass-based emissions measurements set goals in terms of the total short tons of $\mathrm{CO}_{2}$ that may be emitted. Additionally, mass-based emissions can be measured by monitoring emissions from either of the following sets of generating units:

\footnotetext{
${ }^{11}$ See www.dsireusa.org/.

${ }^{12}$ Emissions or renewable policies such as California Assembly Bill 32, primarily affect capacity expansion and operations results near the policy location and locations where contracted imports are likely. Therefore, omissions of these policies are unlikely to significantly affect the results of this analysis.

${ }^{13}$ In particular, two solar generation developments totaling $206 \mathrm{MW}$ in Colorado have recently been announced that are not included in RPM ("Broomfield Firm to Build Colorado's Largest Solar Farm near Pueblo" 2016, "Xcel Energy Flips the Switch on Colorado Solar Power Plant” 2016)
} 
$\circ$ Existing emission sources ${ }^{14}$

- Existing emission sources as well as new-source compliments

- Rate-based emissions measurements that set emissions goals in terms of the pounds of $\mathrm{CO}_{2}$ per megawatt hour produced (lb/MWh). There are two different types of rate standards:

- State-specific emissions rate that accounts for all $\mathrm{CO}_{2}$ emissions from coal, oil steam, and natural gas fired combined cycle energy production within each state.

- Technology-specific emissions rate (one for fossil-steam units, and one for natural gas combined cycle units) that accounts for all $\mathrm{CO}_{2}$ emissions and all energy produced by a specific generator technology within each state.

These four options provide states some flexibility in how to comply with the regulation. In RPM, each of these targets is included as an option for compliance. The compliance target chosen by each state is an input to the model; so multiple different pathways can be examined through scenario-based analysis.

In addition to emissions target setting options, states may choose several pathways to meet their emissions targets. States may choose to comply with emissions targets through reducing generation from higher emission plants and replacing it with generation from lower-emission plants or zero-emission facilities, increasing energy efficiency measures, and improving the heat rates of high emission facilities. In RPM, we model the effects fuel swapping from higher to lower emission facilities and increased use of renewable resources, however RPM does not currently consider the effects energy efficiency and heat rate changes as they relate to CPP compliance.

Interstate emissions trading provides another mechanism for states to meet their emissions goals. Through emissions credit trading, states have the flexibility to coordinate with other states using the same compliance method to jointly meet their state targets. This allows over-compliant states to sell excess credits to states that are otherwise not compliant, and takes different forms for mass-based and rate-based targets. When meeting mass-based targets, states can directly trade mass credits, whereby a state sells the amount of $\mathrm{CO}_{2}$ emissions reductions they have in excess of their target. However, for rate-based targets, emissions are not directly traded. Instead the tradable unit is an emission rate credit (ERC), in units of MWh, which can be used to reduce the total rate of emissions from the purchasing state. ERCs can be generated by 1) zero-emission technologies that began operation after December 31, 2012, 2) gas CC generators that increase their generation over 2012 output to displace coal generation - termed gas-shift ERCs, 3) fossil steam and gas $\mathrm{CC}$ units that perform better than their technology specific emissions standard, and 4) energy efficiency measures. In RPM we allow ERCs to be created by qualifying zeroemission technologies. Gas-shift ERCs are also allowed and may only be purchased by coal generators as per EPA regulation.

\footnotetext{
${ }^{14}$ If emissions are measured only from existing units, states must demonstrate that emissions from new sources wont exceed expected emissions from new sources under the rate-based approach.
} 
To calculate target compliance, all $\mathrm{CO} 2$ emissions from qualifying units are tracked for each state. Additionally, all ERCs from qualifying zero-emission units are recorded, as is the total generation in each state from qualifying generators. Each state is required to balance either the total emissions or the emissions rate from qualifying facilities for each year of the simulation. When groups of states are included, trading may occur through a market system, whereby states with excess credits can sell them in a marketplace and states with too few of credits can buy them. We do not track which states sell to which other states, only those states that are buying and those states that are selling. Thus, all mass credits or ERCs have the same price within a single group. Different groups may have different prices based on the need for ERCs within those groups.

Trading groups may be defined for any arbitrary set of states following any of the policy compliance targets. These groups are allowed to trade mass credits or ERCs depending on the policy followed. However, currently in RPM groups of states following a technology-uniform rate-based plan are not allowed to trade ERCs. States complying with technology-uniform ratebased targets must propose and have approved a group-wide emissions rate for all states. We do not speculate or calculate what these group rates would be, so do not allow trading among these states.

\subsection{Renewable Portfolio Standard Updates}

The representation of renewable portfolio standards (RPSs) was updated in RPM to incorporate recent changes to RPS requirements and more accurately represent how states are allowed to meet their RPS requirements. Several states have recently updated their renewable portfolio standards to increase the amount of renewables required, most notably California and Oregon, or to include RPS carve-outs for specific technologies. We updated our representation of RPSs to include these updated standards. Additionally, we changed the modeled RPSs to better represent the requirements in each state. The new methodology uses a load-weighted average of the statelevel, regional, and local standards as they apply to different utilities (including investor owned utilities, cooperatives, and small utilities).

In the most recent version of the model, we also implemented REC trading as an allowable mechanism to meet a state's RPS requirement. Each state has specific requirements on both which technologies may be counted towards an RPS requirement and the locations or technologies from which RECs may be bought. We used a simplified listing of allowable trade partners from (Holt 2016) to identify which states were allowed to trade RECs to which other states, and whether or not these RECs were required to be bundled with electricity transfers as well. Bundled transfers refer to a requirement by some states that the purchase of a REC used to satisfy an RPS requirement must also be accompanied by an equal amount of transfer of energy from that source. For example, a solar plant in New Mexico can sell $100 \mathrm{MWh}$ of RECs to Arizona if and only if it also sells $100 \mathrm{MWh}$ of energy from that solar plant to users in Arizona. In RPM we are unable to directly account for contracts between a single plant and another entity, so we instead enforce that states requiring bundled RECs must import at least that much energy from the selling state. We also do not allow hydropower to sell RECs to meet other states' RPS requirements due to the complex and non-uniform nature of the way that states treat hydropower in RPS requirements. 


\section{Scenario Framework}

We modeled long-term capacity expansion and electricity system operations under a core reference scenario (REF) and five sensitivity scenarios designed to highlight a range of possible economic futures and CPP compliance pathways. To illustrate the relative impact of different natural gas prices, we use natural gas price projections (see Figure 2) from the Energy Information Administration Annual Energy Outlook to generate a low natural gas price scenario (LO-NG) (EIA 2015). The remaining four scenarios, summarized in Table 2, are intended bookend the possible CPP compliance pathways with two boundary cases for cooperation among states: 1) all states meet their CPP requirements without any trading, and 2) all states within WECC cooperate to meet their CPP requirements. These represent bounds on what may occur within the Western Interconnection; however, any arbitrary combination of state groupings could be formed, including some states cooperating and some states meeting their own targets individually.

None of these scenarios represent a forecast or prediction. The scenarios do not reflect a policy or other recommendations pertaining to the formation of BLM resource management plans, but instead aim to capture a range of possible futures. These scenarios are intended to simulate the broader trends in the future western electricity system, with the results quantifying potential demands on various lands owned by the BLM, other federal agencies, private and other entities.

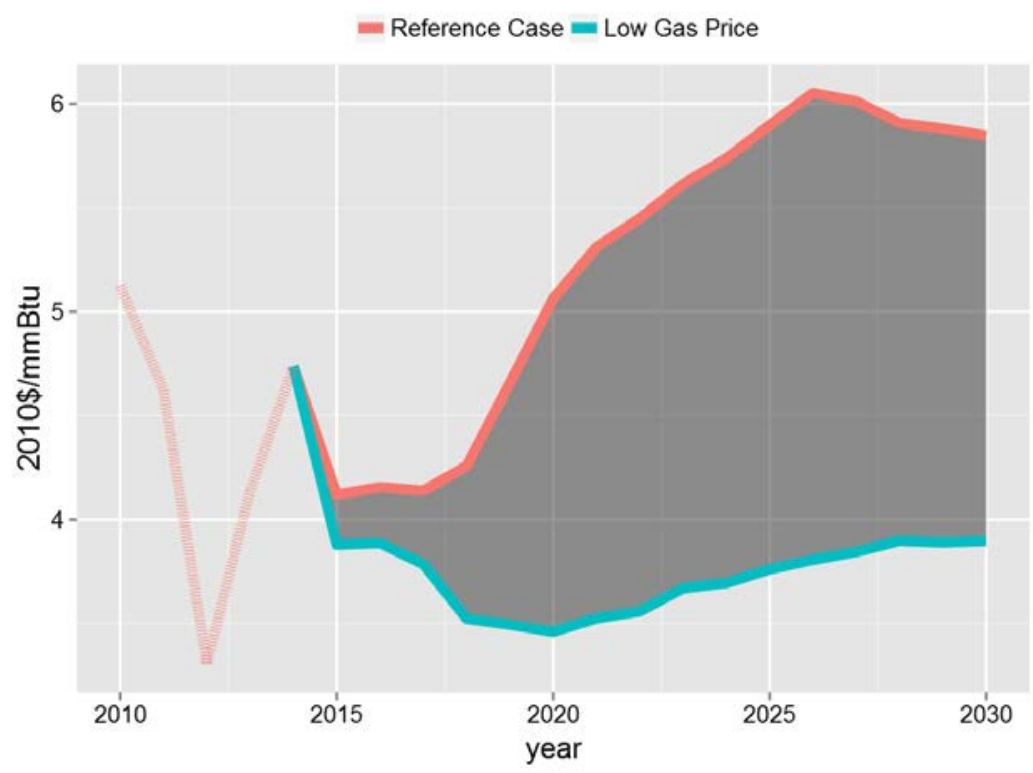

Figure 2. Assumed reference, and Iow AEO 2015 delivered natural gas price trajectories (EIA 2015) 
Table 2. Technology Cost and Performance Assumptions for New Generation
Capacity

\begin{tabular}{|c|c|c|c|c|c|}
\hline $\begin{array}{l}\text { Scenario } \\
\text { Abbreviation }\end{array}$ & Description & NG Price & $\begin{array}{l}\text { CPP } \\
\text { Trading }\end{array}$ & $\begin{array}{l}\text { CPP Target } \\
\text { Calculation }\end{array}$ & $\begin{array}{l}\text { CPP } \\
\text { Technology } \\
\text { Qualification }\end{array}$ \\
\hline REF & $\begin{array}{l}\text { Reference, mid Natural Gas } \\
\text { price trajectory with no CPP } \\
\text { representation }\end{array}$ & $\begin{array}{l}\text { AEO Mid } \\
\text { Resource }\end{array}$ & $\mathrm{N} / \mathrm{A}$ & N/A & $\mathrm{N} / \mathrm{A}$ \\
\hline LO-NG & $\begin{array}{l}\text { Low Natural Gas Price with } \\
\text { no CPP representation }\end{array}$ & $\begin{array}{l}\text { AEO High } \\
\text { Resource }\end{array}$ & $\mathrm{N} / \mathrm{A}$ & $\mathrm{N} / \mathrm{A}$ & $\mathrm{N} / \mathrm{A}$ \\
\hline ST-DRT & $\begin{array}{l}\text { State-level compliance with } \\
\text { technology differentiated } \\
\text { rate targets includes CPP } \\
\text { compliance using technology } \\
\text { differentiated rate-based } \\
\text { targets, with no trading }\end{array}$ & $\begin{array}{l}\text { AEO Mid } \\
\text { Resource }\end{array}$ & None & $\begin{array}{l}\text { Emissions } \\
\text { rate-based } \\
\text { targets }\end{array}$ & $\begin{array}{l}\text { Generator } \\
\text { technology } \\
\text { differentiated } \\
\text { emissions rate } \\
\text { targets }\end{array}$ \\
\hline ST-URT & $\begin{array}{l}\text { State-level compliance with } \\
\text { technology uniform rate } \\
\text { targets includes CPP } \\
\text { compliance using technology } \\
\text { uniform rate-based targets, } \\
\text { with no trading }\end{array}$ & $\begin{array}{l}\text { AEO Mid } \\
\text { Resource }\end{array}$ & None & $\begin{array}{l}\text { Emissions } \\
\text { rate-based } \\
\text { targets }\end{array}$ & $\begin{array}{l}\text { Uniform } \\
\text { emissions rate } \\
\text { targets for all } \\
\text { technologies }\end{array}$ \\
\hline ST-MT & $\begin{array}{l}\text { State-level compliance with } \\
\text { mass targets includes CPP } \\
\text { compliance using mass- } \\
\text { based targets for existing } \\
\text { and new sources, with no } \\
\text { trading }\end{array}$ & $\begin{array}{l}\text { AEO Mid } \\
\text { Resource }\end{array}$ & None & $\begin{array}{l}\text { Emissions } \\
\text { mass-based } \\
\text { targets }\end{array}$ & $\begin{array}{l}\text { Emissions } \\
\text { monitored on } \\
\text { existing and new } \\
\text { sources }\end{array}$ \\
\hline WC-MT & $\begin{array}{l}\text { Cooperation among all } \\
\text { states in the Western } \\
\text { Interconnection includes } \\
\text { CPP compliance using } \\
\text { mass-based targets for } \\
\text { existing and new sources } \\
\text { and trading among all states } \\
\text { in the Western } \\
\text { Interconnection }\end{array}$ & $\begin{array}{l}\text { AEO Mid } \\
\text { Resource }\end{array}$ & $\begin{array}{l}\text { All } \\
\text { states in } \\
\text { the WI }\end{array}$ & $\begin{array}{l}\text { Emissions } \\
\text { mass-based } \\
\text { targets }\end{array}$ & $\begin{array}{l}\text { Emissions } \\
\text { monitored on } \\
\text { existing and new } \\
\text { sources }\end{array}$ \\
\hline
\end{tabular}




\section{Results and Discussion}

RPM simulations for the six scenarios generate trajectories for both energy production and capacity through 2030 . Here, we present the capacity trajectories produced by RPM scenario simulations for the Western Interconnection and the Colorado-centric focus region. The focus region represents the system covered by the Public Service Company of Colorado (PSC) and the Western Area Power Administration, Colorado-Missouri Region (WACM) balancing authorities.

\section{RPM Scenario Results}

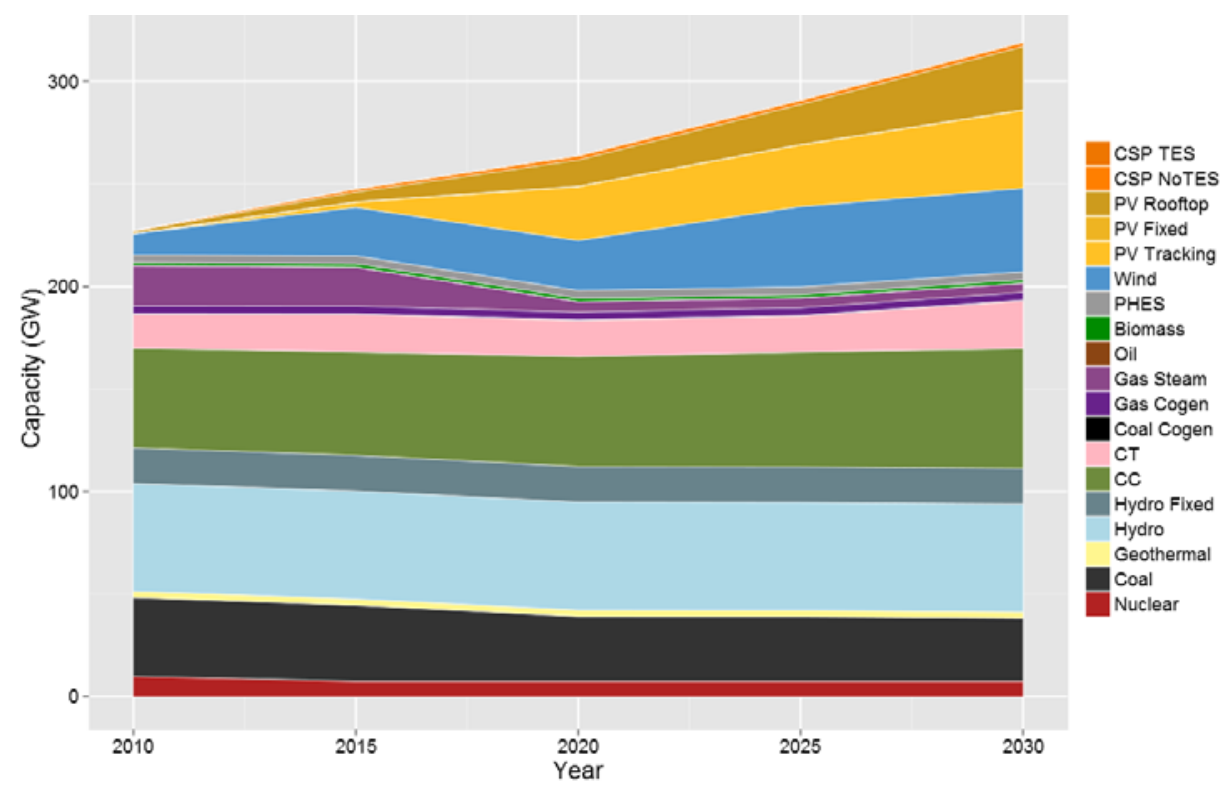

Figure 3. Installed generation capacity in the Western Interconnection for the reference scenario

Figure 3 shows solar photovoltaic generation represents the majority of added capacity in the Western Interconnection through 2030 in the reference scenario. However, Figure 4 shows that in the Colorado-centric focus region, the majority of reference scenario added capacity by 2030 is wind capacity. Since the reference scenario excludes any CPP implementation, capacity expansions are largely driven by load growth assumptions and RPS policies. The simulated wind capacity additions between 2011 and 2030 total 30,000 MW and 2,700 MW for the Western Interconnect and the Colorado-centric focus region, respectively. The simulated solar PV capacity additions total 68,000 MW and 2,700 MW for the Western Interconnect and the Colorado-centric focus region, respectively. The solar PV additions are distributed roughly evenly between rooftop capacity and utility-scale single-axis tracking capacity in both the focus region and throughout the entire Western Interconnect. The simulated capacity additions result in annual Western Interconnect energy penetrations of $14.8 \%$ and $12.8 \%$ for wind and solar, respectively. 


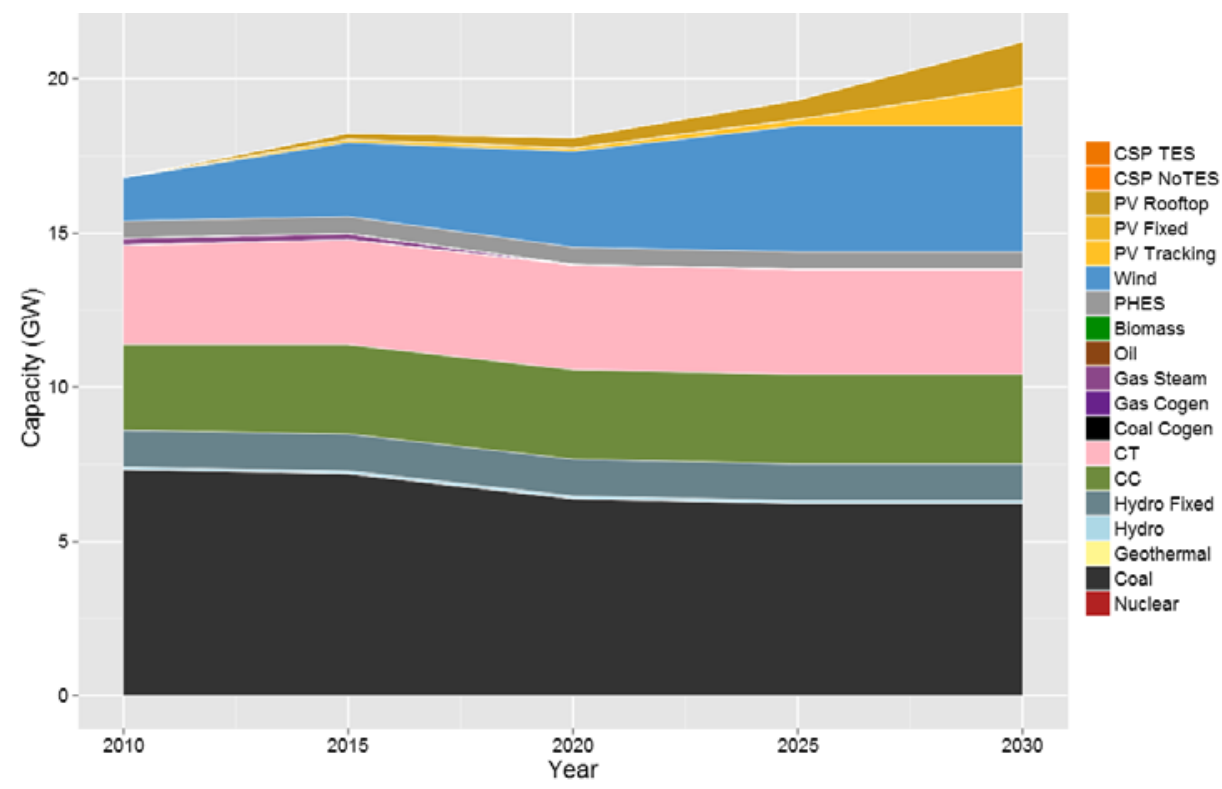

Figure 4. Installed generation capacity in the Colorado-centric focus region for the reference scenario

Differences in capacity expansion between the reference scenario and the five sensitivity scenarios are shown in Figure 5 and Figure 6 for the Western Interconnect and the Coloradocentric focus region, respectively. Relative to the reference scenario, the LO-NG scenario results simulate significantly less wind and solar capacity and slightly more natural gas fired combustion turbine capacity by 2030 , while the remaining four scenarios that enforce the CPP simulate increased wind and solar capacity additions. Figure 5 shows that the ST-DRT and WCMT scenarios both result in small additions of solar capacity in the Western Interconnect.

Otherwise, the scenarios that simulate CPP implementation and state differentiated compliance goals (ST-DRT, ST-URT, ST-MT), all result in significantly more Western Interconnect wind capacity, relative to the reference scenario. Figure 6 shows that when CPP compliance goals are set for each state individually, simulations results in between 2,300 MW and 3,200 MW of additional wind capacity is added in the Colorado-centric focus region. 


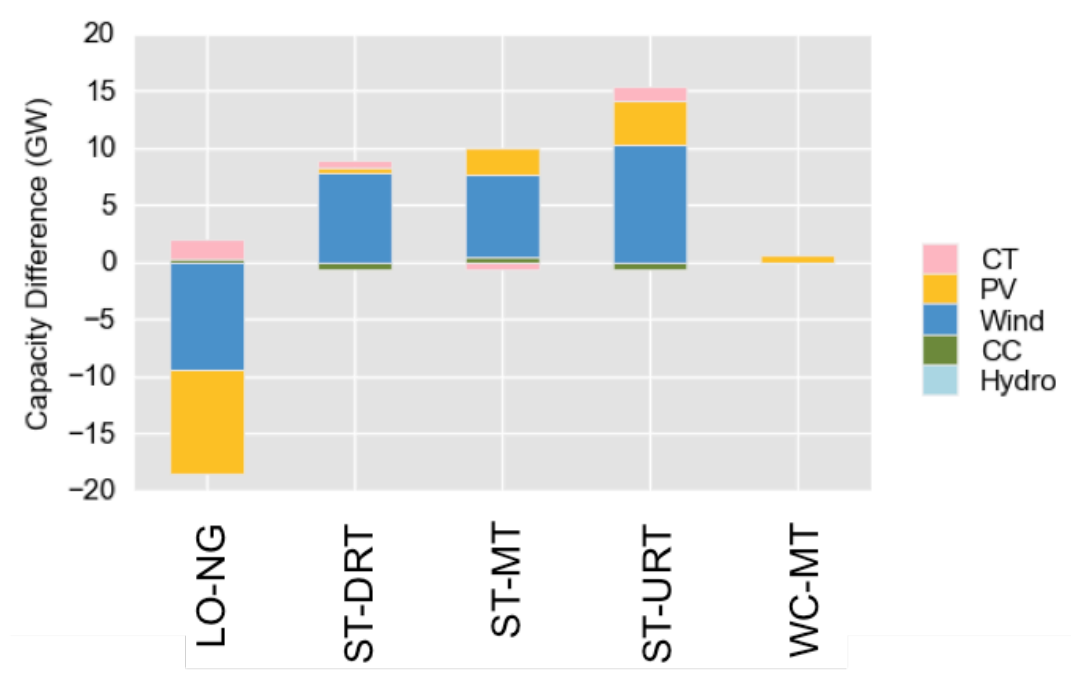

Figure 5. Differences in 2030 capacity in the Western Interconnection with respect to the reference scenario

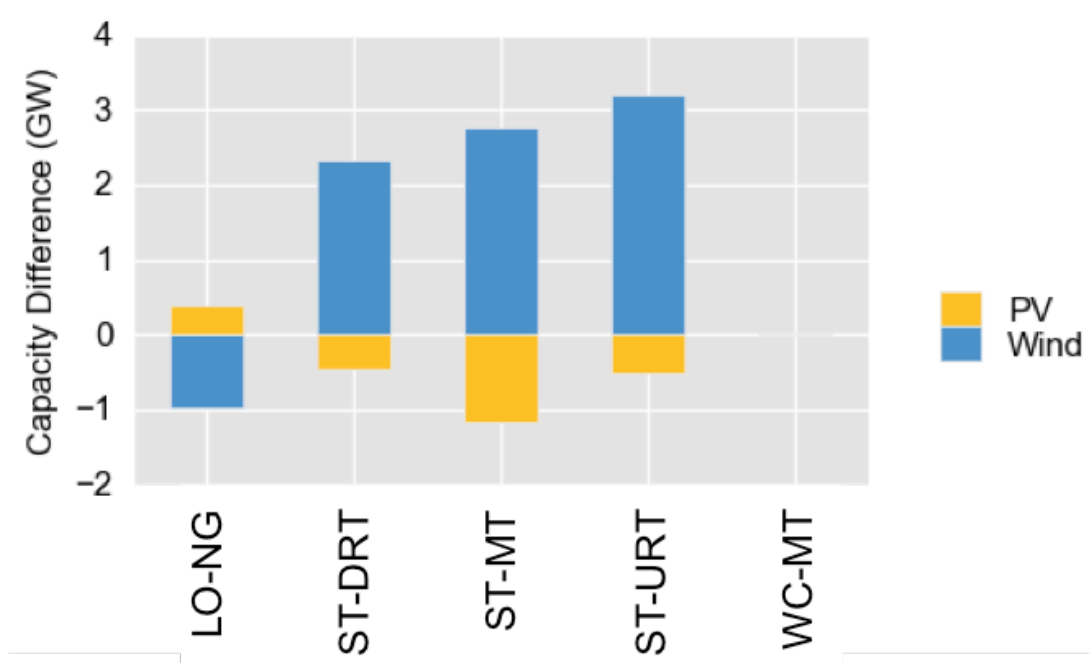

Figure 6. Differences in 2030 capacity in the Western Interconnection with respect to the reference scenario

The capacity expansion differences shown in Figure 5 and Figure 6 are consistent with the effects of the different scenario inputs. In particular, the WC-MT scenario shows only a small capacity difference in the Western Interconnect and no focus region difference from the reference case. The WC-MT scenario simulates a compliance pathway where all western states collaborate to meet mass-based emissions targets, which results in targets that have little impact on the capacity expansion results. By contrast, the more restrictive scenarios that simulate individual state compliance (ST-*, i.e. no emissions credit trading) result in fairly significant capacity expansion differences from the reference scenario. Generally the individual state target scenarios simulate significant increases in wind capacity, a large fraction of which is added in the Colorado-centric focus region. 


\section{Resource Potential Analysis}

\section{Statewide and ECRMP Results}

The abundance of land suitable for wind and solar development in Colorado was demonstrated in the previous analysis (Barrows et al. 2016). The results presented here utilize the same land availability inputs and only change the fuel cost and policy assumptions to generate the six simulation scenarios. The amount of Colorado land area needed to accommodate modeled renewable capacity additions through 2030 range from 250,000 to 640,000 acres across all six modeled scenarios.

Figure 7 and Figure 8 show Colorado lands suitable for wind and solar energy development, respectively. Suitable land availability is analyzed by land ownership within four 'Distance to Transmission' bins, summarized in Table 3 and Table 4. Transmission distances are calculated between each suitable land grid cell $\left(10 \mathrm{~km}^{2}\right)$ and the closest transmission bus. ${ }^{15}$ Suitable land area, in acres, is calculated after applying exclusions described in Lopez et al. (2012) and the MW capacity potential is calculated by applying technology specific land use intensities found in Denholm et al. (2009).

\footnotetext{
${ }^{15}$ Transmission buses considered in this analysis include existing and WECC planned infrastructure at or above 69 $\mathrm{kV}$ nominal voltage ratings.
} 

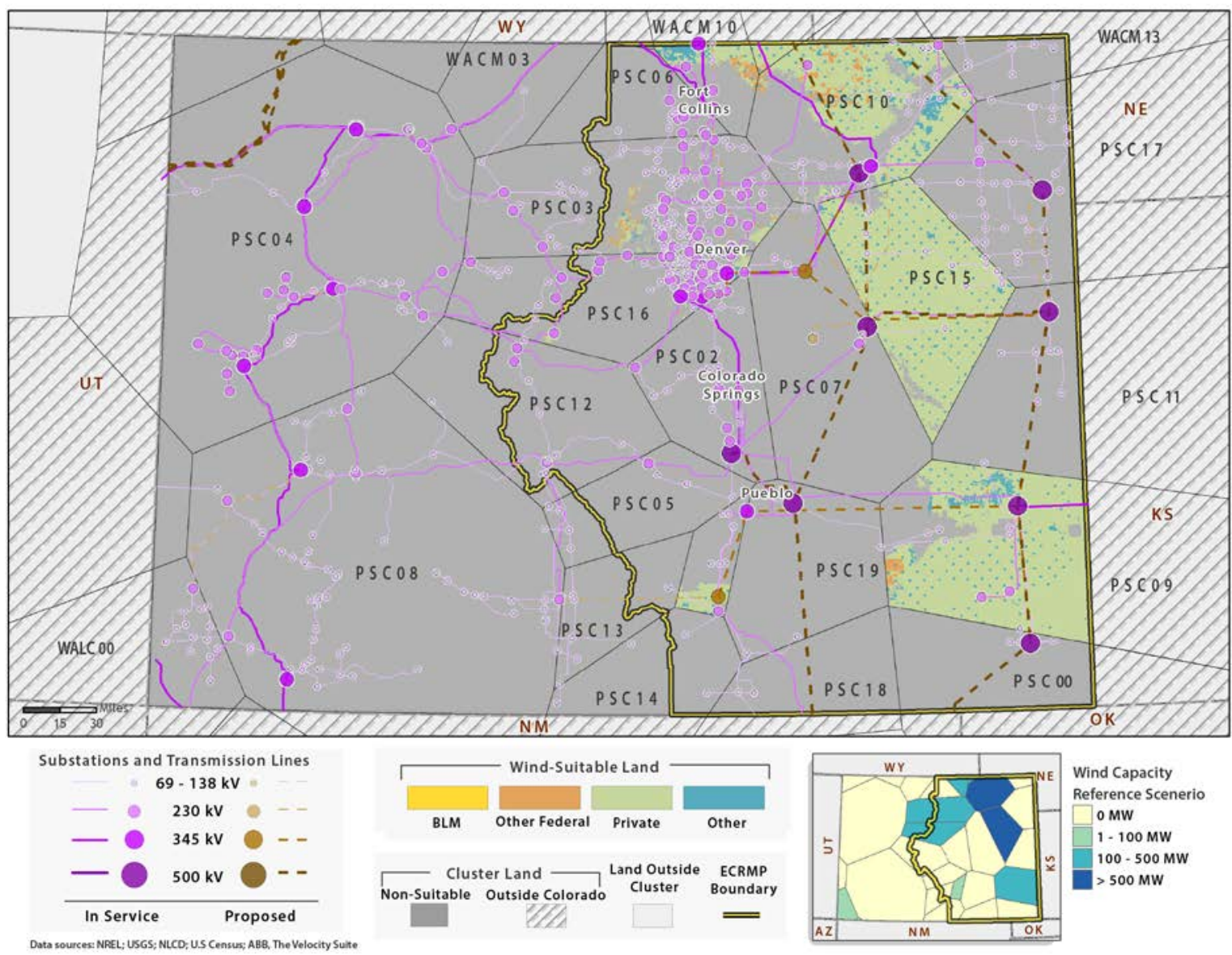

Figure 7. Colorado wind-suitable land

Table 3. Colorado-Wind-Suitable Land: Area and MW Potential

\begin{tabular}{c|cc|cc|cc|cc}
\hline \hline \multirow{2}{*}{$\begin{array}{c}\text { Distance to } \\
\text { Transmission }\end{array}$} & \multicolumn{2}{|c|}{$\mathbf{0 - 1}$ Miles } & \multicolumn{2}{|c|}{$\mathbf{1 - 5}$ Miles } & \multicolumn{2}{c|}{$\mathbf{5 - 1 0}$ Miles } & \multicolumn{2}{c}{$>$ 10 Miles } \\
Acres & MW & Acres & MW & Acres & MW & Acres & MW \\
\hline BLM & 676 & 8 & 10,742 & 130 & 35,485 & 431 & 85,689 & 1,040 \\
Federal & 286 & 3 & 35,028 & 425 & 152,692 & 1,854 & 747,768 & 9,078 \\
Other & 14,855 & 180 & 286,770 & 3,482 & 403,691 & 4,901 & 630,510 & 7,655 \\
Private & 170,090 & 2,065 & $3,482,771$ & 42,283 & $5,609,683$ & 68,105 & $8,660,317$ & 105,141 \\
\hline \hline
\end{tabular}



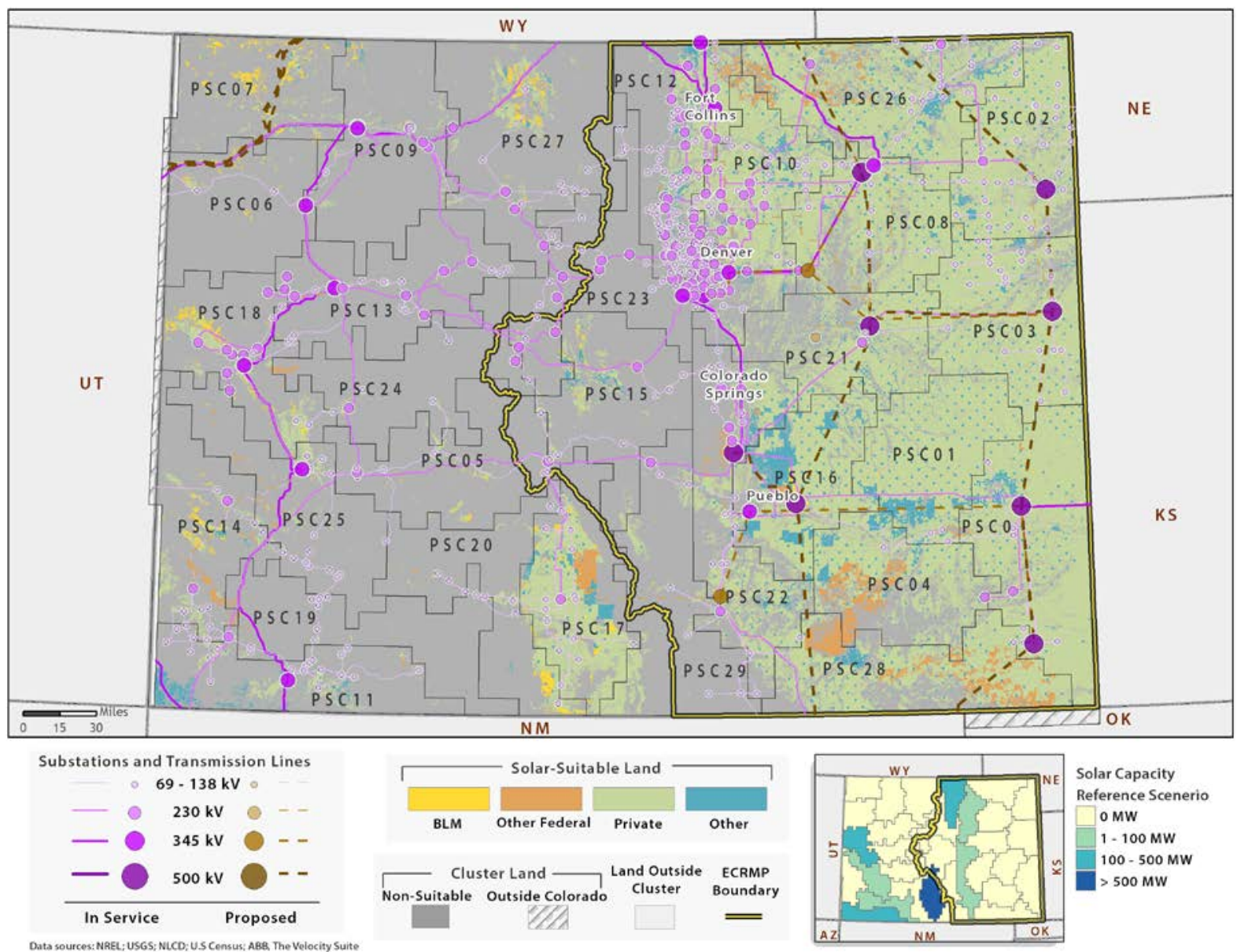

Figure 8. Colorado utility-scale solar-suitable land

Table 4. Colorado-Solar-Suitable Land: Area and MW Potential

\begin{tabular}{c|cc|cc|cc|cc}
\hline \hline \multirow{2}{*}{$\begin{array}{c}\text { Distance to } \\
\text { Transmission }\end{array}$} & \multicolumn{2}{|c|}{$\mathbf{0 - 1}$ Miles } & \multicolumn{2}{|c|}{$\mathbf{1 - 5}$ Miles } & \multicolumn{2}{c|}{$\mathbf{5 - 1 0}$ Miles } & \multicolumn{2}{c}{$>$ 10 Miles } \\
Acres & MW & Acres & MW & Acres & MW & Acres & MW \\
\hline BLM & 542 & 155 & 53,225 & 15,251 & 111,854 & 32,050 & 259,125 & 74,248 \\
Federal & 936 & 268 & 65,781 & 18,848 & 212,993 & 61,030 & 605,166 & 173,400 \\
Other & 18,784 & 5,382 & 321,219 & 92,040 & 489,051 & 140,129 & $1,050,674$ & 301,053 \\
Private & 311,631 & 89,293 & $5,025,581$ & $1,439,995$ & $5,892,545$ & $1,688,408$ & $9,035,090$ & $2,588,851$ \\
\hline \hline
\end{tabular}

Table 5. Colorado-Modeled Wind and Solar Capacity (MW)

\begin{tabular}{l|cccccc}
\hline \hline & Ref & LO-NG & ST-DRT & ST-MT & ST-URT & WC-MT \\
Wind & 3,983 & 2,996 & 6,034 & 7,767 & 6,082 & 3,981 \\
Solar & 1,280 & 1,658 & 2,749 & 110 & 3,479 & 1,280 \\
\hline \hline
\end{tabular}

Using RPM, we simulated statewide solar and wind capacity expansions through 2030 for each simulation scenario. The simulation results are described in Table 5 and show significantly more wind capacity is added than solar capacity in Colorado. Statewide land usage for wind 
development ranges from about 246,000 to 640,000 acres. Statewide land usage for utility scale solar development ranges from about 180 to 6,000 acres. Comparison of the results presented in Table 5 and the availability of suitable land by ownership in Table 3 and Table 4 demonstrates a statewide abundance of wind-suitable private land and solar-suitable lands of all ownership types. These results suggest that Colorado could accommodate significantly more RE development than simulated, even if development was prohibited on some lands.

The ECRMP region is comprised of the eastern portion of the state and is bounded by the continental divide on the west and state borders on the north, east, and south (see yellow border in Figure 7). Table 6 and Table 7 show the wind and solar-suitable land availability in the ECRMP. Comparison of the ECRMP-suitable land availability with the Colorado land availability demonstrates that the majority of wind-suitable land in Colorado exists within the ECRMP boundary. Table 8 shows that all of the added wind capacity, except $25 \mathrm{MW}$ allocated to areas that primarily exist in NM and AZ, are allocated inside the ECRMP boundary. Despite an abundance of solar-suitable land in the ECRMP, we find that the majority of Colorado solar capacity expansions in the western portion of the state.

Table 6. ECRMP-Wind-suitable Land: Area and MW Potential

\begin{tabular}{|c|c|c|c|c|c|c|c|c|}
\hline \multirow{2}{*}{$\begin{array}{l}\text { Distance to } \\
\text { Transmission }\end{array}$} & \multicolumn{2}{|c|}{ 0-1 Miles } & \multicolumn{2}{|c|}{ 1-5 Miles } & \multicolumn{2}{|c|}{ 5-10 Miles } & \multicolumn{2}{|c|}{$>10$ Miles } \\
\hline & Acres & MW & Acres & MW & Acres & MW & Acres & MW \\
\hline BLM & 660 & 8 & 10,262 & 125 & 33,696 & 409 & 22,132 & 269 \\
\hline Federal & 276 & 3 & 33,679 & 409 & 148,468 & 1,802 & 732,313 & 8,891 \\
\hline Other & 14,855 & 180 & 286,284 & 3,476 & 403,365 & 4,897 & 624,398 & 7,581 \\
\hline Private & 169,934 & 2,063 & $3,479,603$ & 42,244 & $5,595,939$ & 67,938 & $8,625,066$ & 104,713 \\
\hline
\end{tabular}

Table 7. ECRMP-Solar-suitable Land: Area and MW Potential

\begin{tabular}{c|cc|cc|cc|cc}
\hline \hline \multirow{2}{*}{ Distance to } & \multicolumn{2}{|c|}{$\mathbf{0 - 1}$ Miles } & \multicolumn{2}{|c|}{$\mathbf{1 - 5}$ Miles } & \multicolumn{2}{c|}{$\mathbf{5 - 1 0}$ Miles } & \multicolumn{2}{c}{$>$ 10 Miles } \\
Transmission & Acres & MW & Acres & MW & Acres & MW & Acres & MW \\
\hline BLM & 43 & 12 & 3,296 & 945 & 12,376 & 3,546 & 24,173 & 6,926 \\
Federal & 731 & 209 & 47,607 & 13,641 & 117,043 & 33,537 & 549,218 & 157,369 \\
Other & 17,180 & 4,923 & 289,844 & 83,050 & 425,478 & 121,914 & 877,034 & 251,299 \\
Private & 264,183 & 75,697 & $4,292,574$ & $1,229,964$ & $5,237,288$ & $1,500,655$ & $8,428,131$ & $2,414,937$ \\
\hline \hline
\end{tabular}

Table 8. ECRMP-Modeled Wind and Solar Capacity (MW)

\begin{tabular}{l|cccccc}
\hline \hline & Ref & LO-NG & ST-DRT & ST-MT & ST-URT & WC-MT \\
Wind & 3,983 & 2,996 & 5,033 & 5,964 & 5,380 & 3,981 \\
Solar & 988 & 902 & 415 & 109 & 228 & 977 \\
\hline \hline
\end{tabular}

\section{Resource Region Specific Results}

To provide additional detail on wind and solar resource availability and the locations of simulated RE developments, the following figures and tables present information on specific wind and solar resource regions within Colorado. The maps are designed to portray the location of lands suitable for wind and solar development, and with the exception of the reference scenario capacity thumbnail in the bottom right, each map remains unchanged from the previous 
report (Barrows et al. 2016). The bar charts are designed to portray the results of the six simulated scenarios within three possible land development preferences. The figures also demonstrate the proximity of lands to existing and planned transmission infrastructure to give the reader a sense of the relative costs that might be incurred for RE development on various lands. Here, we present analysis for two Colorado resource regions within the ECRMP boundary, one wind and one solar. Other resource regions where simulation results indicate wind or utility-scale solar capacity expansions in Colorado are presented in the Appendix.

Figure 9 highlights lands with wind energy development potential within the PSC10 wind region. Additionally, Table 9 summarizes the wind-suitable land area and MW potential in the PSC10 wind resource region by land ownership type. Table 9 also describes the distance to transmission infrastructure for lands with wind energy development potential. Transmission distances are calculated between each suitable land grid cell $\left(10 \mathrm{~km}^{2}\right)$ and the closest transmission bus, regardless of whether or not the bus resides within the resource region boundary. Figure 9 and Table 9 demonstrate transmission infrastructure is not typically located near lands that are suitable for wind energy developments in the PSC10 region. Additionally, the wind development opportunities in the PSC10 region exist on private lands while BLM administered land suitable for wind development is extremely limited. 


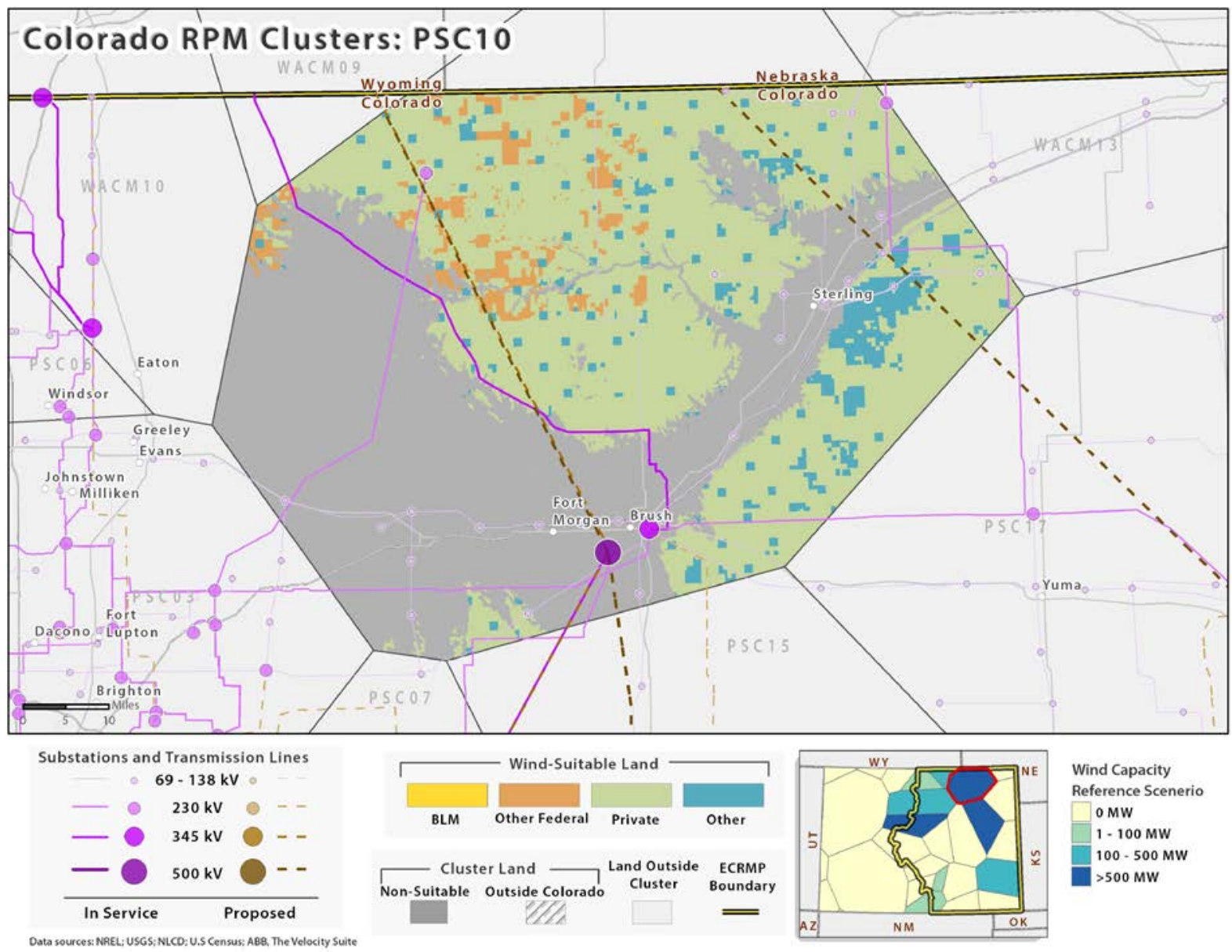

Figure 9. PSC10 wind resource region ${ }^{16}$

Table 9. PSC10-Wind-suitable Land Area and MW Potential

\begin{tabular}{c|cc|cc|cc|cc}
\hline \hline Distance to & \multicolumn{2}{|c|}{$\mathbf{0 - 1}$ Miles } & \multicolumn{2}{|c|}{$\mathbf{1 - 5}$ Miles } & \multicolumn{2}{c|}{ 5-10 Miles } & \multicolumn{2}{c}{$>$ 10 Miles } \\
Transmission & Acres & MW & Acres & MW & Acres & MW & Acres & MW \\
\hline BLM & 0 & 0 & 0 & 0 & 105 & 1 & 56 & 0 \\
Federal & 0 & 0 & 4,289 & 52 & 16,839 & 204 & 70,446 & 856 \\
Other & 2,283 & 27 & 54,102 & 657 & 58,238 & 707 & 43,326 & 526 \\
Private & 15,575 & 189 & 275,559 & 3,348 & 524,775 & 6,377 & 537,298 & 6,529 \\
\hline \hline
\end{tabular}

Table 10. PSC10-Modeled Wind Capacity (MW)

\begin{tabular}{cccccc}
\hline \hline Ref & LO-NG & ST-DRT & ST-MT & ST-URT & WC-MT \\
1,001 & 1,001 & 1,001 & 1,001 & 1,001 & 1,001 \\
\hline \hline
\end{tabular}

\footnotetext{
${ }^{16}$ For a complete description of the various information displayed, refer to the text at the beginning of the Appendix.
} 

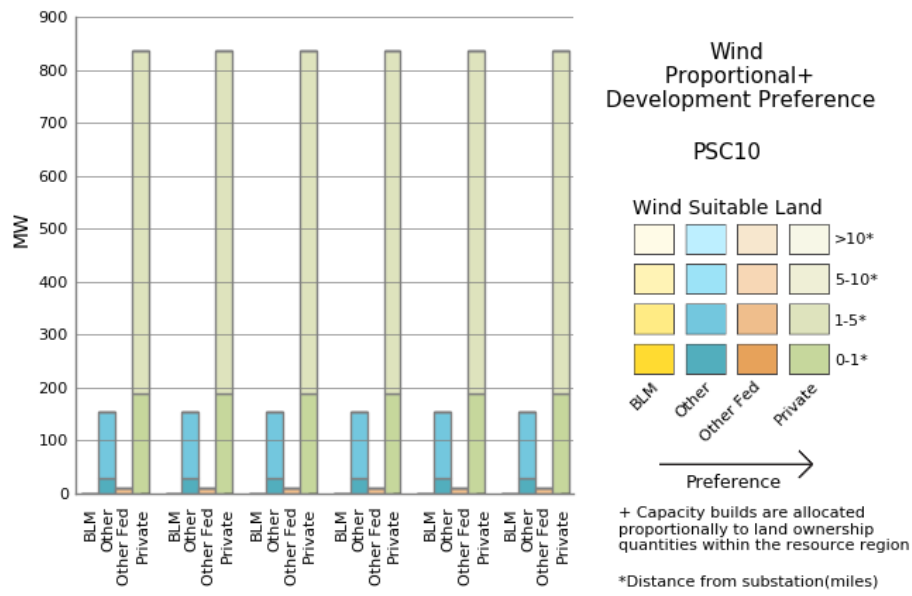

REF LO-NG ST-DRT SC-MT SC-URT WC-MT

*Distance from substation(miles)

\section{Figure 10. Wind: PSC10_proportional development preference}

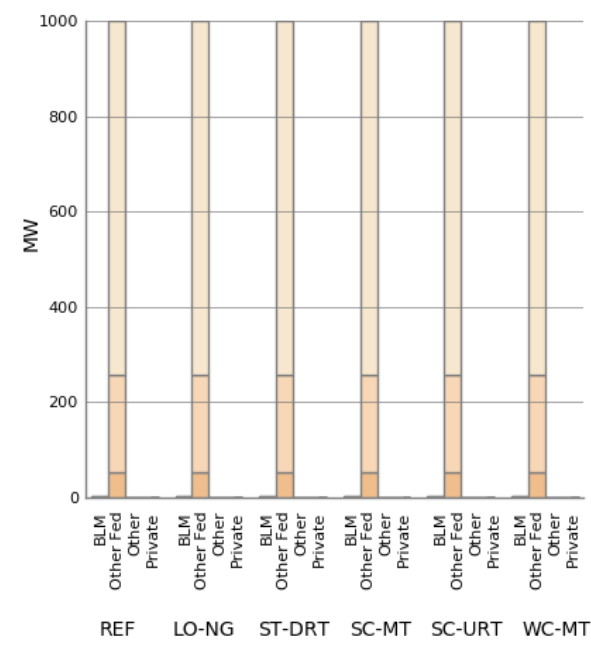

Wind BLM
Development Preference

PSC10

Wind Suitable Land

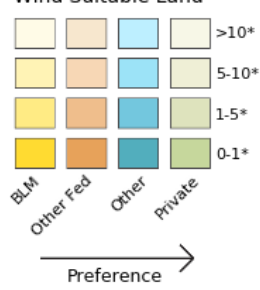

*Distance from substation(miles)

Figure 11. Wind: PSC10—BLM development preference
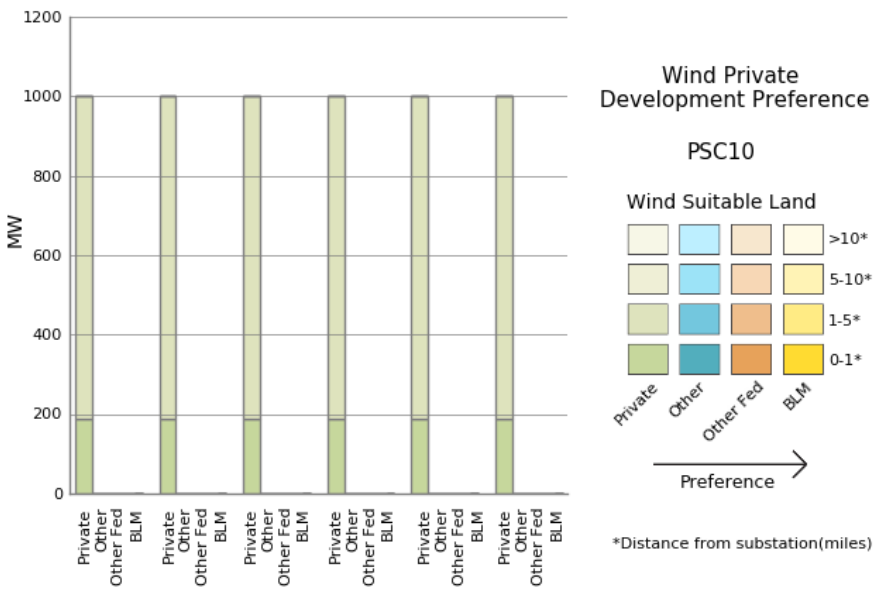

REF LO-NG ST-DRT SC-MT SC-URT WC-MT

Figure 12. Wind: PSC10_private development preference 
Despite the relatively long transmission connection distances of wind-suitable lands in PSC10, Table 10 shows significant wind capacity expansions in PSC10 from all RPM simulations. Table 10 shows 1,001 MW of wind capacity expansion in PSC10 in all of the simulation scenarios. By comparing the results presented in Table 10 and the availability of suitable land by ownership, we describe three potential wind development pathways in Figure 10, Figure 11, and Figure 12. Figure 10 shows the land allocation of wind capacity expansion result for each scenario assuming that development takes place proportionally to the amount of wind-suitable land available on each land ownership type within the PSC10 wind resource region. Figure 11 shows wind capacity expansion allocations assuming development takes place with the following priority order: BLM-administered land gets developed first, and other federal lands, other and private land, get developed second, third and last. Conversely, Figure 12 describes the allocation of wind capacity expansions assuming the opposite development preference order where private land gets developed with greatest priority. Figure 12 shows that a strong preference for developing private land in PSC10 could accommodate all of the RPM-simulated capacity expansions in each scenario without utilizing any BLM, other federal, or other land for wind development.

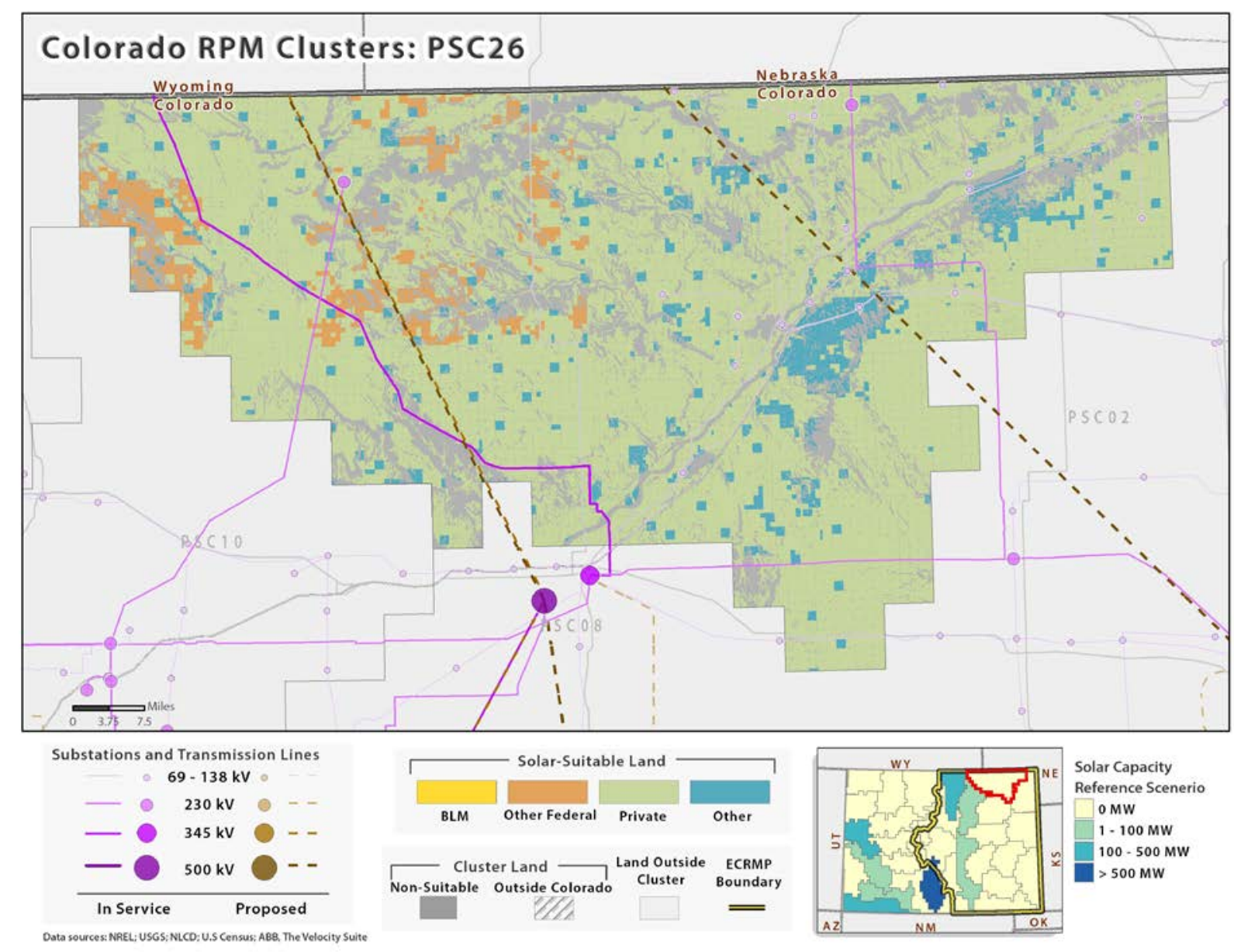

Figure 13. PSC26 solar resource region 
Table 11. PSC26-Solar-suitable Land: Area and MW Potential

\begin{tabular}{c|cc|cc|cc|cc}
\hline Distance to & \multicolumn{2}{|c|}{$\mathbf{0 - 1}$ Miles } & \multicolumn{2}{c|}{$\mathbf{1 - 5}$ Miles } & \multicolumn{2}{c|}{5 -10 Miles } & \multicolumn{2}{c}{$>$ 10 Miles } \\
Transmission & Acres & MW & Acres & MW & Acres & MW & Acres & MW \\
\hline BLM & 0 & 0 & 17 & 2 & 87 & 11 & 45 & 6 \\
Federal & 0 & 0 & 1,445 & 183 & 12,119 & 1,534 & 92,805 & 11,747 \\
Other & 3,081 & 390 & 62,334 & 7,890 & 68,247 & 8,639 & 48,961 & 6,198 \\
Private & 29,382 & 3,719 & 458,014 & 57,977 & 670,581 & 84,884 & 772,551 & 97,791 \\
\hline \hline
\end{tabular}

Table 12. PSC26-Modeled Solar Capacity (MW)

\begin{tabular}{cccccc}
\hline \hline Ref & LO-NG & ST-DRT & ST-MT & ST-URT & WC-MT \\
4 & 19 & 0 & 0 & 0 & 4 \\
\hline \hline
\end{tabular}
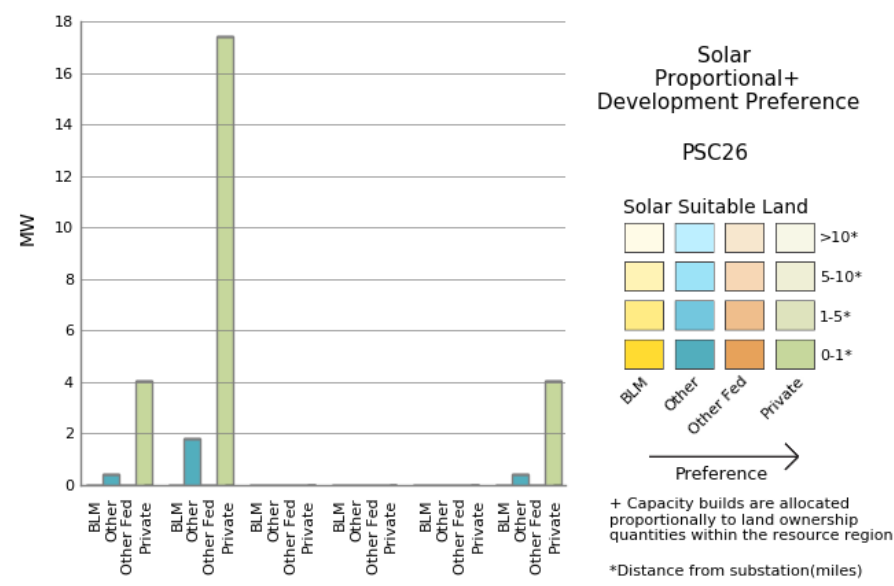

REF LO-NG ST-DRT SC-MT SC-URT WC-MT

Figure 14. Solar: PSC26—proportional development preference

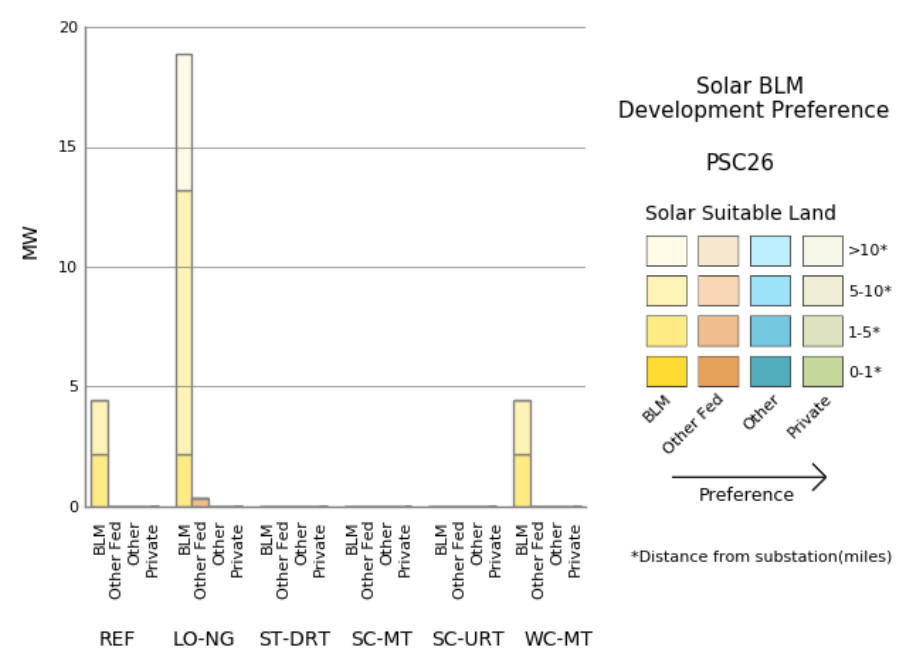

Figure 15. Solar: PSC26—BLM development preference 


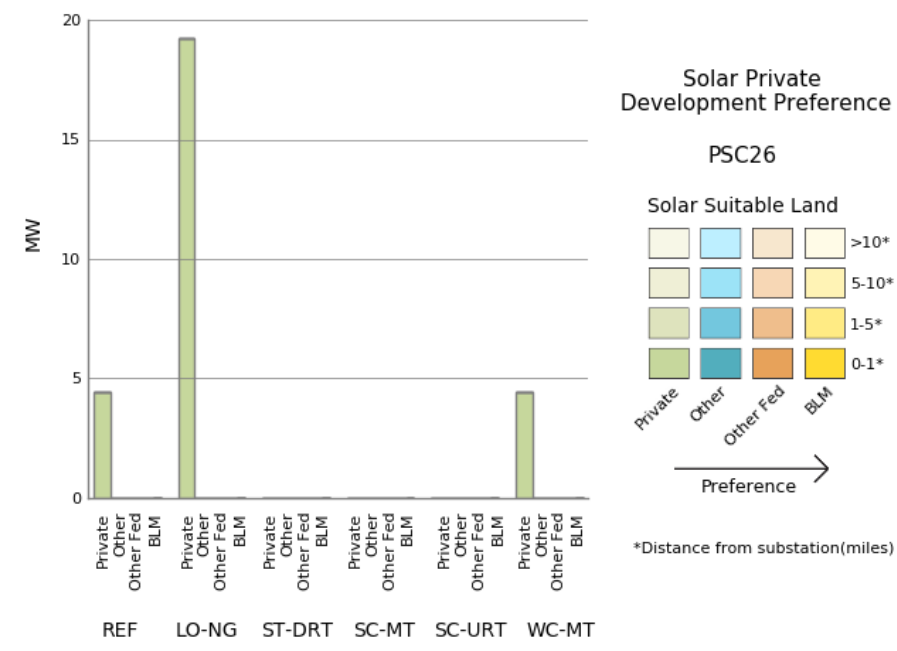

Figure 16. Solar: PSC26_-private development preference

Figure 13 through Figure 16, and Table 11 and Table 12 present the same resource potential and GIS post-processing analysis on the PSC26 solar resource region. Table 11 shows that the majority of solar-suitable land is located at distances greater than $5 \mathrm{mi}$ from existing and planned transmission infrastructure. Table 12 shows that between 0 and $19 \mathrm{MW}$ of solar capacity is added in PSC26 across scenarios. At this modest development level, any land ownership type except BLM administered lands could accommodate the RPM simulated solar capacity expansions. While "Other" and private lands could accommodate the simulated capacity on land within a mile of existing and planned transmission infrastructure. Due to the private ownership of the majority of solar-suitable lands, the proportional development preference chart in Figure 14 allocates most solar development in PSC26 to private lands. However, Figure 15 shows that if a BLM solar development preference existed, BLM-administered lands could accommodate the entire RPM simulated solar capacity expansion in PSC26 for all scenarios except the LO-NG scenario where a modest amount of Other Federal land would be required.

The Appendix contains similar figures and tables for each resource region within Colorado where RPM results indicate wind or solar development is likely.

\section{Implications for BLM Resource Management Planning in Colorado}

While the results of scenarios representing the CPP regulations generate significant capacity expansion changes within Colorado and throughout the Western Interconnect, the implications for BLM land management remain relatively limited. The limited amount of BLM-administered lands in close proximity to transmission substations in combination with abundance of lands suitable for wind and solar development throughout the state create a situation where BLMadministered lands appear to be less likely development candidates than other land ownerships.

Consistent with the previous analysis in (Barrows et al. 2016), the BLM-administered lands in Huerfano County have strong wind resource potential and are located close to transmission infrastructure. Additionally, RPM wind resource regions PSC01, PSC13 and PSC14 (see Appendix: Wind Resource Regions), which primarily represent lands in Huerfano County, show significant wind capacity expansions in the ST-URT and ST-MT scenarios. Although wind capacity expansions in and around Huerfano County vary widely across the sensitivities, the 
availability and proximity to transmission of BLM administered lands presents potentially attractive development opportunities.

The RPM simulation results suggest a limited amount of utility-scale solar PV development in Colorado. Table 5 and Table 8 shows that utility-scale PV development results are sensitive to the assumptions represented across the various scenarios. In particular, Table 8 shows that ECRMP solar development results are highly sensitive state coordination choices for CPP compliance. However, the Colorado utility-scale PV capacity expansion results are relatively modest across scenarios. Furthermore, BLM-administered lands with solar resource potential tend to be located further from transmission infrastructure than other land ownerships. The resource potential of non-BLM-administered lands is again more than sufficient to accommodate simulated solar capacity expansions in Colorado. While the majority of PV suitable land exists in Eastern Colorado, the majority of RPM simulated PV capacity expansion occurs outside the ECRMP boundary in Western and Southern portions of the state. Overall, attractive solar PV development opportunities on BLM lands are minimal, especially in the ECRMP region. The most attractive areas for solar PV development exist in the PSC22 solar resource region, which largely covers the San Luis Valley (see Appendix). We simulate modest utility-scale PV development in PSC22 through 2030, ranging from $92 \mathrm{MW}$ in the ST-MT scenario to $825 \mathrm{MW}$ in the Reference scenario. Additionally, significant solar capacity expansion is simulated in the PSC18 solar resource region for three of the six scenarios (REF, LO-NG, and WC-MT). The PSC 18 region covers lands near the city of Grand Junction and has an abundance of BLM administered lands within relatively close proximities to transmission infrastructure. 


\section{Conclusions}

The above analysis presents an extension to a previously published report (Barrows et al. 2016) on the potential for renewable energy development opportunities on BLM-administered lands.

The six simulation scenarios presented in this report represent several capacity expansion model enhancements that enable representation of updated policies and fuel price trajectories, relative to the scenarios presented in the previous report. Specifically, four scenarios that represent a range of possibilities for Western states to comply with the requirements of the EPAs Clean Power Plan are included in this analysis. Following the template established by the previous report, the Appendix contains detailed maps, tables, and figures for each wind and solar resource region where we simulate capacity expansions in any scenario. The maps highlight suitable land for renewable energy developments and provide a visual assessment of the proximity of various land ownerships to transmission infrastructure. The Appendix tables summarize the land availability data and the RPM results for each scenario. Finally, a set of three development preference figures is presented for each wind and solar resource region. The development preference figures describe the land usage allocations according to proportional, BLM, and private land development preferences. ${ }^{17}$ The analysis presented in the previous report highlighted several broad conclusions that remain. This analysis appends those findings and highlights several trends based on model updates and potential renewable energy policies.

- We find that capacity additions in Colorado are dominated by Wind capacity in the northeastern portion of the state. The limited intersection of high quality wind resource and BLM land administration in northeastern Colorado presents few opportunities for wind development on BLM-administered lands.

- Solar development is simulated to occur primarily in the San Luis Valley and other parts of Western and Southern Colorado. The increased solar development in Western and Southern Colorado suggests that BLM-administered lands in those areas could be attractive for utility-scale solar development.

- The improved policy and technology cost representations included in this analysis drive increased solar capacity expansion, relative to the reference scenario in the previous report.

- Depending upon the compliance pathways chosen by Western states, CPP implementation has the potential to drive significant renewable energy deployment, particularly if states chose to forgo emissions credit trading options.

- Absent additional policies and regulations, lower natural gas prices relative to EIA predictions (LO-NG scenario) would likely result in decreased wind and solar expansions in Colorado and the Western U.S.

The results suggest a healthy demand for utility scale renewable energy developments within the state of Colorado. The analysis suggests that optimal locations for wind and solar developments

\footnotetext{
${ }^{17}$ For a more complete description of the three development preferences, refer to the text in the Appendix.
} 
are sensitive to a number of factors, including energy policy, renewable energy resources, technology costs, access to transmission infrastructure, and others. The land ownership impact on renewable energy development potential remains unknown. However, these results suggest that there exist ample opportunities for partnerships between renewable energy developers and various landowners. While the proportion of Colorado renewable energy development that occurs on BLM-administered lands may be small, there exist several locations throughout the state where high quality wind and solar resources could provide attractive development opportunities on BLM-administered land.

The results presented in this report do not represent forecasts or predictions. Real-world decision making around facility citing is informed by a number of factors beyond the economic and technical factors represented in RPM. As such, future energy development in Colorado and the West will certainly differ from any result presented here. The land development preferences and conclusions do not reflect any existing policy or other recommendation pertaining to the formation of BLM resource management plans. Instead, the results and conclusions presented here aim to capture a range of possible futures and the corresponding development opportunities on various lands, including BLM-administered lands. 


\section{References}

Barrows, Clayton, Trieu Mai, Scott Haase, Jennifer Melius, and Meghan Mooney, eds. 2016. "Renewable Energy Deployment in Colorado and the West: A Modeling Sensitivity and GIS Analysis."

Blair, Nate, Karlynn Cory, Maureen Hand, Linda Parkhill, Bethany Speer, Tyler Stehly, David Feldman, et al. 2015. Annual Technology Baseline (Including Supporting Data). NREL (National Renewable Energy Laboratory).

“Broomfield Firm to Build Colorado's Largest Solar Farm near Pueblo.” 2016. Accessed January 29. http://www.denverpost.com/business/ci_28676186/broomfield-firm-build-stateslargest-solar-farm-near.

Cole, Wesley, Trieu Mai, Jeffrey Logan, Daniel Steinberg, James McCall, and James Richards. 2016. "2016 Standard Scenarios Report: A US Electricity Sector Outlook." National Renewable Energy Laboratory. http://www.nrel.gov/docs/fy17osti/66939.pdf.

Denholm, Paul, Maureen Hand, Maddalena Jackson, and Sean Ong. 2009. Land-Use Requirements of Modern Wind Power Plants in the United States. National Renewable Energy Laboratory Golden, CO.

DOE. 2015. "Wind Vision." U.S. Department of Energy. https://www.energy.gov/sites/prod/files/WindVision_Report_final.pdf.

EIA. 2015. Annual Energy Outlook. Washington: Office of Energy Markets and End Use, U.S. Dept. of Energy: Supt. of Docs., U.S. GPO, [distributor]. Accessed August 5. http://www.eia.gov/forecasts/aeo/index.cfm.

Energy Information Administration (EIA). 2014. "Annual Energy Outlook 2014 with Projections to 2040.” DOE/EIA-0383(2014). Washington, D.C.: U.S. Energy Information Association.

Holt, Ed. 2016. “POTENTIAL RPS MARKETS FOR RENEWABLE ENERGY GENERATORS.” Ed Holt \& Associates. http://cesa.org/assets/2014-Files/Potential-RPSMarkets-Report-Holt-January-2014.pdf.

Lopez, A., B. Roberts, D. Heimiller, N. Blair, and G. Porro. 2012. U.S. Renewable Energy Technical Potentials: A GIS-Based Analysis. http://www.osti.gov/scitech/servlets/purl/1047328.

Mai, T., C. Barrows, A. Lopez, E. Hale, M. Dyson, and K. Eurek. 2015. Implications of Model Structure and Detail for Utility Planning: Scenario Case Studies Using the Resource Planning Model.

Margolis, R, C Coggeshall, and J Zuboy. 2012. "SunShot Vision Study." US Dept. of Energy.

NERC. 2013. "2013 Summer Reliability Assessment." http://www.nerc.com/pa/RAPA/ra/Reliability\%20Assessments\%20DL/2013SRA_Final.p df.

"Review of the Clean Power Plan." 2017. Federal Register. April 4. https://www.federalregister.gov/documents/2017/04/04/2017-06522/review-of-the-cleanpower-plan.

Sigrin, Ben, Michael Gleason, Robert Preus, Ian Baring-Gould, and Robert Margolis. 2016. "The Distributed Generation Market Demand Model (dGen): Documentation." Technical Report NREL/TP-6A20-65231. Golden, Colorado: National Renewable Energy Laboratory (NREL). http://www.nrel.gov/docs/fy16osti/65231.pdf.

US EPA, OAR. 2015. “Clean Power Plan Final Rule.” Policies and Guidance. Accessed October 15. http://www2.epa.gov/cleanpowerplan/clean-power-plan-final-rule. 
"Xcel Energy Flips the Switch on Colorado Solar Power Plant." 2016. Denver Business Journal. Accessed January 29.

http://www.bizjournals.com/denver/blog/earth_to_power/2015/12/colorado-gets-massiveboost-in-solar-power.html. 


\section{Appendix}

The following figures and tables show the renewable resource regions within Colorado in which any RPM simulation scenario results in wind or utility-scale solar photovoltaic capacity expansions. Each resource region section contains several figures and tables of information designed to communicate the resource availability, land ownership, transmission proximity, and RPM simulation results. Each section is structured with the following information:

\section{- Resource region maps:}

- The thumbnail map in the bottom right shows the location of the highlighted resource region with the red outline. The map displays the Reference scenario simulated wind or solar capacity expansion as shaded resource regions. The map also contains the yellow border outlining the area covered by the ECRMP.

- The main "Colorado RPM Clusters" map featured in the figure focuses in on an individual resource region. Land area shaded in dark grey is unsuitable for resource development, while the land area highlighted in color is suitable for resource development following the exclusion rules outlined in (Lopez et al. 2012). The different colors of the shaded land area represent the different land ownerships (BLM, Other Federal ${ }^{18}$, Private, and Other ${ }^{19}$ ). In service and proposed transmission lines and substations are displayed in shades of purple and brown, respectively. The voltage rating of transmission infrastructure follows the legend in the bottom left of the figure. Finally, geographic information such as town names and road networks are displayed in light grey.

\section{- Suitable land area and MW potential tables:}

- Tables display the available land in acres and the corresponding resource potential in MW for lands of each ownership type within distances of 0-1 mi, 1-5 mi, 5-10 $\mathrm{mi}$, and $>10 \mathrm{mi}$ from the nearest in-service or proposed substation.

\section{- Modeled capacity tables:}

- The modeled capacity tables display the MW capacity expansion of each resource by 2030 in each RPM simulation scenario.

\section{- Proportional development preference grouped bar chart:}

- The proportional preference grouped bar chart describes a possible distribution of capacity sighting across land ownership types for each RPM simulation scenario. The distribution assumes that capacity expansion simulated in RPM scenarios is

\footnotetext{
${ }^{18}$ Other Federal: Bureau of Reclamation (BOR), Department of Defense (DOD), Department of Energy (DOE), Fish and Wildlife Service (FWS), National Parks Service (NPS), US Forest Service (USFS), Other/Unknown Federal

${ }^{19}$ Other: Jointly Owned, Non-Governmental Organization, Regional/Local, State, Tribal, Unknown
} 
built on each category of land ownership proportional to the distribution of suitable land area of each ownership type within the resource region. Each capacity bar is also shaded by the amount of suitable land within the various distances to transmission substations.

\section{- BLM development preference grouped bar chart:}

- The BLM preference grouped bar chart describes a possible distribution of capacity sighting across land ownership types assuming development takes place with the following priority order: BLM-administered land gets developed first, and other federal, "other", and private lands get developed second, third, and last. For example, consider a situation where we simulates a 30MW capacity expansion within a particular resource region. If BLM only administers enough land to accommodate $20 \mathrm{MW}$ of capacity within the resource region, the 20MW of capacity is allocated to BLM lands, and the remainder of the simulated capacity expansion is allocated first to other federal, then "other", and finally to private lands if necessary.

\section{- Private development preference grouped bar chart:}

- The private preference grouped bar chart describes a possible distribution of capacity sighting across land ownership types assuming development takes place with the following priority order: private land gets developed first, and "other", other federal, and BLM lands get developed second, third, and last. For example, consider a situation where we simulate a $30 \mathrm{MW}$ capacity expansion within a particular resource region. If private lands only account for enough land to accommodate $20 \mathrm{MW}$ of capacity within the resource region, the 20MW of capacity is allocated to private lands, and the remainder of the simulated capacity expansion is allocated first to "other", then other federal, and finally to BLM lands if necessary. 


\section{Wind Resource Regions}

\section{Colorado Wind Resource Regions}

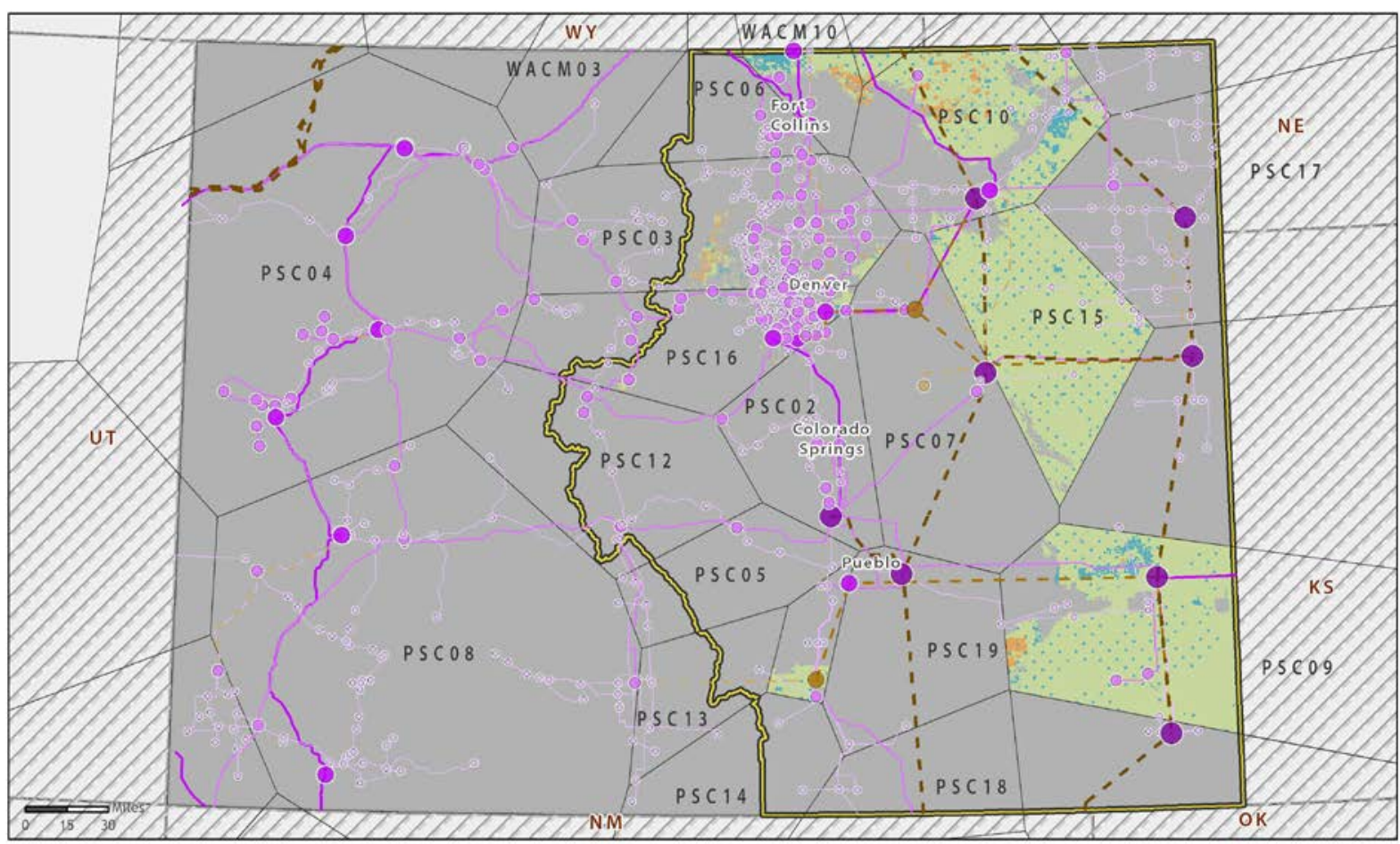

Substations and Transmission Lines
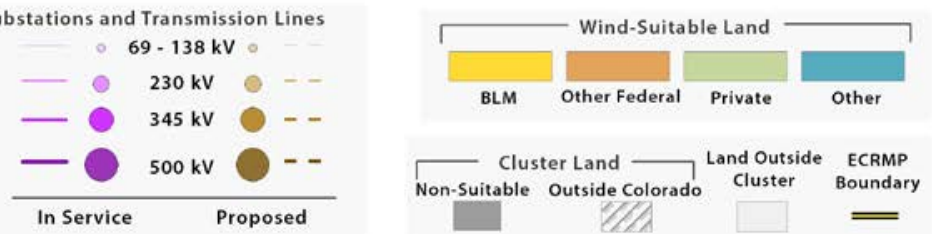

Duta Sources: NREL: USGS: NLCD:US Census: ABR The Yelocity Suite

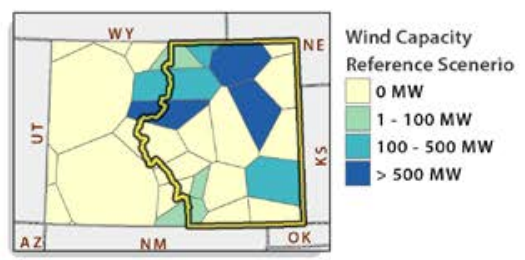

\begin{tabular}{c|cc|cc|cc|cc}
\hline \hline \multicolumn{8}{|c|}{ Colorado-Wind-Suitable Land: Area and MW Potential } \\
\hline Distance to & \multicolumn{2}{|c|}{$\mathbf{0 - 1}$ Miles } & \multicolumn{2}{c}{$\mathbf{1 - 5}$ Miles } & \multicolumn{2}{c}{$\mathbf{5 - 1 0}$ Miles } & \multicolumn{2}{c}{$>$ 10 Miles } \\
Transmission & Acres & MW & Acres & MW & Acres & MW & Acres & MW \\
\hline BLM & 676 & 8 & 10,742 & 130 & 35,485 & 431 & 85,689 & 1,040 \\
Federal & 286 & 3 & 35,028 & 425 & 152,692 & 1,854 & 747,768 & 9,078 \\
Other & 14,855 & 180 & 286,770 & 3,482 & 403,691 & 4,901 & 630,510 & 7,655 \\
Private & 170,090 & 2,065 & $3,482,771$ & 42,283 & $5,609,683$ & 68,105 & $8,660,317$ & 105,141 \\
\hline \hline
\end{tabular}

\begin{tabular}{cccccc}
\hline \hline \multicolumn{7}{l}{ Colorado - Modeled Wind Capacity } \\
\hline Ref & LO-NG & SC-DRT & SC-MT & SC-URT & WC-MT \\
3,983 & 2,996 & 6,034 & 7,767 & 6,082 & 3,981 \\
\hline \hline
\end{tabular}




\section{ECRMP Wind Resource Regions}

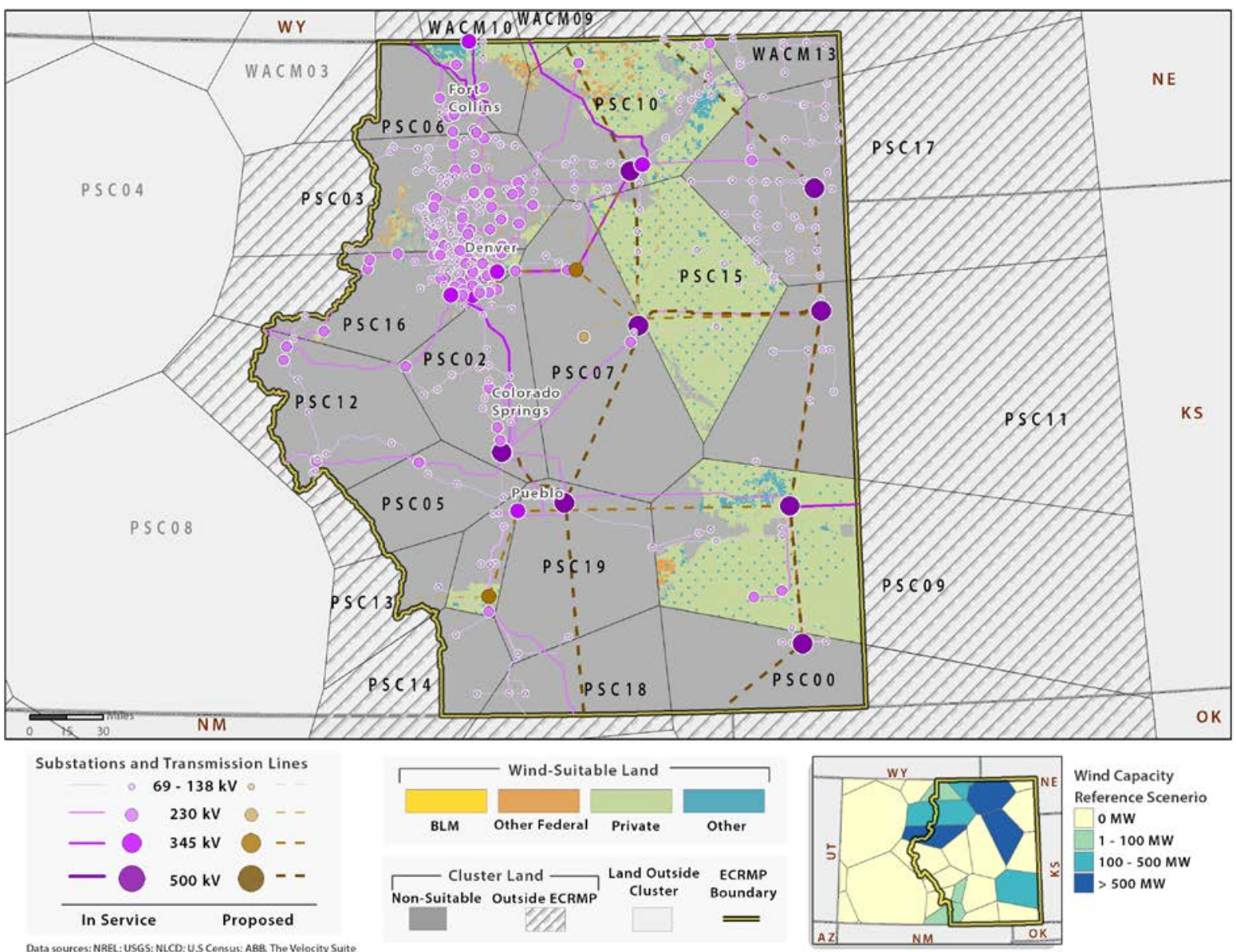

\begin{tabular}{c|cc|cc|cc|cc}
\hline \hline \multicolumn{10}{c}{ ECRMP-Wind-Suitable Land: Area and MW Potential } \\
\hline $\begin{array}{c}\text { Distance to } \\
\text { Transmission }\end{array}$ & \multicolumn{2}{c|}{$\mathbf{0 - 1}$ Miles } & \multicolumn{2}{c}{$\mathbf{1 - 5}$ Miles } & \multicolumn{2}{c}{$\mathbf{5 - 1 0}$ Miles } & \multicolumn{2}{c}{$>$ 10 Miles } \\
\hline BLres & MW & Acres & MW & Acres & MW & Acres & MW \\
\hline Federal & 660 & 8 & 10,262 & 125 & 33,696 & 409 & 22,132 & 269 \\
Other & 276 & 3 & 33,679 & 409 & 148,468 & 1,802 & 732,313 & 8,891 \\
Private & 14,855 & 180 & 286,284 & 3,476 & 403,365 & 4,897 & 624,398 & 7,581 \\
\hline \hline
\end{tabular}

\begin{tabular}{|c|c|c|c|c|c|}
\hline \multicolumn{6}{|c|}{ ECRMP - Modeled Wind Capacity } \\
\hline Ref & LO-NG & $S C-D R T$ & $S C-M T$ & $S C-U R T$ & WC-MT \\
\hline 3,983 & 2,996 & 5,033 & 5,964 & 5,380 & 3,981 \\
\hline
\end{tabular}




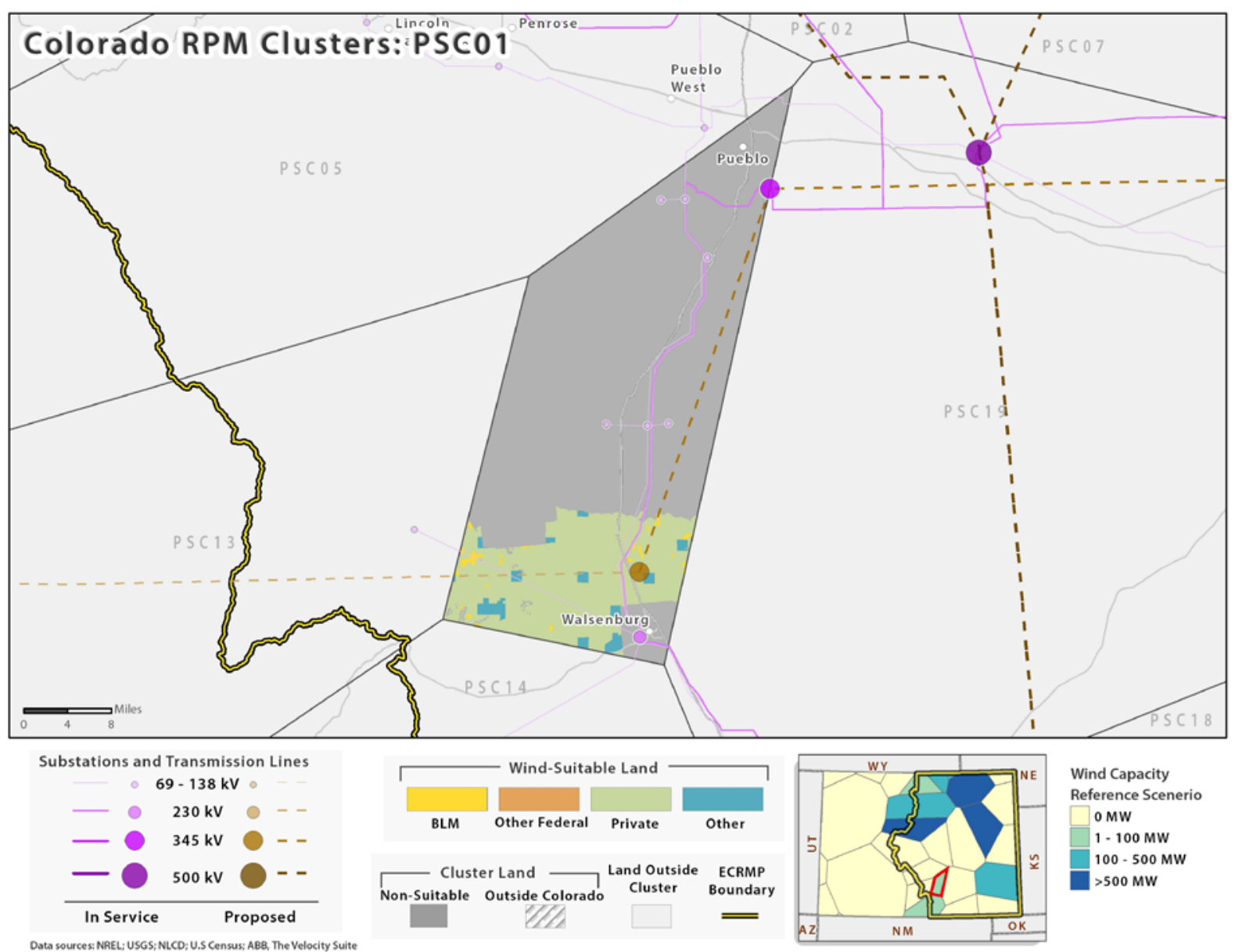

\begin{tabular}{c|cc|cc|cc|cc}
\hline \hline \multicolumn{1}{c}{ PSC1-Wind-Suitable Land: Area and MW Potential } \\
\hline Distance to & \multicolumn{2}{c|}{$\mathbf{0 - 1}$ Miles } & \multicolumn{2}{c|}{$\mathbf{1 - 5}$ Miles } & \multicolumn{2}{c}{$\mathbf{5 - 1 0}$ Miles } & \multicolumn{2}{c}{$>$ 10 Miles } \\
Transmission & Acres & MW & Acres & MW & Acres & MW & Acres & MW \\
\hline BLM & 0 & 0 & 926 & 11 & 1,626 & 20 & 160 & 2 \\
Federal & 0 & 0 & 0 & 0 & 0 & 0 & 0 & 0 \\
Other & 228 & 3 & 3,311 & 40 & 2,947 & 36 & 1,764 & 21 \\
Private & 1,781 & 22 & 43,220 & 525 & 61,155 & 742 & 11,224 & 136 \\
\hline \hline
\end{tabular}

\begin{tabular}{cccccc}
\hline \hline \multicolumn{2}{l}{ PSC01 } & Modeled Wind Capacity \\
\hline Ref & LO-NG & SC-DRT & SC-MT & SC-URT & WC-MT \\
29 & 29 & 29 & 29 & 29 & 29 \\
\hline \hline
\end{tabular}



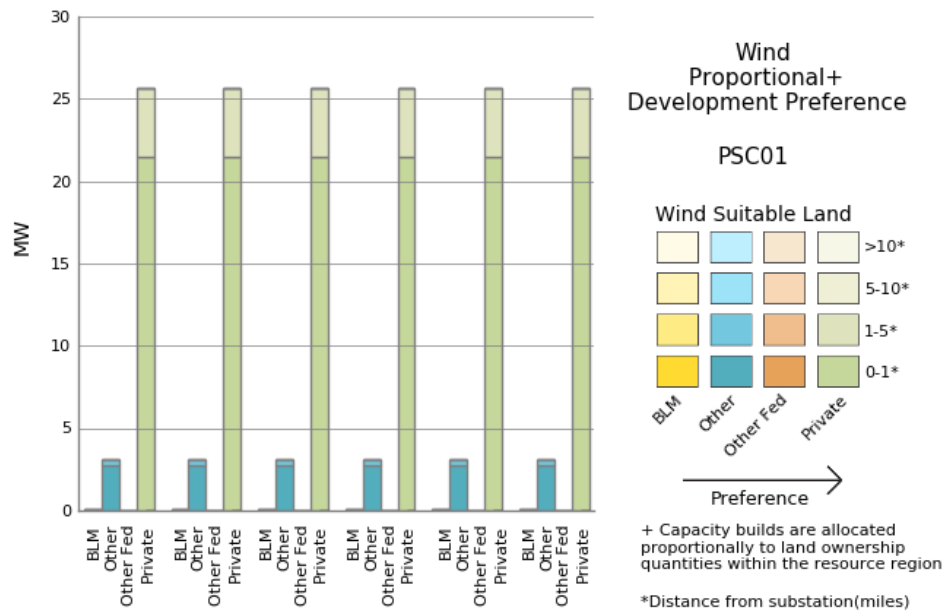

REF LO-NG ST-DRT ST-MT ST-URT WC-MT
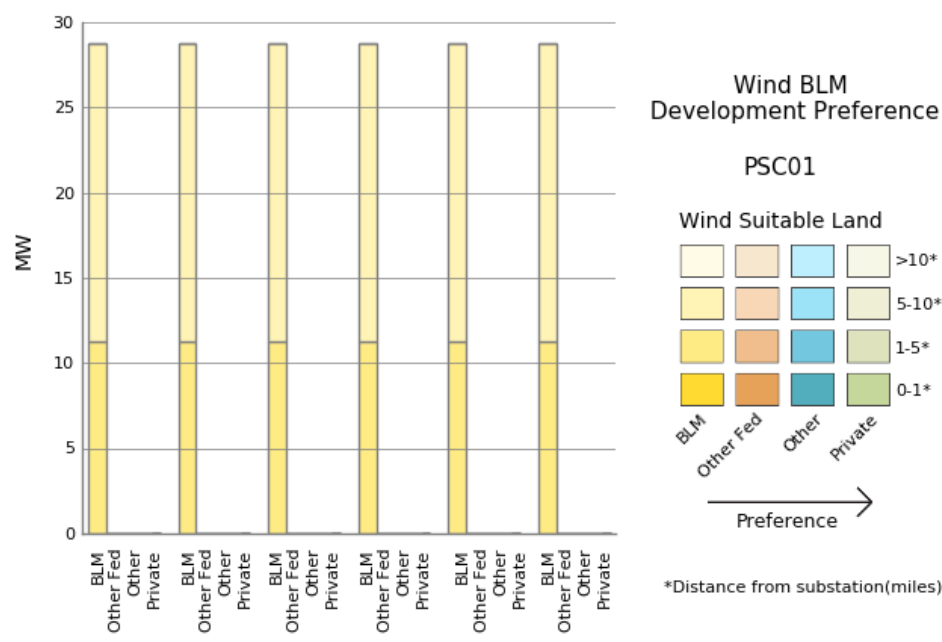

PSC01

Wind Suitable Land $\square \square \square \square>10^{*}$

$\square \square \square \square$ 5-10* $\square \square \square \square-1-5 *$ $\square \square \square \square \square^{0-1^{*}}$

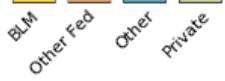
$\longrightarrow$ Preference $>$

REF LO-NG ST-DRT ST-MT ST-URT WC-MT *Distance from substation(miles)

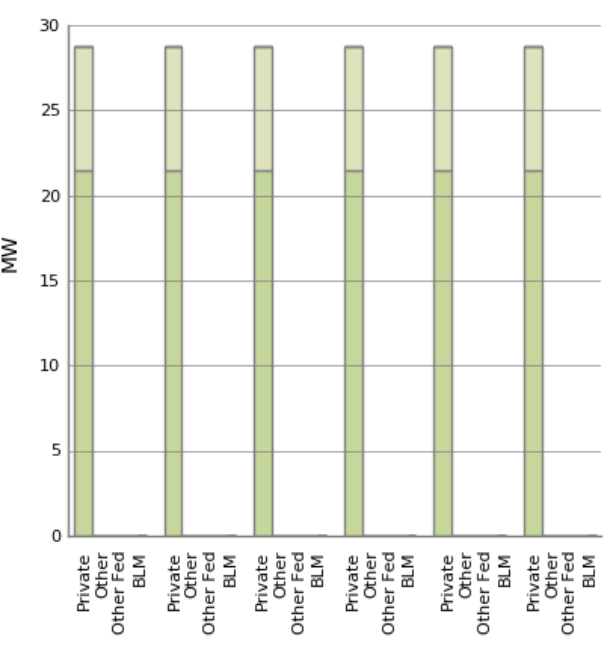

Wind Private Development Preference

PSC01

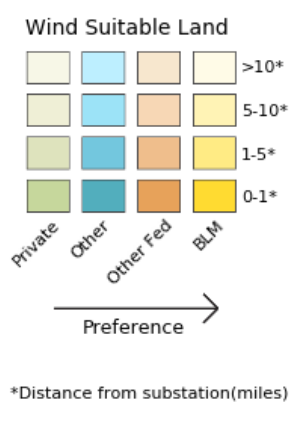

REF LO-NG ST-DRT ST-MT ST-URT WC-MT 


\section{PSC03 Wind Resource Region}

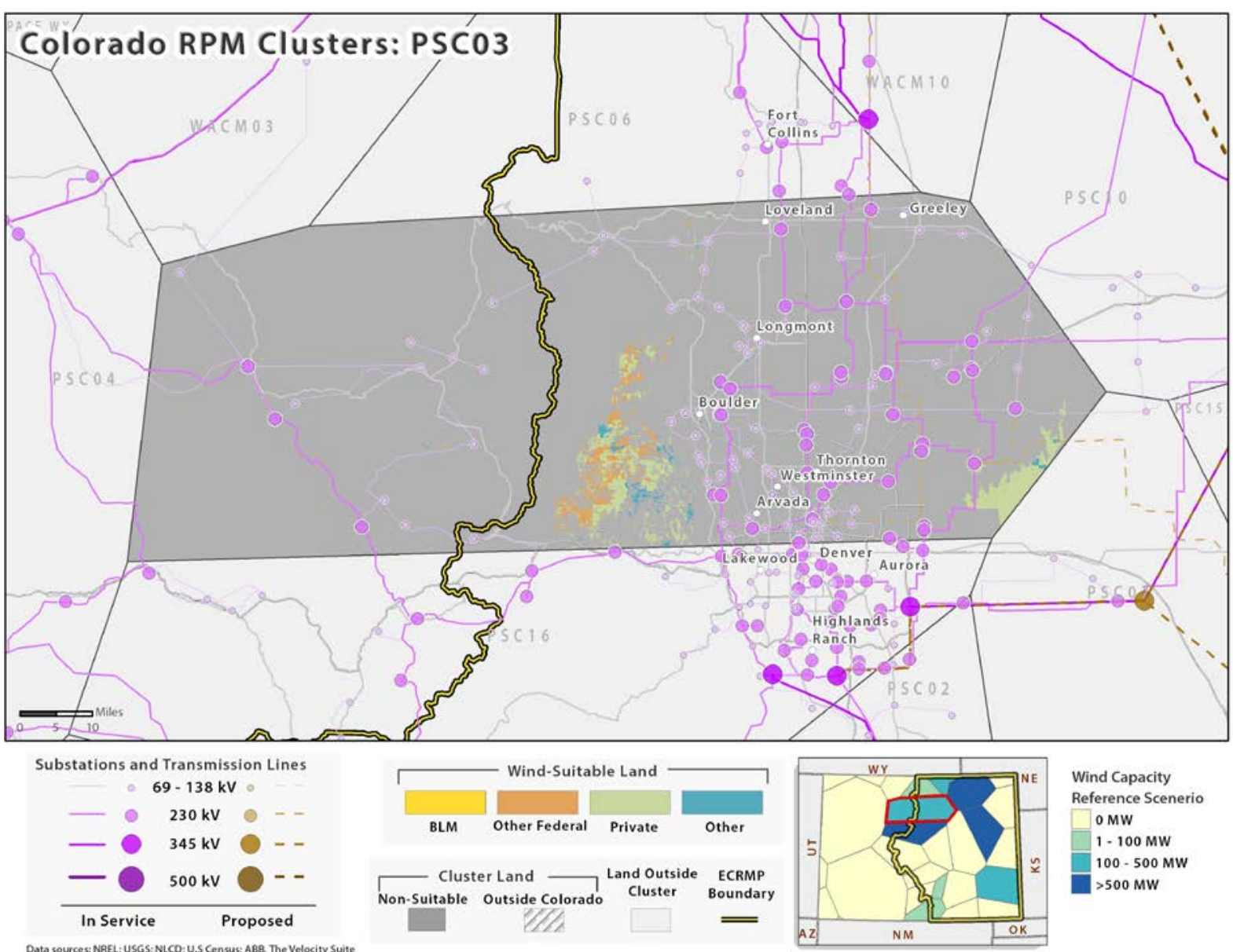

\begin{tabular}{c|cc|cc|cc|cc}
\hline \hline \multicolumn{8}{c}{ PSC03-Wind-Suitable Land: Area and MW Potential } \\
\hline Distance to & \multicolumn{2}{c|}{$\mathbf{0 - 1}$ Miles } & \multicolumn{2}{c|}{$\mathbf{1 - 5}$ Miles } & \multicolumn{2}{c}{5 -10 Miles } & \multicolumn{2}{c}{$>$ 10 Miles } \\
Transmission & Acres & MW & Acres & MW & Acres & MW & Acres & MW \\
\hline BLM & 0 & 0 & 90 & 1 & 238 & 2 & 0 & 0 \\
Federal & 0 & 0 & 1,960 & 23 & 21,570 & 262 & 5,964 & 72 \\
Other & 0 & 0 & 2,579 & 31 & 6,627 & 80 & 216 & 2 \\
Private & 499 & 6 & 9,675 & 117 & 58,891 & 715 & 6,394 & 77 \\
\hline \hline
\end{tabular}

\begin{tabular}{cccccc}
\hline \hline \multicolumn{7}{l}{ PSC03 } & Modeled Wind Capacity \\
\hline$R e f$ & LO-NG & SC-DRT & SC-MT & SC-URT & WC-MT \\
275 & 275 & 275 & 383 & 275 & 275 \\
\hline \hline
\end{tabular}



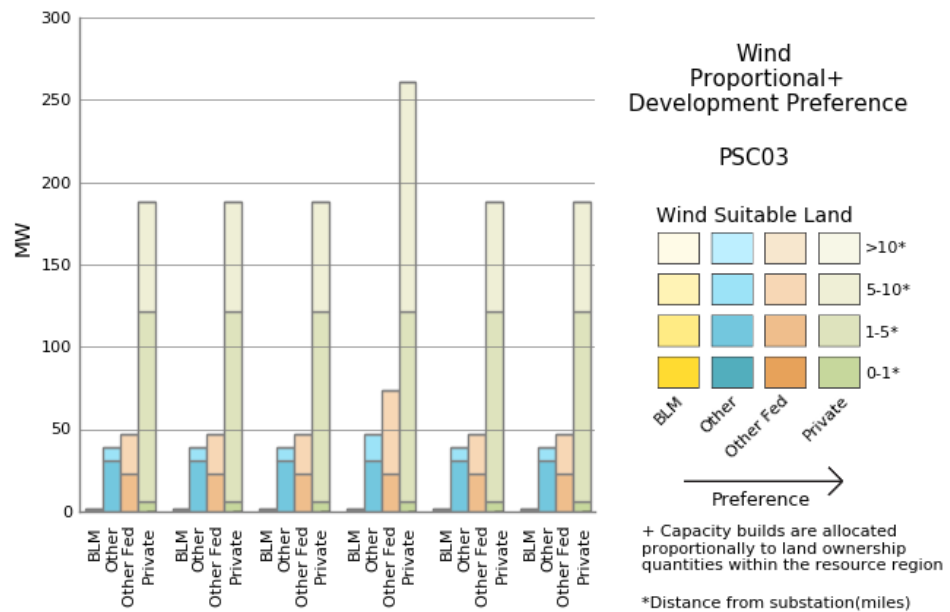

REF LO-NG ST-DRT ST-MT ST-URT WC-MT
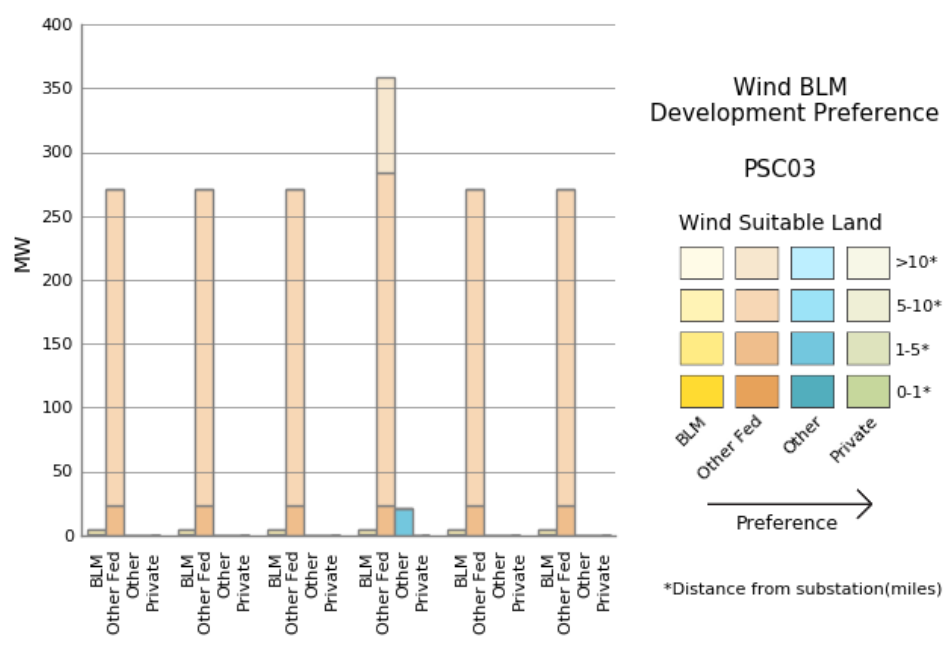

$\mathrm{PSC} 03$

Wind Suitable Land $\square \square \square \square>10 *$ $\square \square \square-\square-10$ * $\square \square \square \square 1-5^{*}$ $\square \square \square \square-\square^{0} 1^{*}$

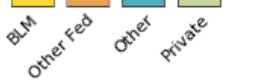
$\underset{\text { Preference }}{>}$

REF LO-NG ST-DRT ST-MT ST-URT WC-MT *Distance from substation(miles)

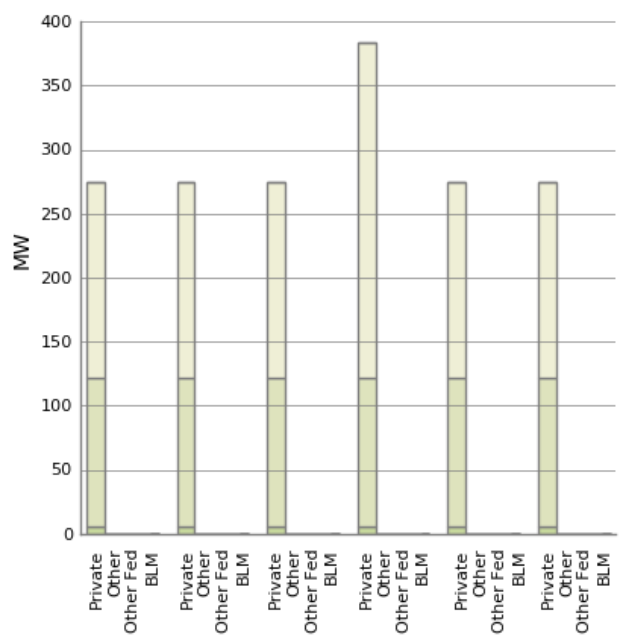

Wind Private Development Preference

\section{PSC03}

Wind Suitable Land

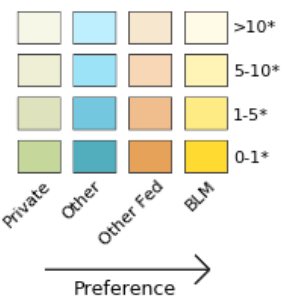

*Distance from substation(miles)

REF LO-NG ST-DRT ST-MT ST-URT WC-MT 


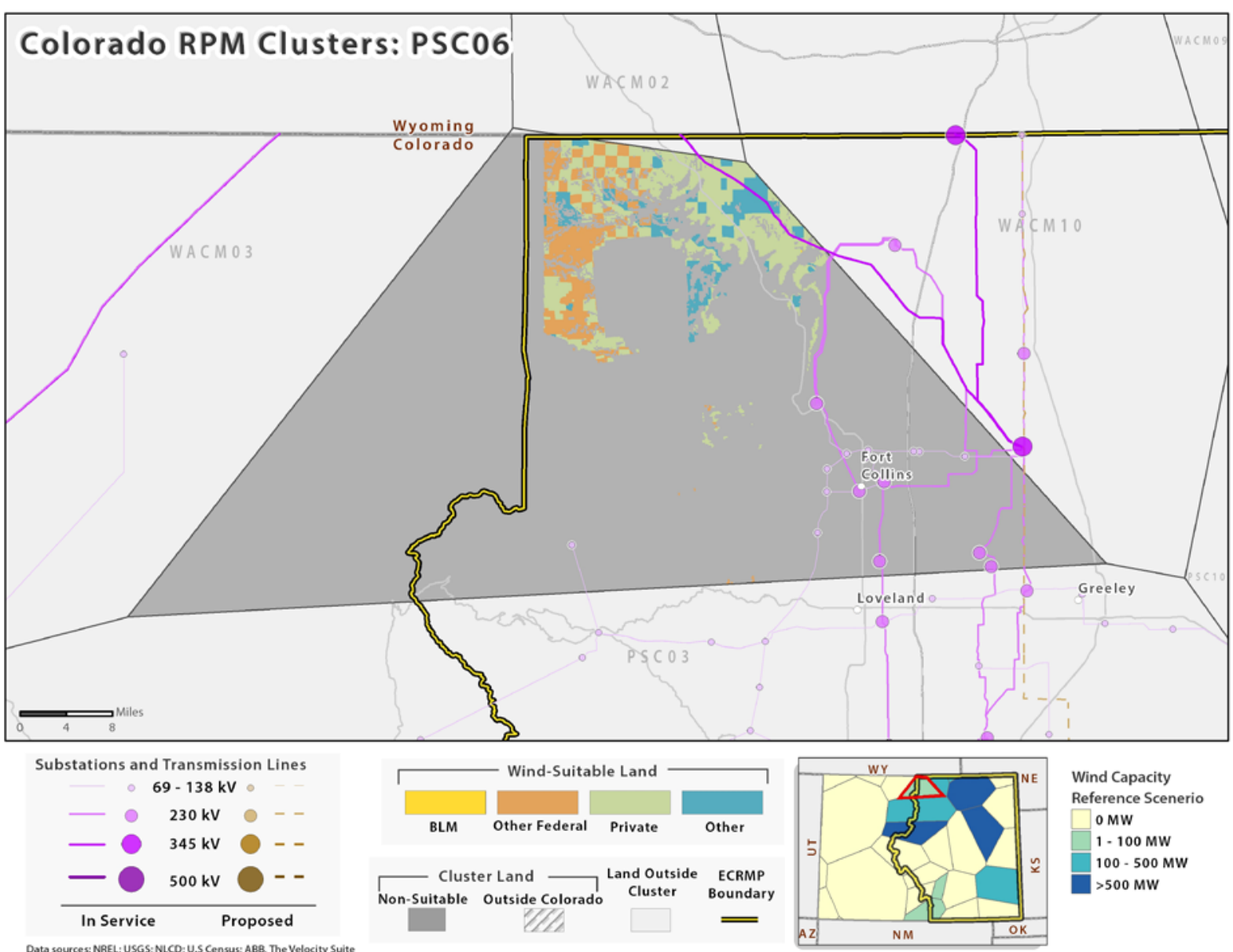

\begin{tabular}{|c|c|c|c|c|c|c|c|c|}
\hline \multicolumn{9}{|c|}{ PSC06-Wind-Suitable Land: Area and MW Potential } \\
\hline \multirow{2}{*}{$\begin{array}{l}\text { Distance to } \\
\text { Transmission }\end{array}$} & \multicolumn{2}{|c|}{ 0-1 Miles } & \multicolumn{2}{|c|}{ 1-5 Miles } & \multicolumn{2}{|c|}{ 5-10 Miles } & \multicolumn{2}{|c|}{$>10$ Miles } \\
\hline & Acres & MW & Acres & MW & Acres & MW & Acres & MW \\
\hline BLM & 0 & 0 & 0 & 0 & 16 & 0 & 0 & 0 \\
\hline Federal & 0 & 0 & 0 & 0 & 283 & 3 & 34,608 & 420 \\
\hline Other & 0 & 0 & 0 & 0 & 1,184 & 14 & 19,870 & 241 \\
\hline Private & 0 & 0 & 183 & 2 & 8,824 & 107 & 58,789 & 714 \\
\hline
\end{tabular}

\begin{tabular}{cccccc}
\hline \hline \multicolumn{7}{l}{ PSC06 - Modeled Wind Capacity } \\
\hline Ref & LO-NG & SC-DRT & SC-MT & SC-URT & WC-MT \\
14 & 0 & 969 & 942 & 957 & 14 \\
\hline \hline
\end{tabular}




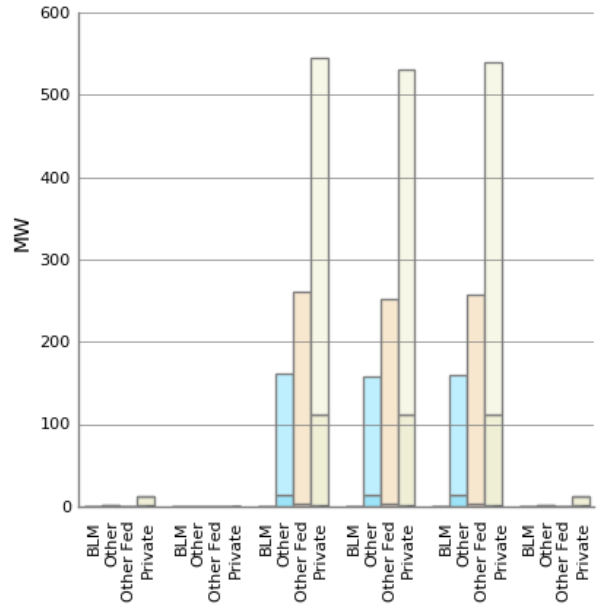

REF LO-NG ST-DRT ST-MT ST-URT WC-MT

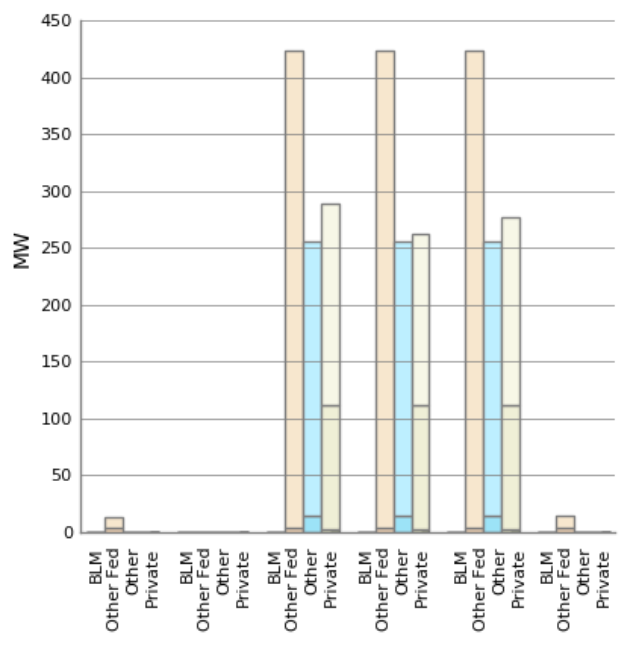

REF LO-NG ST-DRT ST-MT ST-URT WC-MT

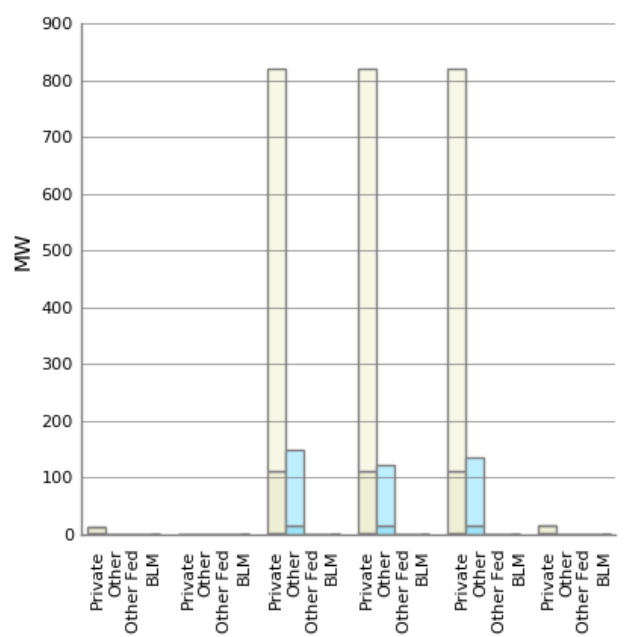

REF LO-NG ST-DRT ST-MT ST-URT WC-MT
Wind
Proportional+ Development Preference

PSC06

Wind Suitable Land

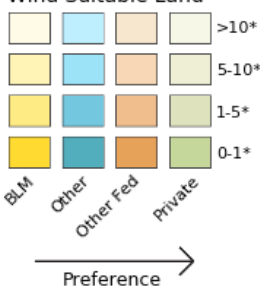

+ Capacity builds are allocated proportionally to land ownership

*Distance from substation(miles)

Wind BLM Development Preference

PSC06

Wind Suitable Land $\square \square \square \square>10 *$ $\square \square \square \square$ 5-10* $\square \square \square \square(-5 *$ $\square \square \square \square-1 *$

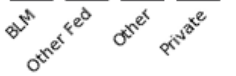
Preference $>$

*Distance from substation(miles)

Wind Private Development Preference

PSC06

Wind Suitable Land

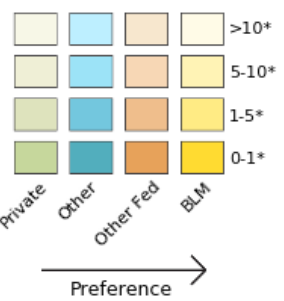

*Distance from substation(miles) 


\section{PSC09 Wind Resource Region}

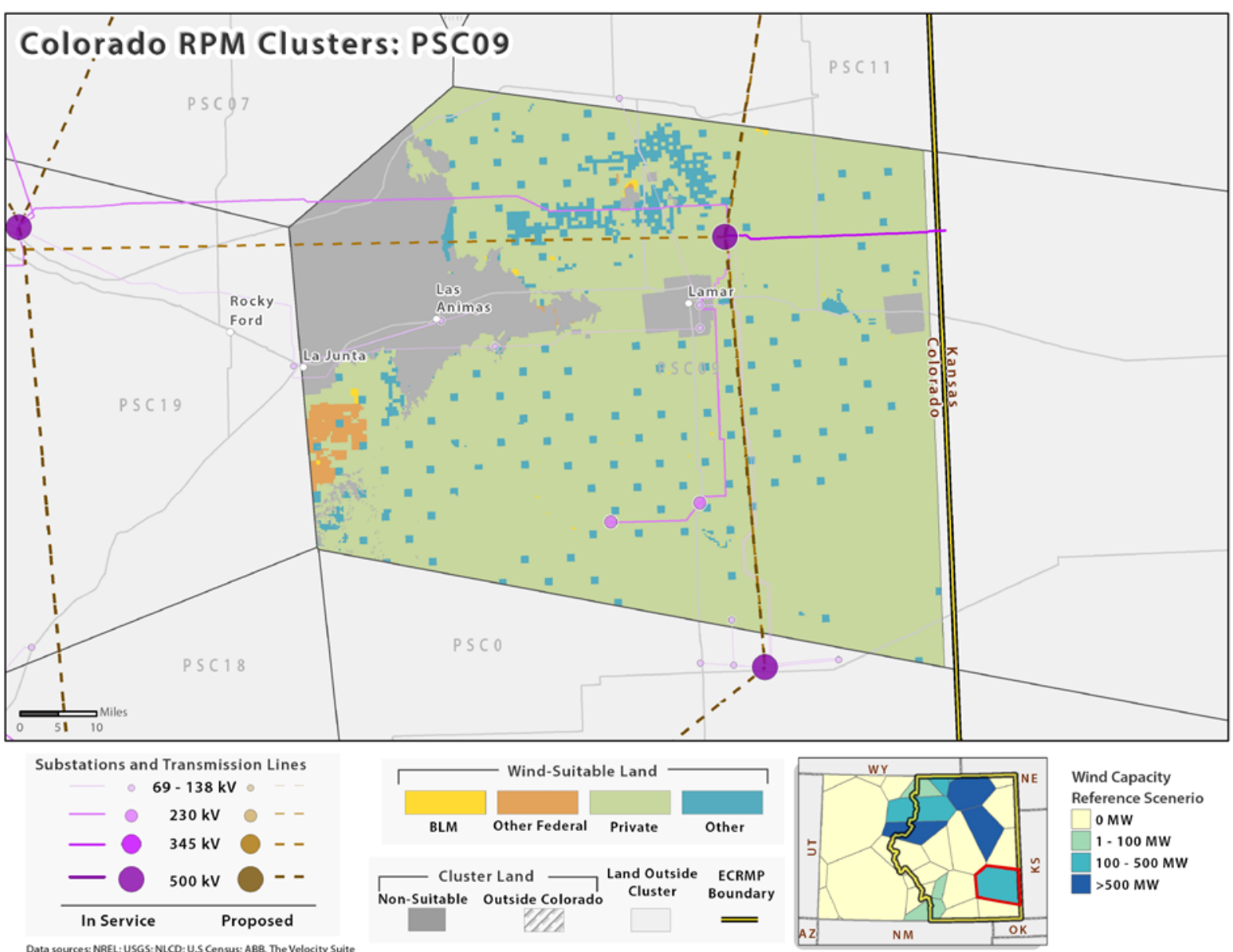

\begin{tabular}{c|cc|cc|cc|cc}
\hline \hline \multicolumn{10}{c}{ PSC09-Wind-Suitable Land: Area and MW Potential } \\
\hline Distance to & \multicolumn{2}{|c|}{$\mathbf{0 - 1}$ Miles } & \multicolumn{2}{|c|}{ 1-5 Miles } & \multicolumn{2}{c}{ 5-10 Miles } & \multicolumn{2}{c}{$>$ 10 Miles } \\
Transmission & Acres & MW & Acres & MW & Acres & MW & Acres & MW \\
\hline BLM & 0 & 0 & 90 & 1 & 1,809 & 21 & 1,882 & 22 \\
Federal & 0 & 0 & 33 & 0 & 13,469 & 163 & 18,803 & 228 \\
Other & 533 & 6 & 12,491 & 151 & 57,470 & 698 & 106,279 & 1,291 \\
Private & 9,041 & 109 & 262,287 & 3,187 & 720,178 & 8,752 & $1,698,638$ & 20,643 \\
\hline \hline
\end{tabular}

\begin{tabular}{cccccc}
\hline \hline \multicolumn{7}{l}{ PSC09 } & Modeled Wind Capacity \\
\hline Ref & LO-NG & SC-DRT & SC-MT & SC-URT & WC-MT \\
237 & 237 & 237 & 237 & 237 & 237 \\
\hline \hline
\end{tabular}



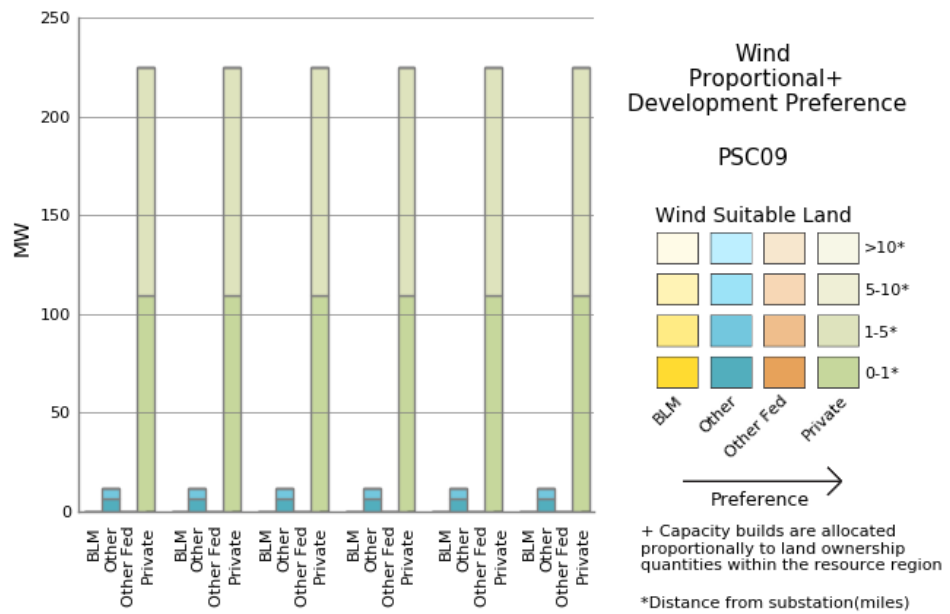

REF LO-NG ST-DRT ST-MT ST-URT WC-MT
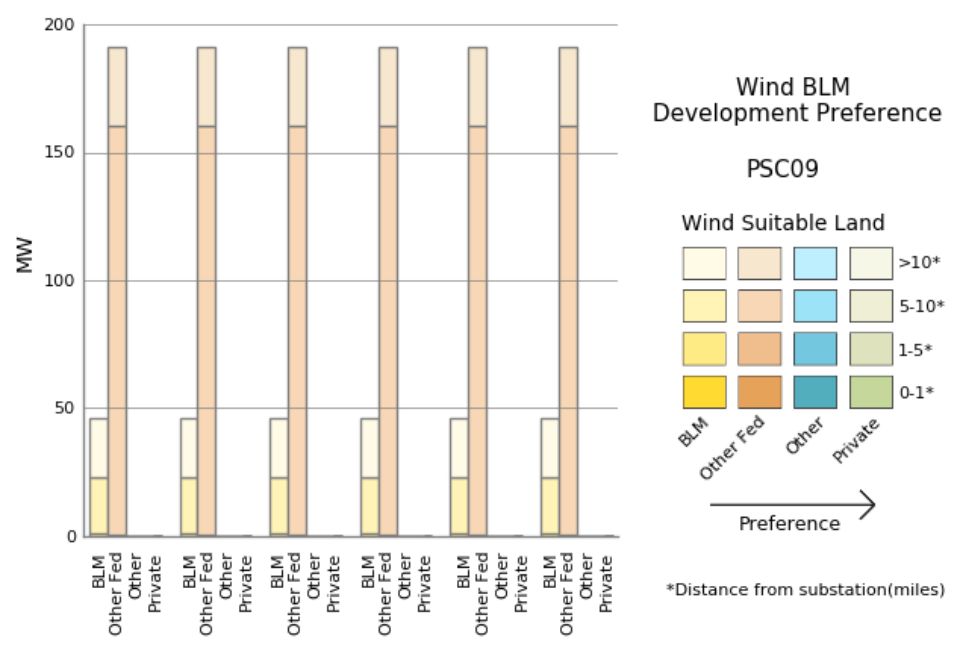

PSC09

Wind Suitable Land $\square \square \square \square>10^{*}$ $\square \square \square \square{ }_{5-10^{*}}$ $\square \square \square \square \square_{1.5 *}$

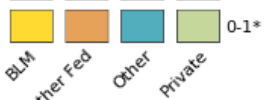

REF LO-NG ST-DRT ST-MT ST-URT WC-MT

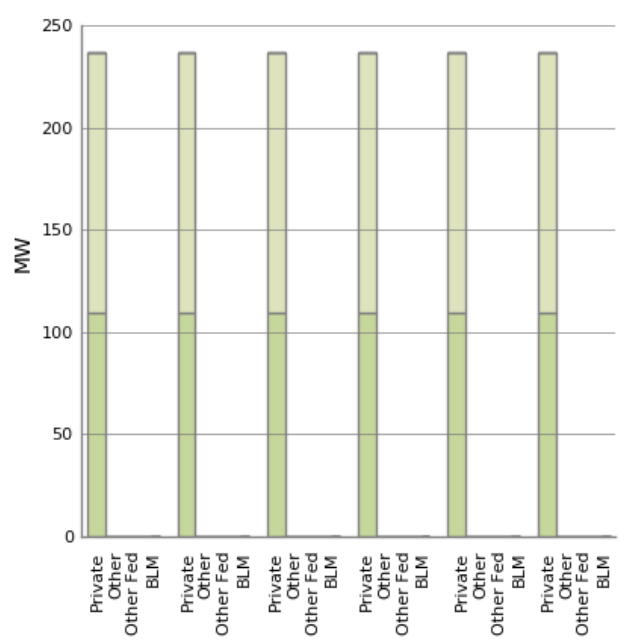

Wind Private Development Preference

PSC09

Wind Suitable Land

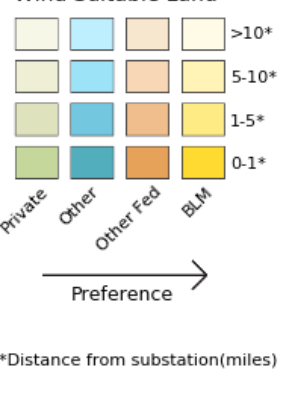

REF LO-NG ST-DRT ST-MT ST-URT WC-MT

This report is available at no cost from the National Renewable Energy Laboratory at www.nrel.gov/publications. 


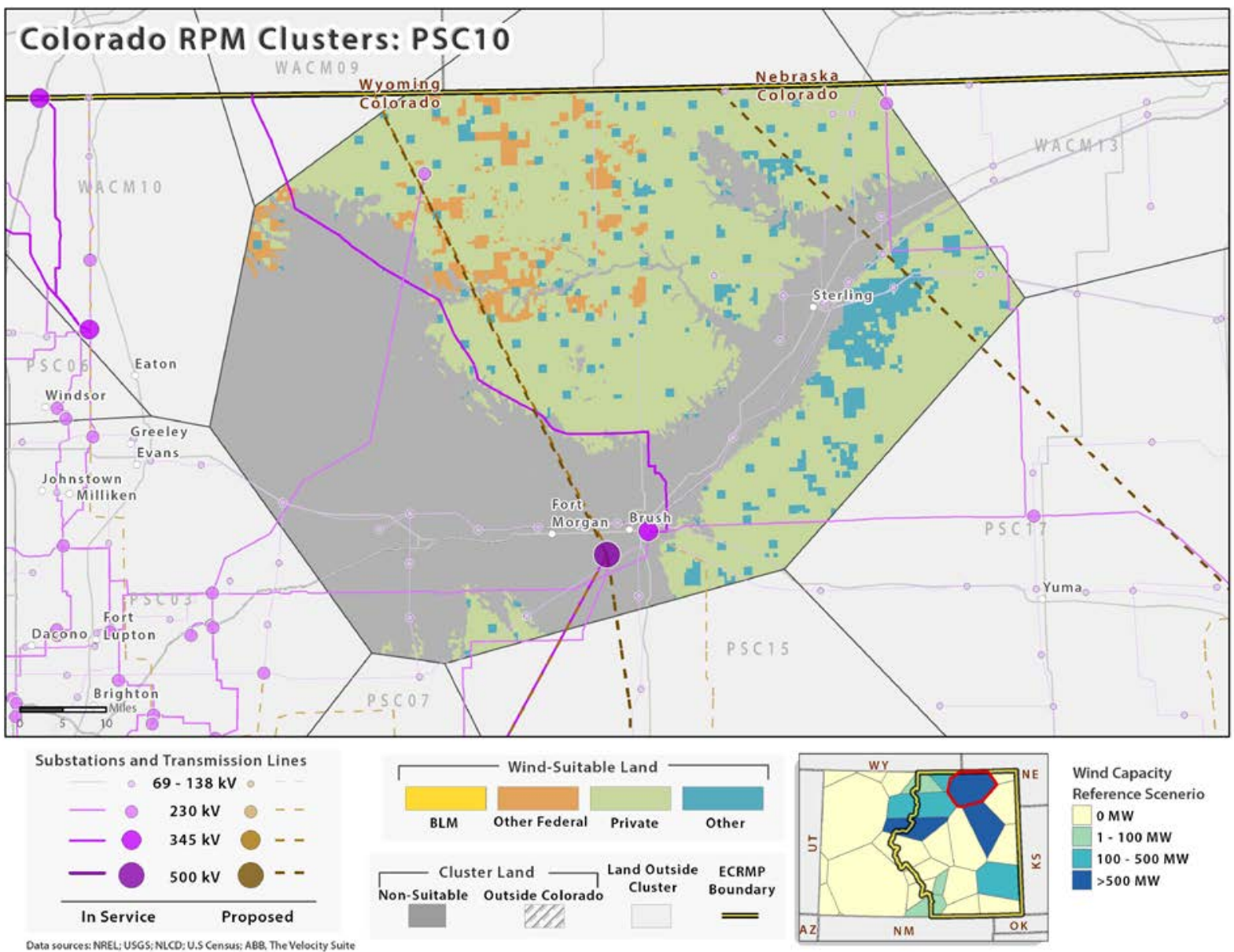

\begin{tabular}{c|cc|cc|cc|cc}
\hline \hline \multicolumn{1}{c}{ PSC10-Wind-Suitable Land: Area and MW Potential } \\
\hline Distance to & \multicolumn{2}{c|}{$\mathbf{0 - 1}$ Miles } & \multicolumn{2}{c|}{ 1-5 Miles } & \multicolumn{2}{c}{ 5-10 Miles } & \multicolumn{2}{c}{$>$ 10 Miles } \\
Transmission & Acres & MW & Acres & MW & Acres & MW & Acres & MW \\
\hline BLM & 0 & 0 & 0 & 0 & 105 & 1 & 56 & 0 \\
Federal & 0 & 0 & 4,289 & 52 & 16,839 & 204 & 70,446 & 856 \\
Other & 2,283 & 27 & 54,102 & 657 & 58,238 & 707 & 43,326 & 526 \\
Private & 15,575 & 189 & 275,559 & 3,348 & 524,775 & 6,377 & 537,298 & 6,529 \\
\hline \hline
\end{tabular}

\begin{tabular}{|c|c|c|c|c|c|}
\hline \multicolumn{6}{|c|}{ PSC10 - Modeled Wind Capacity } \\
\hline Ref & $L O-N G$ & $S C-D R T$ & $S C-M T$ & $S C-U R T$ & WC-MT \\
\hline 1,001 & 1,001 & 1,001 & 1,001 & 1,001 & 1,001 \\
\hline
\end{tabular}




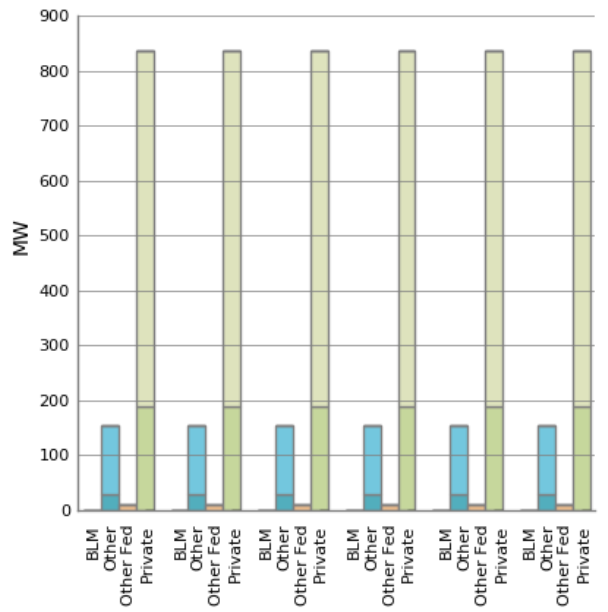

Wind
Proportional+
Development Preference

PSC10

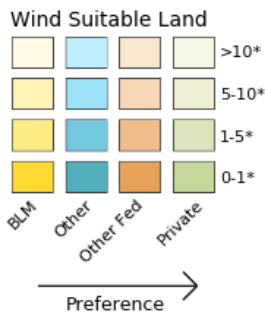

+ Capacity builds are allocated proportionally to land ownership

(Distance from substation(miles)

REF LO-NG ST-DRT ST-MT ST-URT WC-MT

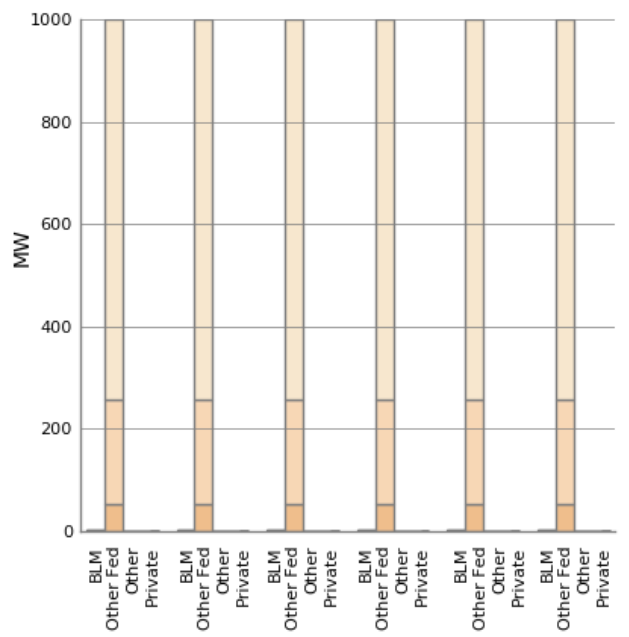

Wind BLM Development Preference

PSC10

Wind Suitable Land $\square \square \square \square>10 *$ $\square \square \square-\square-10^{*}$ $\square \square \square \square 1-5 *$ $\square \square \square-\square^{*}$

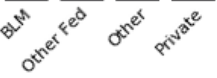
$\underset{\text { Preference }}{>}$

*Distance from substation(miles)

REF LO-NG ST-DRT ST-MT ST-URT WC-MT

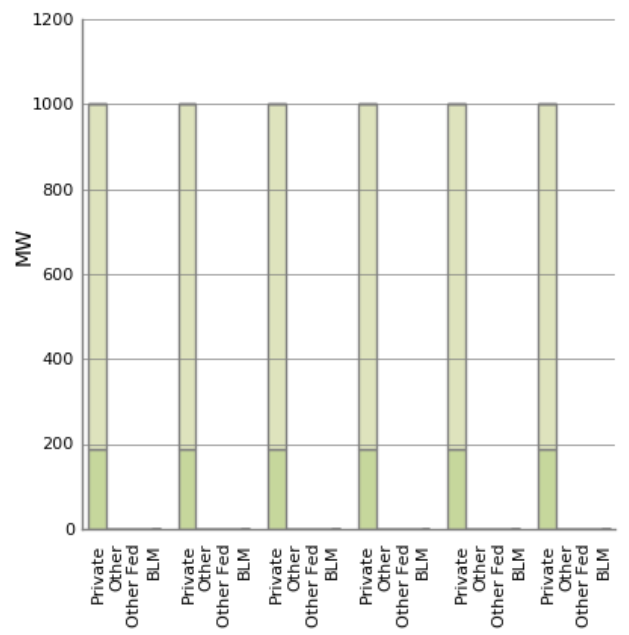

Wind Private Development Preference

PSC10

Wind Suitable Land

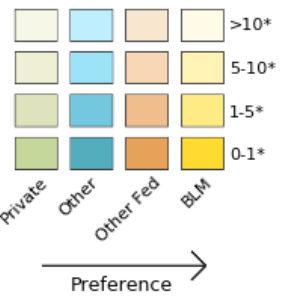

*Distance from substation(miles)

REF LO-NG ST-DRT ST-MT ST-URT WC-MT

This report is available at no cost from the National Renewable Energy Laboratory at www.nrel.gov/publications. 


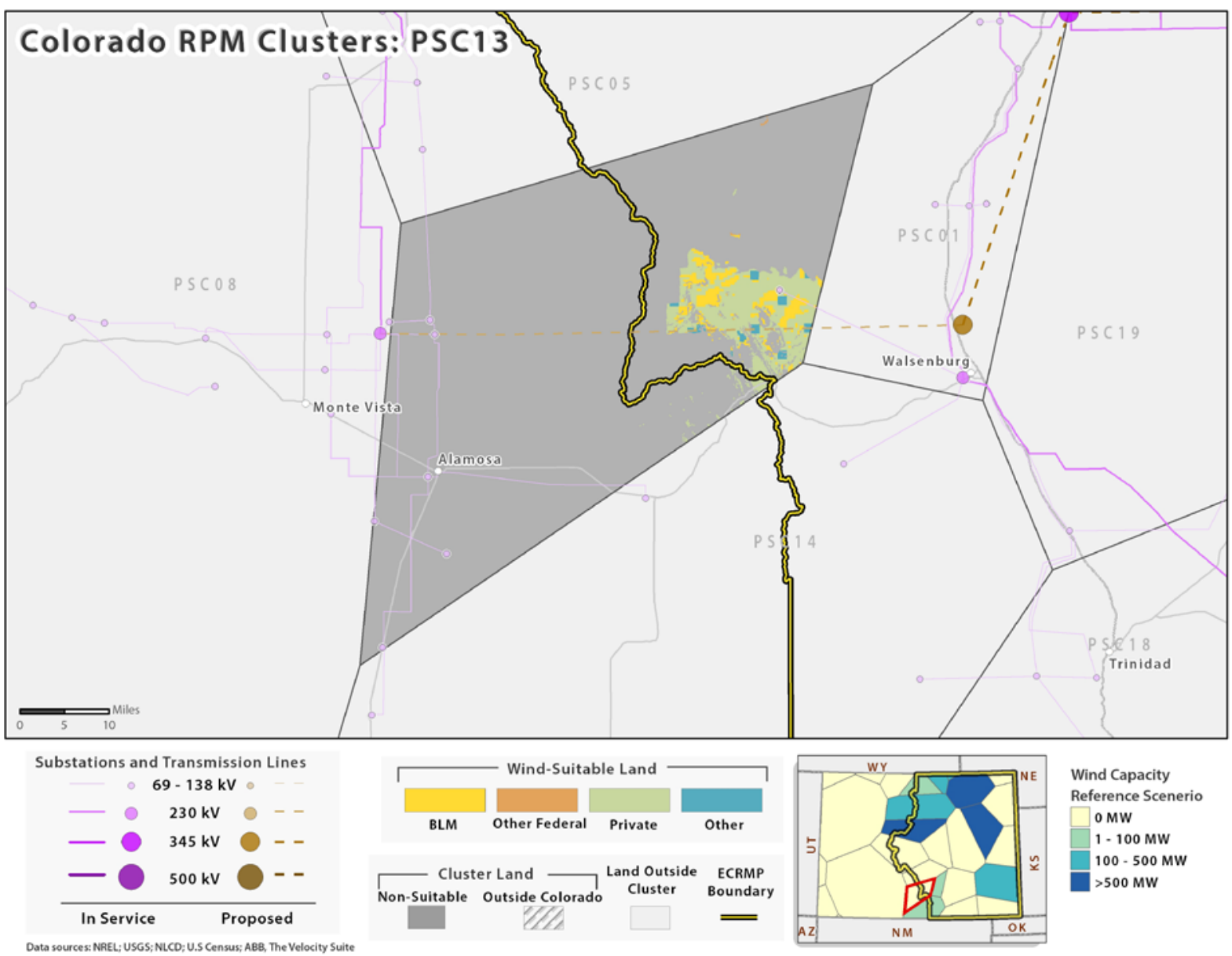

\begin{tabular}{c|cc|cc|cc|cc}
\hline \hline \multicolumn{1}{|c|}{ PSC13-Wind-Suitable Land: Area and MW Potential } \\
\hline Distance to & \multicolumn{2}{|c|}{$\mathbf{0 - 1}$ Miles } & \multicolumn{2}{c|}{$\mathbf{1 - 5}$ Miles } & \multicolumn{2}{c}{$\mathbf{5 - 1 0}$ Miles } & \multicolumn{2}{c}{$>$ >10 Miles } \\
Transmission & Acres & MW & Acres & MW & Acres & MW & Acres & MW \\
\hline BLM & 430 & 5 & 6,933 & 84 & 10,654 & 129 & 2,168 & 26 \\
Federal & 0 & 0 & 0 & 0 & 92 & 1 & 165 & 2 \\
Other & 148 & 1 & 1,517 & 18 & 2,027 & 24 & 696 & 8 \\
Private & 1,432 & 17 & 23,758 & 288 & 27,619 & 335 & 10,253 & 124 \\
\hline \hline
\end{tabular}

\begin{tabular}{cccccc}
\hline \hline \multicolumn{7}{l}{ PSC13 } & Modeled Wind Capacity \\
\hline Ref & LO-NG & SC-DRT & SC-MT & SC-URT & WC-MT \\
0 & 0 & 0 & 290 & 306 & 0 \\
\hline \hline
\end{tabular}



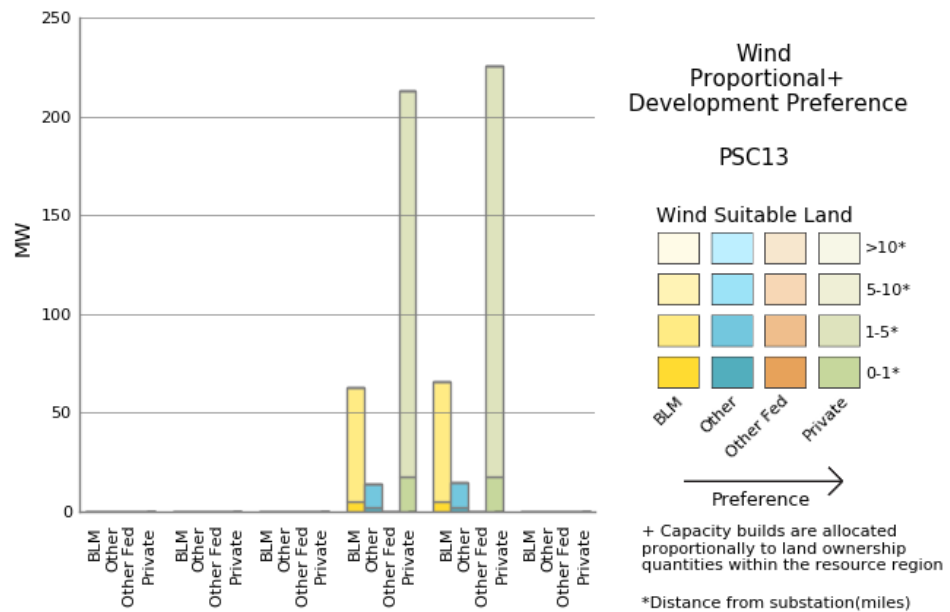

REF LO-NG ST-DRT ST-MT ST-URT WC-MT
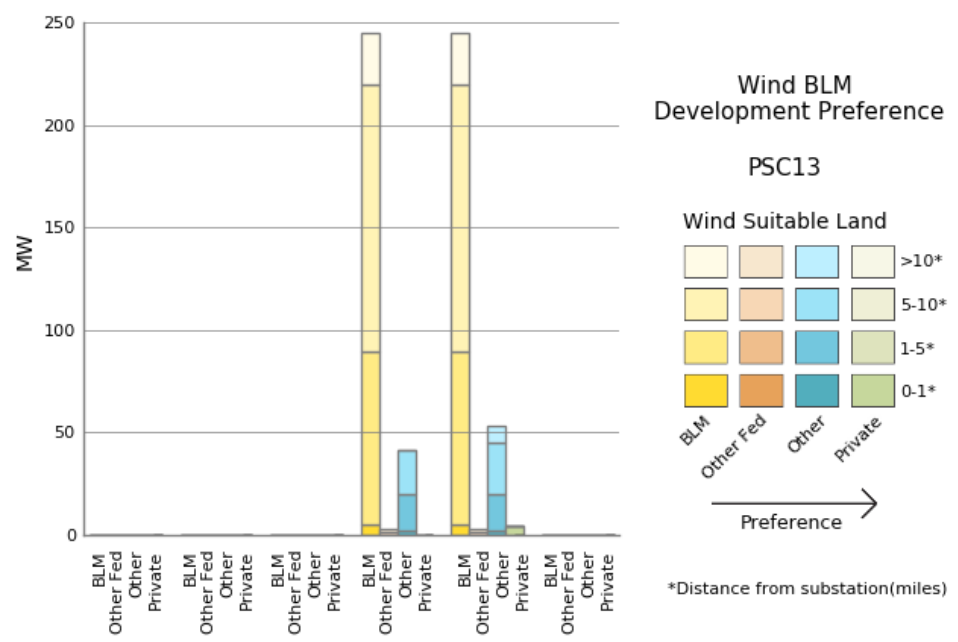

REF LO-NG ST-DRT ST-MT ST-URT WC-MT
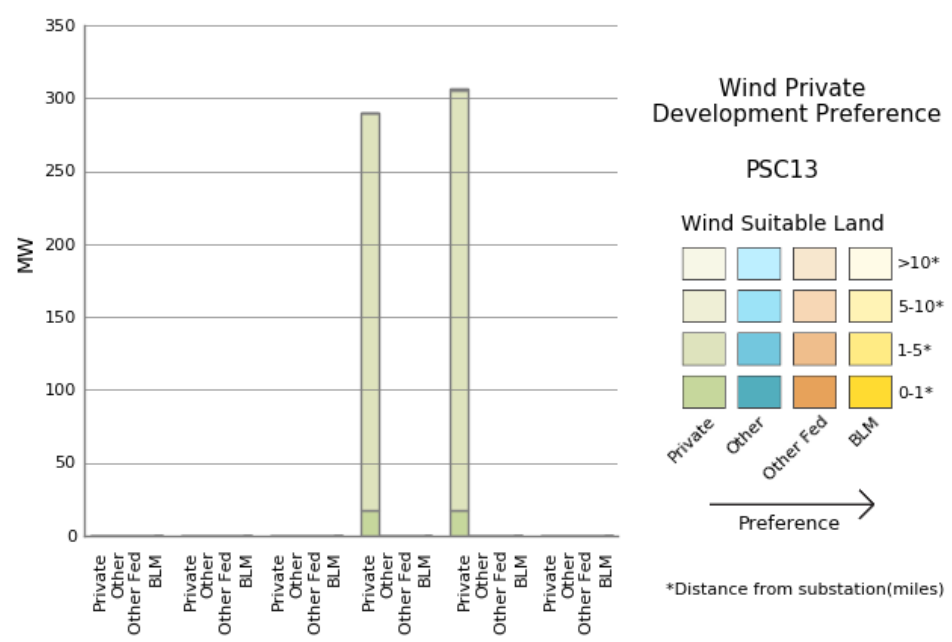

$\mathrm{PSC} 13$

Wind Suitable Land

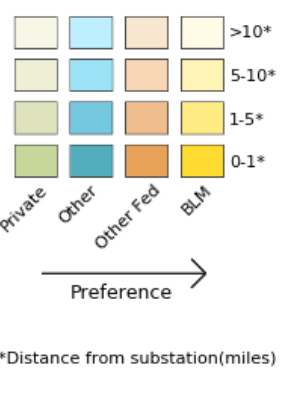

REF LO-NG ST-DRT ST-MT ST-URT WC-MT

This report is available at no cost from the National Renewable Energy Laboratory at www.nrel.gov/publications. 


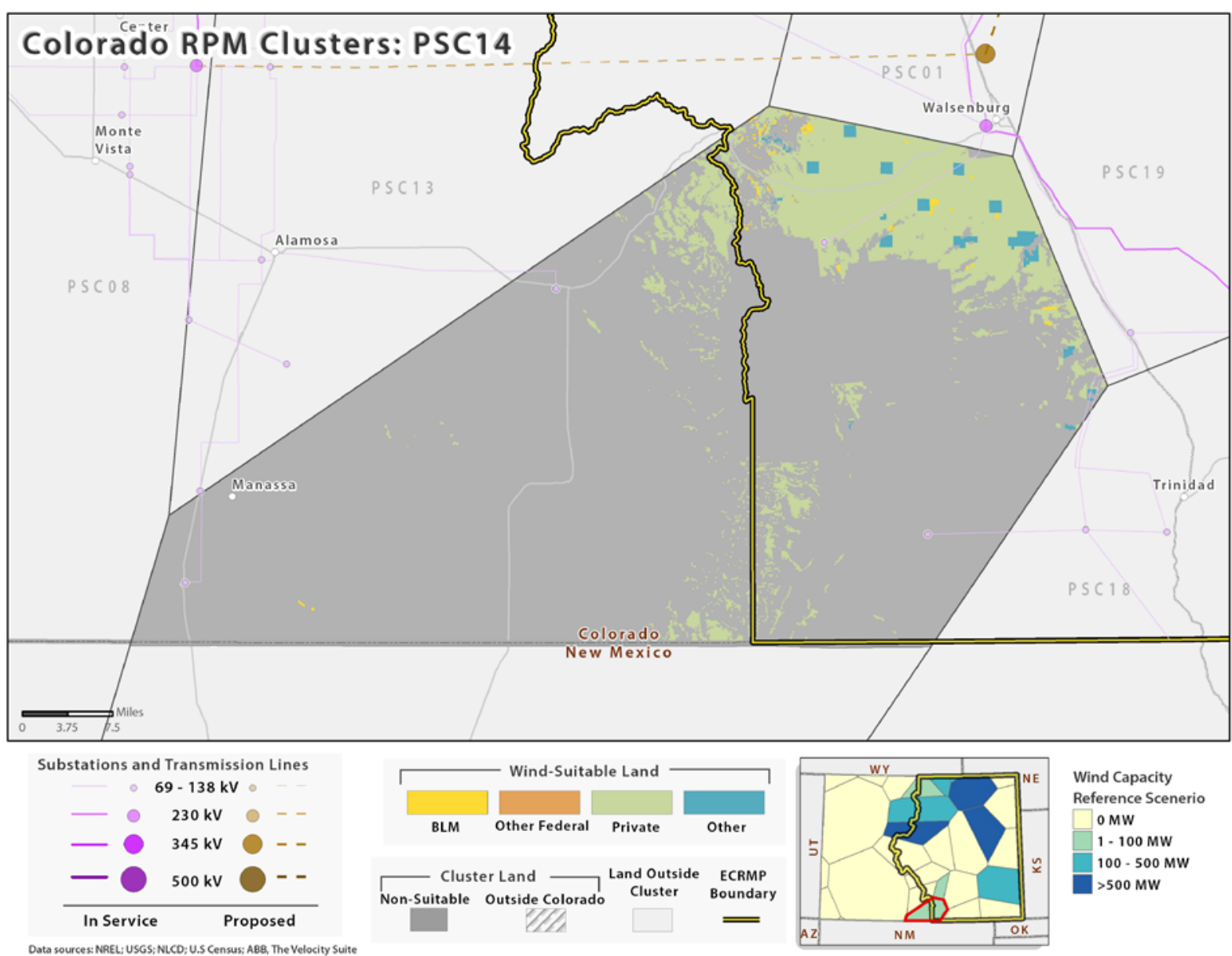

\begin{tabular}{c|cc|cc|cc|cc}
\hline \hline \multicolumn{1}{|c|}{ PSC14-Wind-Suitable Land: Area and MW Potential } \\
\hline Distance to & \multicolumn{2}{c|}{$\mathbf{0 - 1}$ Miles } & \multicolumn{2}{c|}{$\mathbf{1 - 5}$ Miles } & \multicolumn{2}{c}{$\mathbf{5 - 1 0}$ Miles } & \multicolumn{2}{c}{$>$ >10 Miles } \\
Transmission & Acres & MW & Acres & MW & Acres & MW & Acres & MW \\
\hline BLM & 0 & 0 & 174 & 2 & 2,331 & 28 & 534 & 6 \\
Federal & 0 & 0 & 0 & 0 & 0 & 0 & 0 & 0 \\
Other & 0 & 0 & 811 & 9 & 6,825 & 82 & 1,585 & 19 \\
Private & 1,789 & 21 & 37,196 & 452 & 103,813 & 1,261 & 51,224 & 622 \\
\hline \hline
\end{tabular}

\begin{tabular}{cccccc}
\hline \hline \multicolumn{7}{l}{ PSC14 } & Modeled Wind Capacity \\
\hline Ref & LO-NG & SC-DRT & SC-MT & SC-URT & WC-MT \\
81 & 0 & 19 & 540 & 0 & 78 \\
\hline \hline
\end{tabular}




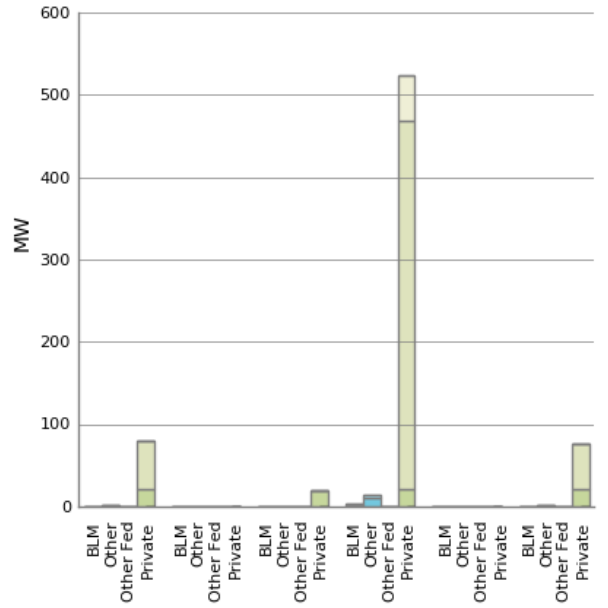

REF LO-NG ST-DRT ST-MT ST-URT WC-MT

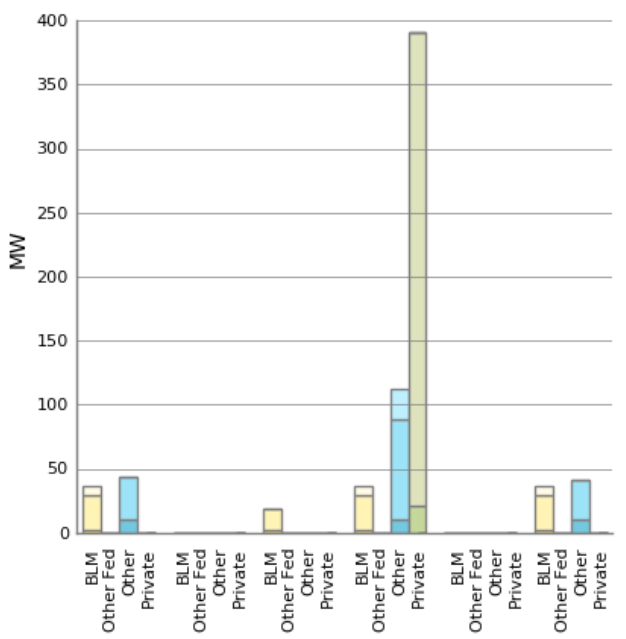

REF LO-NG ST-DRT ST-MT ST-URT WC-MT

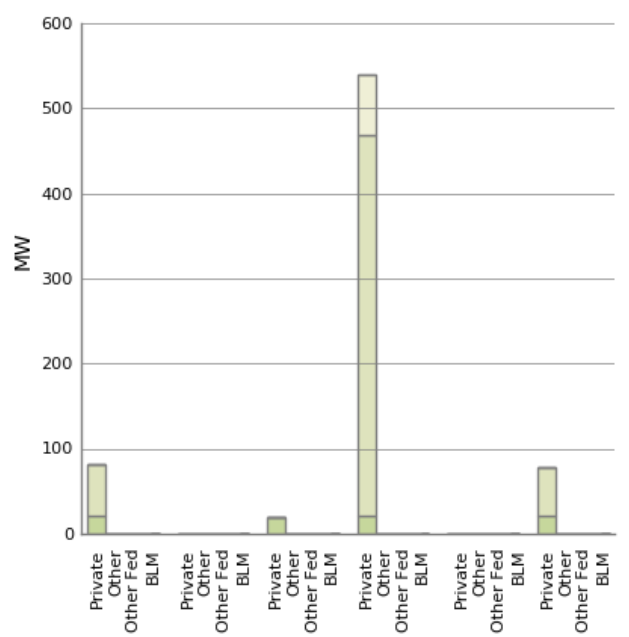

REF LO-NG ST-DRT ST-MT ST-URT WC-MT
Wind
Proportional + Development Preference

PSC14

Wind Suitable Land

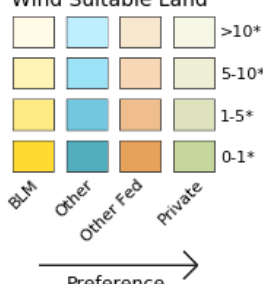

+ Capacity builds are allocated proportionally to land ownership

*Distance from substation(miles)

Wind BLM Development Preference

PSC14

Wind Suitable Land $\square \square \square \square>10 *$ $\square \square \square \square$ 5-10* $\square \square \square \square 1-5 *$ $\square \square \square-\square^{*}$

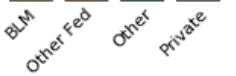
Preference $>$

*Distance from substation(miles)

Wind Private Development Preference

PSC14

Wind Suitable Land

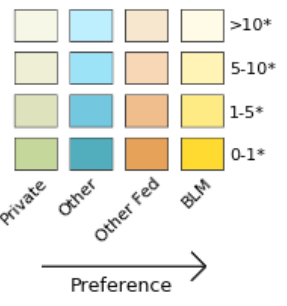

*Distance from substation(miles) 


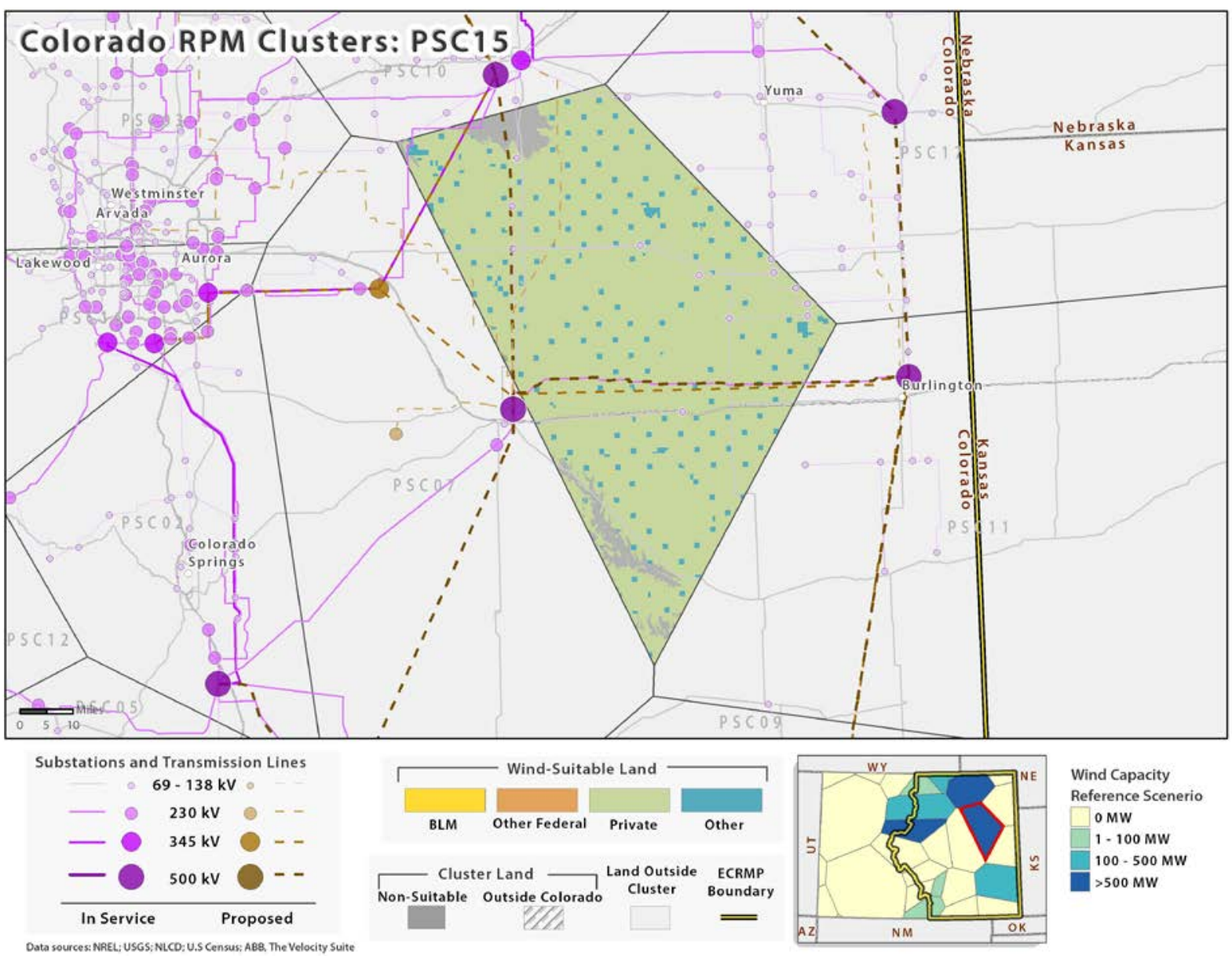

\begin{tabular}{c|cc|cc|cc|cc}
\hline \hline \multicolumn{1}{|c|}{ PSC15-Wind-Suitable Land: Area and MW Potential } \\
\hline Distance to & \multicolumn{2}{|c|}{$\mathbf{0 - 1}$ Miles } & \multicolumn{2}{c|}{$\mathbf{1 - 5}$ Miles } & \multicolumn{2}{c}{$\mathbf{5 - 1 0}$ Miles } & \multicolumn{2}{c}{$>$ >10 Miles } \\
Transmission & Acres & MW & Acres & MW & Acres & MW & Acres & MW \\
\hline BLM & 0 & 0 & 0 & 0 & 157 & 1 & 240 & 2 \\
Federal & 0 & 0 & 613 & 7 & 0 & 0 & 0 & 0 \\
Other & 135 & 1 & 22,795 & 277 & 45,961 & 558 & 52,738 & 640 \\
Private & 23,295 & 283 & 434,978 & 5,286 & 908,865 & 11,045 & $1,205,957$ & 14,655 \\
\hline \hline
\end{tabular}

\begin{tabular}{cccccc}
\hline \hline \multicolumn{7}{l}{ PSC15 } & - Modeled Wind Capacity \\
\hline Ref & LO-NG & SC-DRT & SC-MT & SC-URT & WC-MT \\
643 & 643 & 643 & 643 & 643 & 643 \\
\hline \hline
\end{tabular}




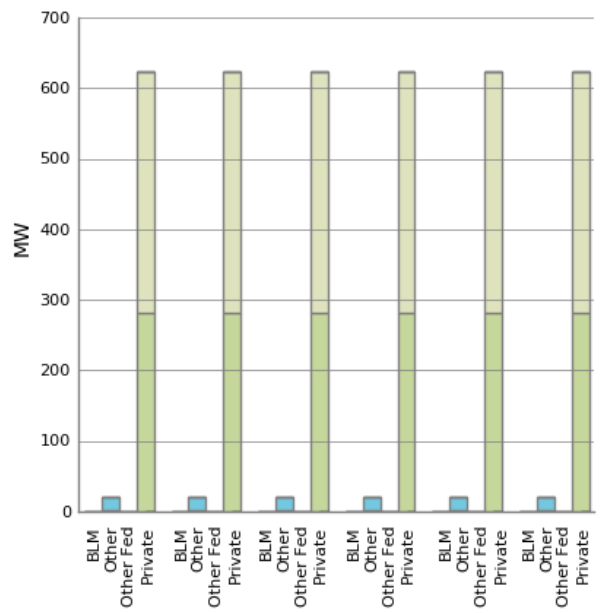

Wind
Proportional+
Development Preference

PSC15

Wind Suitable Land

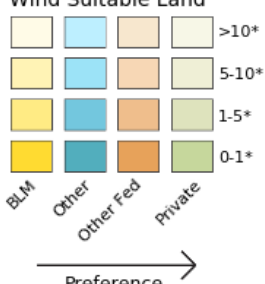

+ Capacity builds are allocated quantities within the resource region

*Distance from substation(miles)

REF LO-NG ST-DRT ST-MT ST-URT WC-MT

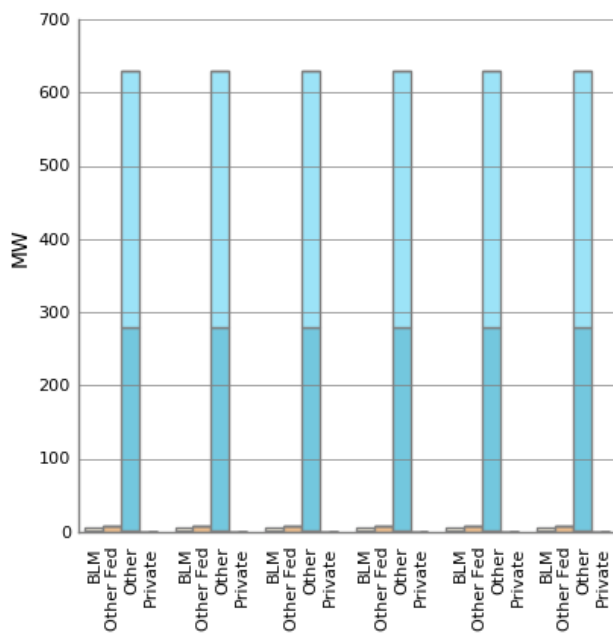

Wind BLM

Development Preference

PSC15

Wind Suitable Land

$\square \square \square \square>10 *$

$\square \square \square \square$ 5-10*

$\square \square \square \square 1-5 *$

$\square \square \square \square 0-1 *$

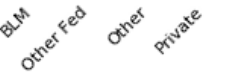

Preference $>$

*Distance from substation(miles)

REF LO-NG ST-DRT ST-MT ST-URT WC-MT

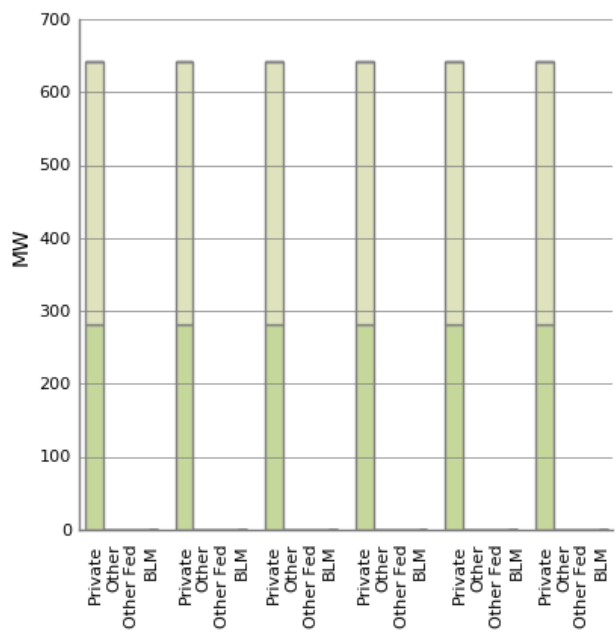

Wind Private Development Preference

PSC15

Wind Suitable Land

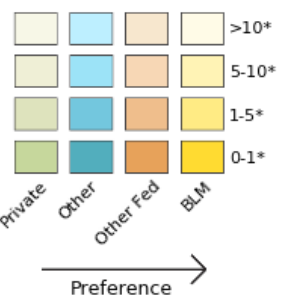

*Distance from substation(miles)

REF LO-NG ST-DRT ST-MT ST-URT WC-MT

This report is available at no cost from the National Renewable Energy Laboratory at www.nrel.gov/publications. 


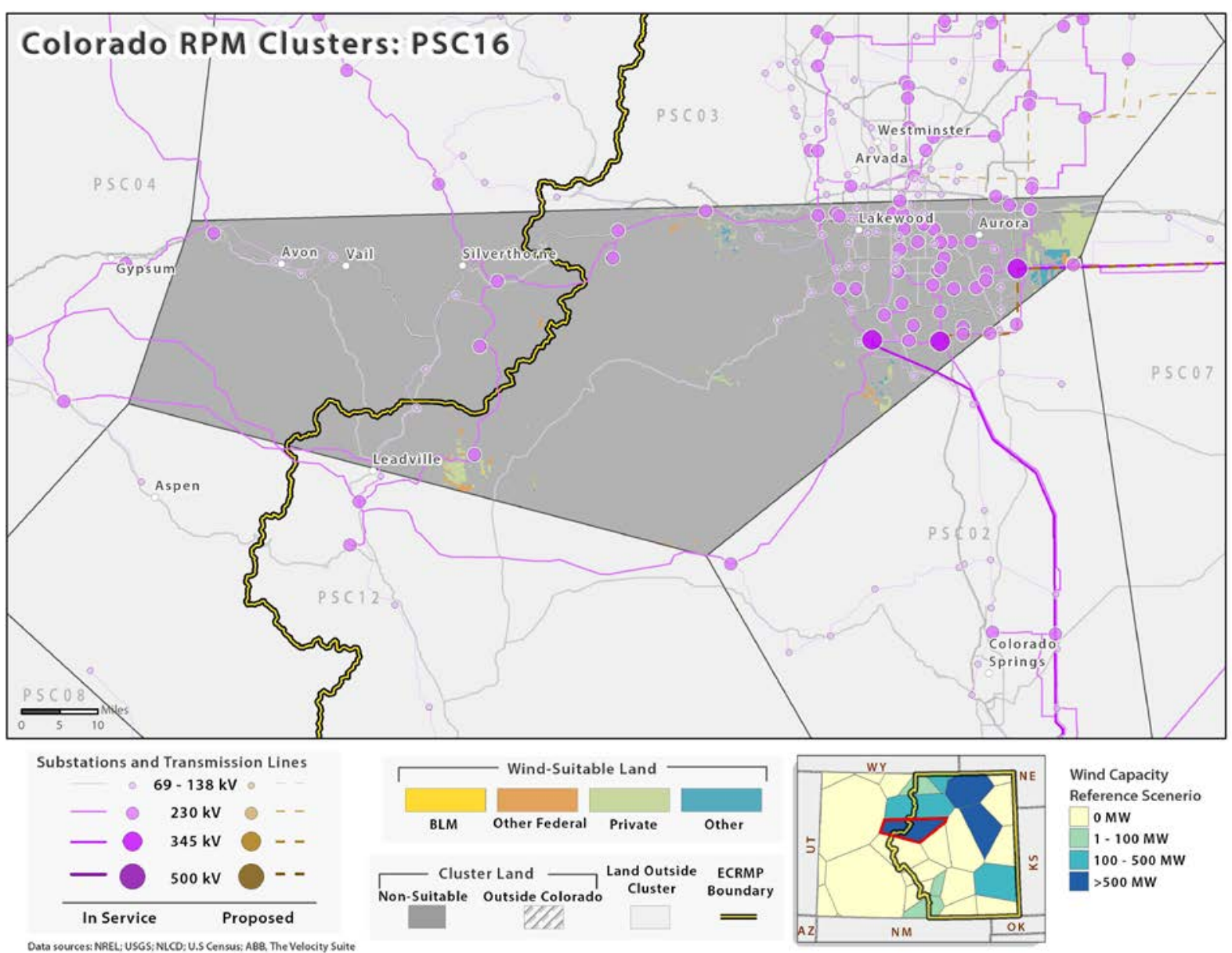

\begin{tabular}{c|cc|cc|cc|cc}
\hline \hline \multicolumn{1}{|c|}{ PSC16-Wind-Suitable Land: Area and MW Potential } \\
\hline Distance to & \multicolumn{2}{|c|}{$\mathbf{0 - 1}$ Miles } & \multicolumn{2}{|c|}{$\mathbf{1 - 5}$ Miles } & \multicolumn{2}{c}{$\mathbf{5 - 1 0}$ Miles } & \multicolumn{2}{c}{$>$ >10 Miles } \\
Transmission & Acres & MW & Acres & MW & Acres & MW & Acres & MW \\
\hline BLM & 0 & 0 & 80 & 1 & 72 & 1 & 0 & 0 \\
Federal & 274 & 3 & 3,191 & 38 & 2,229 & 27 & 128 & 2 \\
Other & 136 & 2 & 7,097 & 87 & 259 & 3 & 66 & 1 \\
Private & 455 & 6 & 25,073 & 305 & 6,556 & 80 & 875 & 11 \\
\hline \hline
\end{tabular}

\begin{tabular}{|c|c|c|c|c|c|}
\hline \multicolumn{6}{|c|}{ PSC16 - Modeled Wind Capacity ${ }^{20}$} \\
\hline Ref & $L O-N G$ & $S C-D R T$ & $S C-M T$ & $S C-U R T$ & WC-MT \\
\hline 1,329 & 438 & 1,377 & 1,418 & 1,448 & 1,329 \\
\hline
\end{tabular}

\footnotetext{
${ }^{20}$ The total MW potential for wind-suitable lands in PSC16 is 567 MW. RPM capacity expansion consistently exceeds this number. Excess capacity expansion results in certain regions are due to non-coterminous resource availability and prescribed capacity expansion data sets.
} 

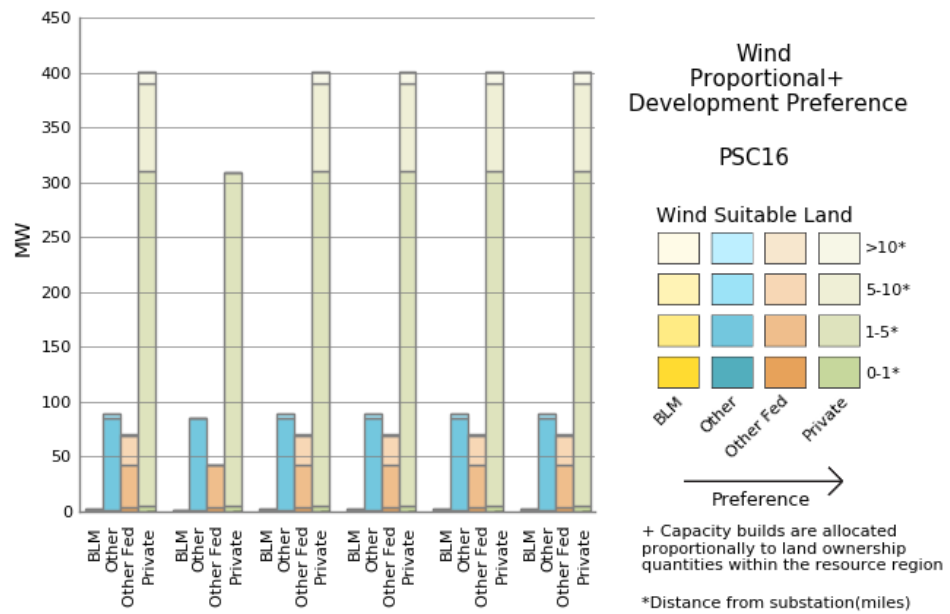

REF LO-NG ST-DRT ST-MT ST-URT WC-MT

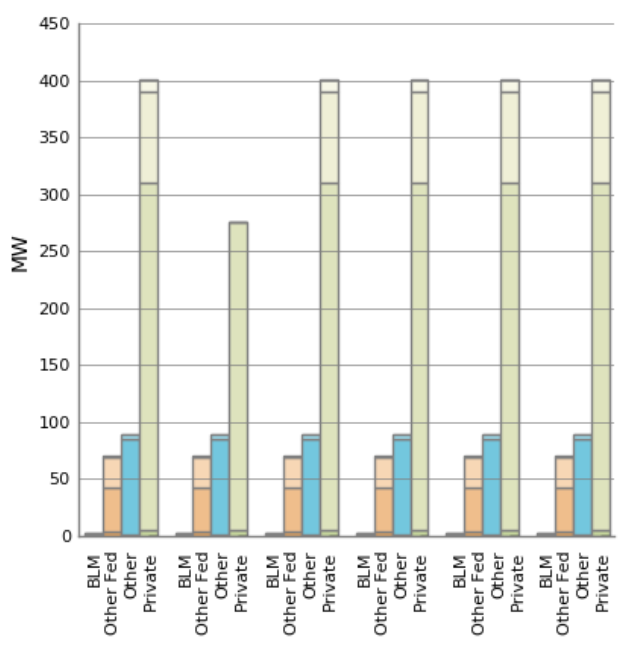

Wind BLM

Development Preference

PSC16

Wind Suitable Land

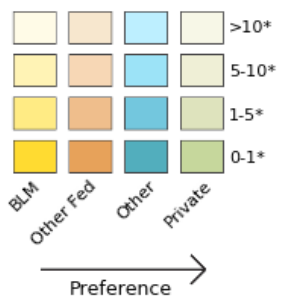

*Distance from substation(miles)

REF LO-NG ST-DRT ST-MT ST-URT WC-MT

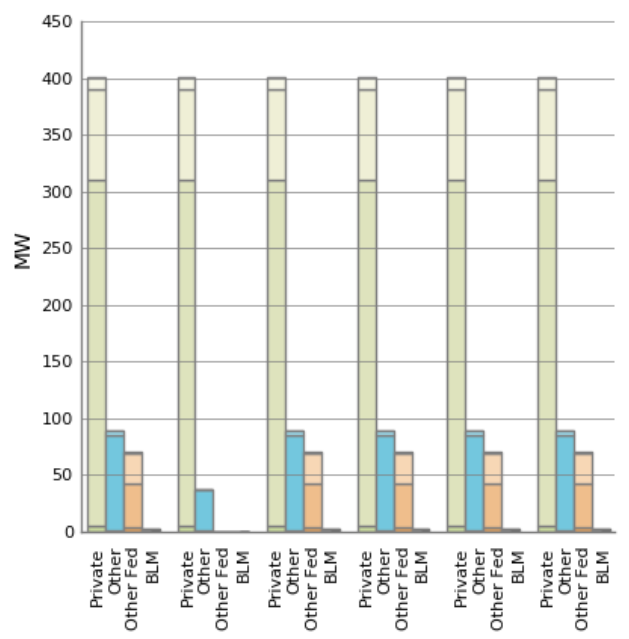

Wind Private Development Preference

PSC16

Wind Suitable Land

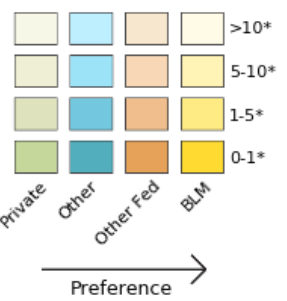

*Distance from substation(miles)

REF LO-NG ST-DRT ST-MT ST-URT WC-MT 


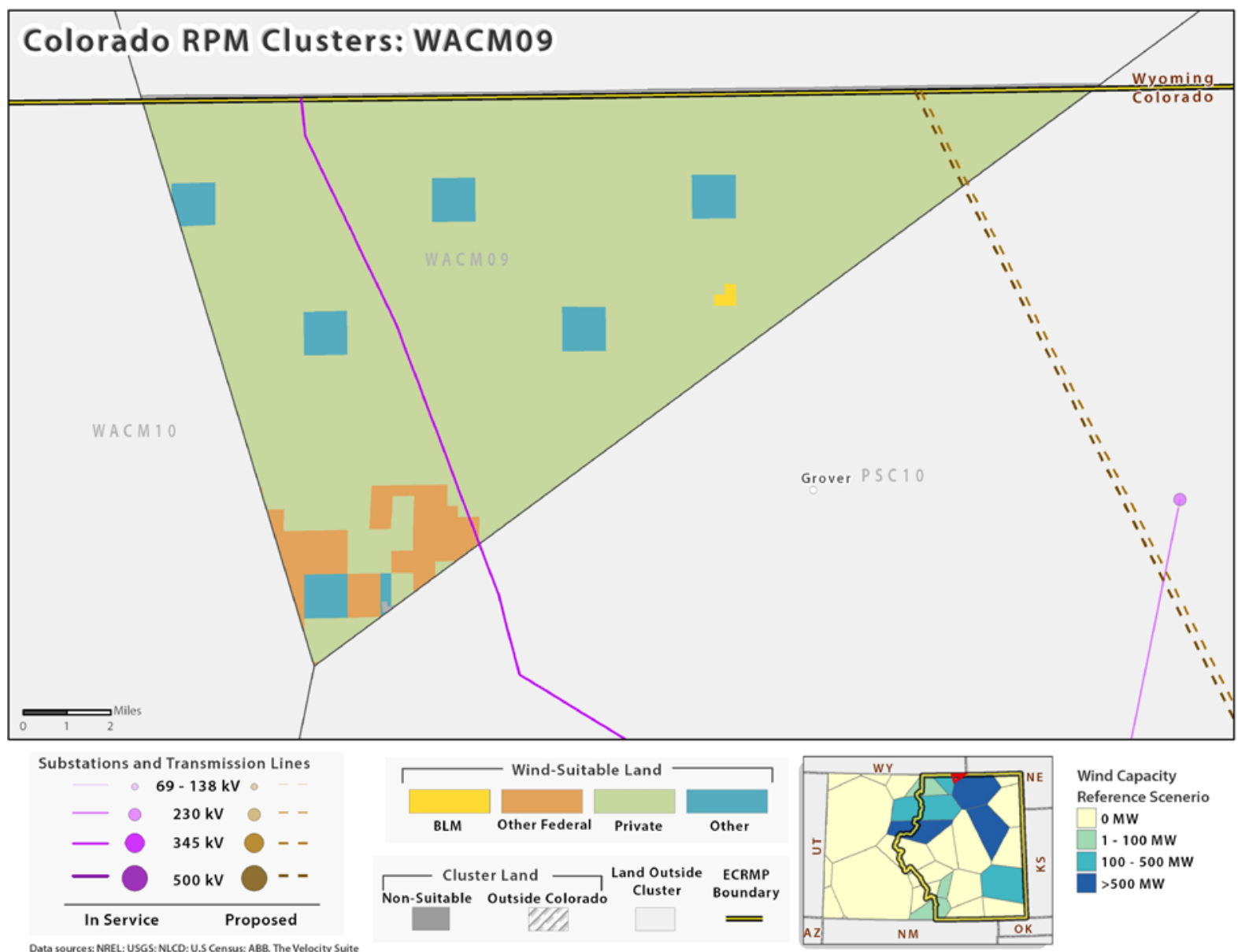

\begin{tabular}{c|cc|cc|cc|cc}
\hline \hline \multicolumn{8}{c}{ WACM09-Wind-Suitable Land: Area and MW Potential } \\
\hline Distance to & \multicolumn{2}{|c|}{-1 Miles } & \multicolumn{2}{|c|}{$\mathbf{1 - 5}$ Miles } & \multicolumn{2}{c}{$\mathbf{5 - 1 0}$ Miles } & \multicolumn{2}{c}{$>$ >10 Miles } \\
Transmission & Acres & MW & Acres & MW & Acres & MW & Acres & MW \\
\hline BLM & 0 & 0 & 0 & 0 & 0 & 0 & 122 & 1 \\
Federal & 0 & 0 & 0 & 0 & 0 & 0 & 3,806 & 46 \\
Other & 0 & 0 & 0 & 0 & 0 & 0 & 3,909 & 47 \\
Private & 0 & 0 & 0 & 0 & 5,180 & 62 & 77,048 & 936 \\
\hline \hline
\end{tabular}

\begin{tabular}{|c|c|c|c|c|c|}
\hline \multicolumn{6}{|c|}{ WACM09 - Modeled Wind Capacity } \\
\hline Ref & $L O-N G$ & $S C-D R T$ & $S C-M T$ & $S C-U R T$ & WC-MT \\
\hline 251 & 251 & 251 & 251 & 251 & 251 \\
\hline
\end{tabular}




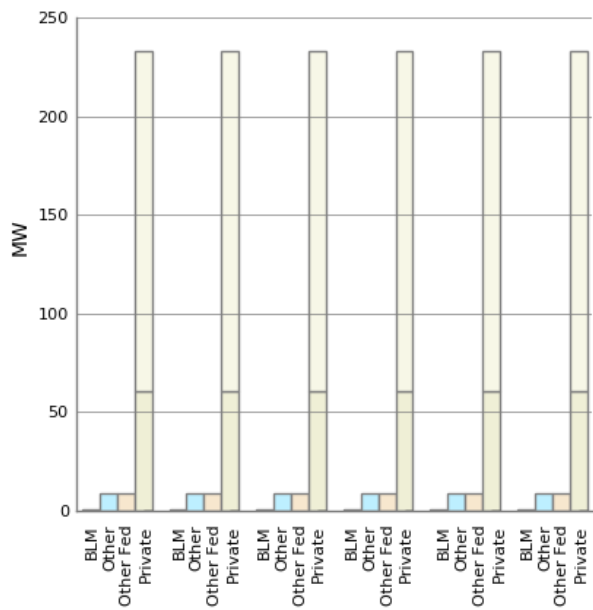

Wind
Proportional+
Development Preference

WACM09

Wind Suitable Land

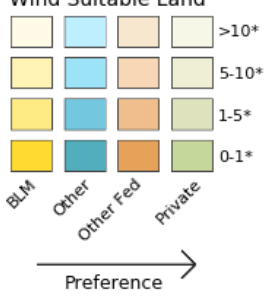

+ Capacity builds are allocated quantities within the resourshe region

*Distance from substation(miles)

REF LO-NG ST-DRT ST-MT ST-URT WC-MT

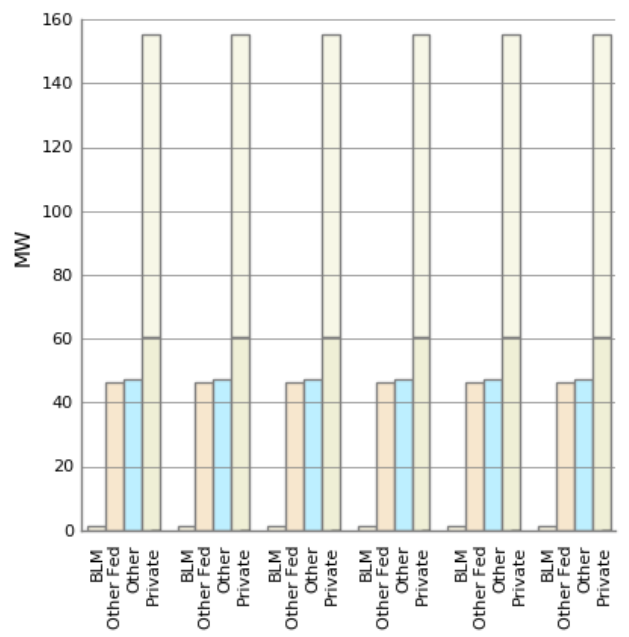

Wind BLM Development Preference

WACM09

Wind Suitable Land $\square \square \square \square>10 *$ $\square \square \square \square$ 5-10 $\square \square \square \square 1-5 *$ $\square+\square-1^{*}$

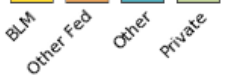
$\underset{\text { Preference }}{>}$

*Distance from substation(miles)

REF LO-NG ST-DRT ST-MT ST-URT WC-MT

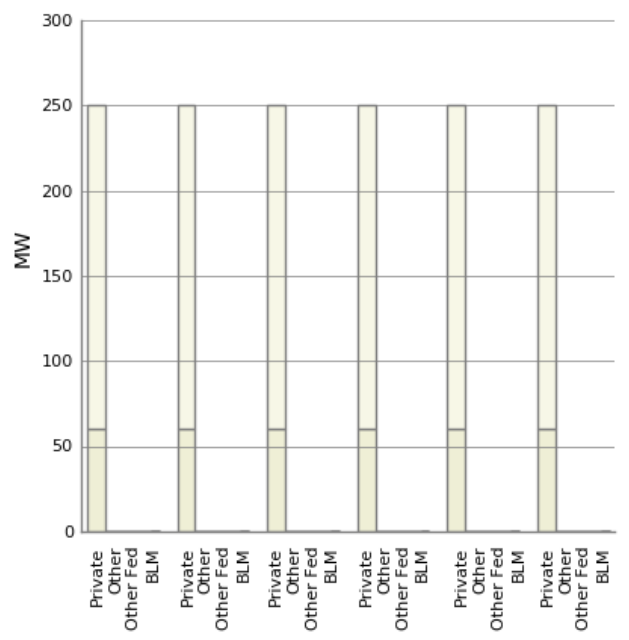

Wind Private Development Preference

WACM09

Wind Suitable Land

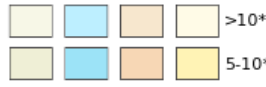

$\square \square \square \square$ 1-5*

$\square+\square \square^{0} \square^{0-1 *}$

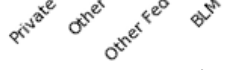

$\underset{\text { Preference }}{\longrightarrow}$

*Distance from substation(miles)

REF LO-NG ST-DRT ST-MT ST-URT WC-MT

This report is available at no cost from the National Renewable Energy Laboratory at www.nrel.gov/publications. 


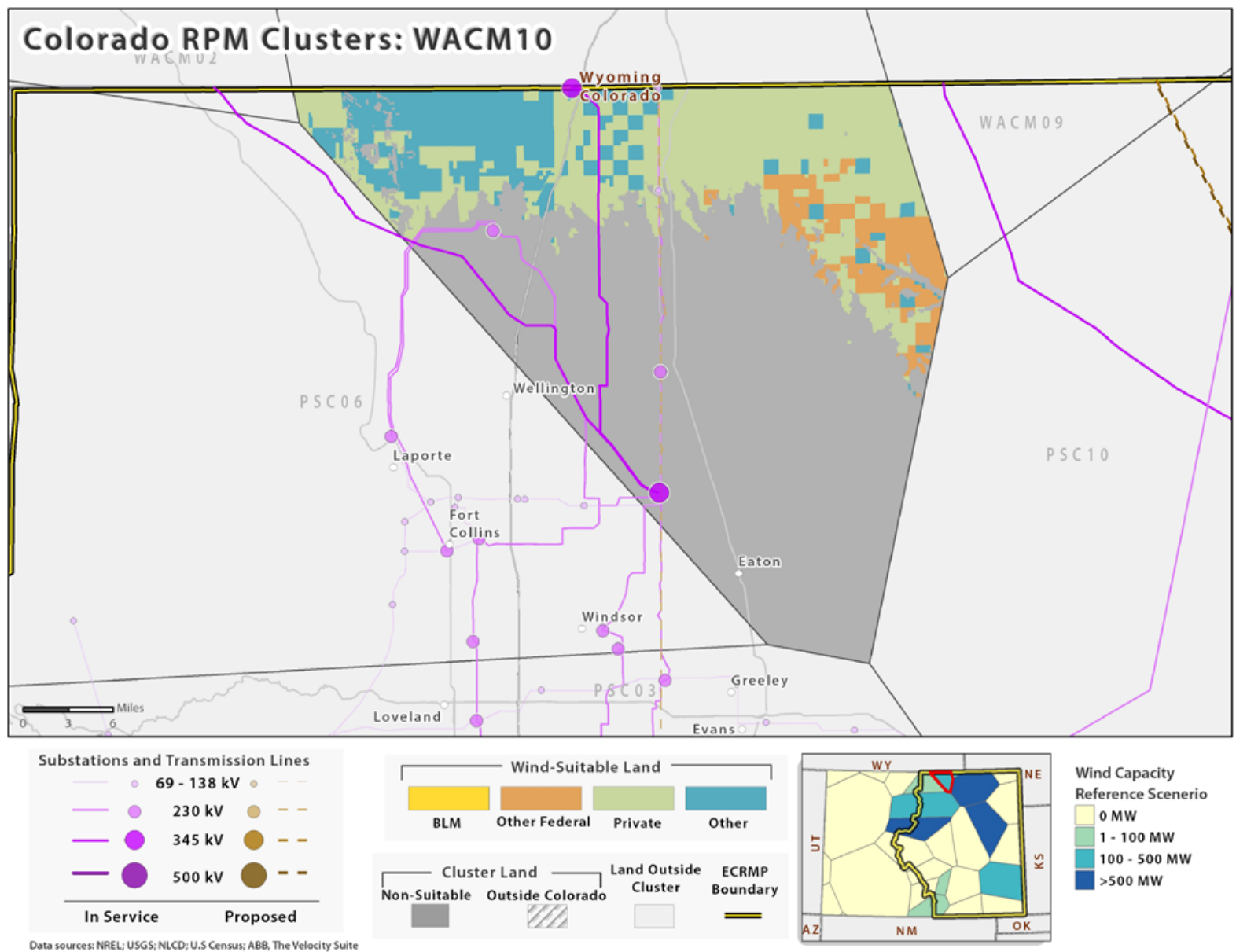

\begin{tabular}{c|cc|cc|cc|cc}
\hline \hline \multicolumn{8}{c}{ WACM10-Wind-Suitable Land: Area and MW Potential } \\
\hline Distance to & \multicolumn{2}{c|}{$\mathbf{0 - 1}$ Miles } & \multicolumn{2}{c}{$\mathbf{1 - 5}$ Miles } & \multicolumn{2}{c}{5 -10 Miles } & \multicolumn{2}{c}{$>$ 10 Miles } \\
Transmission & Acres & MW & Acres & MW & Acres & MW & Acres & MW \\
\hline BLM & 0 & 0 & 0 & 0 & 0 & 0 & 0 & 0 \\
Federal & 0 & 0 & 503 & 6 & 4,675 & 56 & 25,570 & 310 \\
Other & 1,022 & 12 & 23,833 & 289 & 26,700 & 324 & 13,622 & 165 \\
Private & 2,718 & 33 & 51,209 & 622 & 35,043 & 425 & 51,276 & 623 \\
\hline \hline
\end{tabular}

\begin{tabular}{|c|c|c|c|c|c|}
\hline \multicolumn{6}{|c|}{ WACM10 - Modeled Wind Capacity } \\
\hline Ref & LO-NG & $S C-D R T$ & $S C-M T$ & $S C-U R T$ & WC-MT \\
\hline 123 & 123 & 123 & 123 & 123 & 123 \\
\hline
\end{tabular}




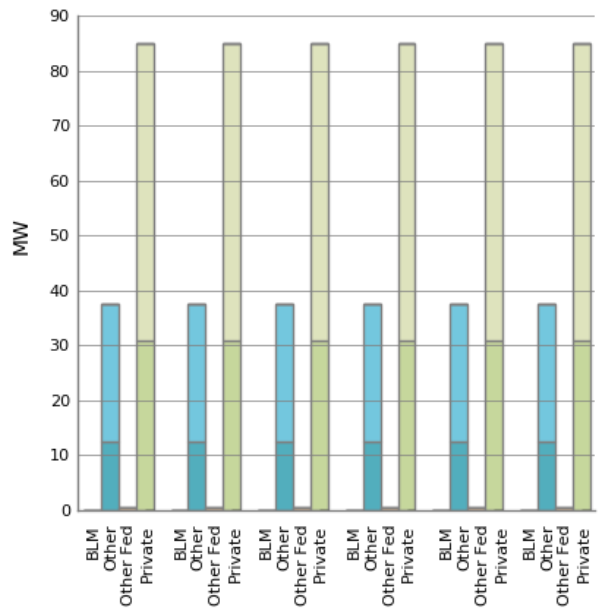

$$
\begin{gathered}
\text { Wind } \\
\text { Proportional+ } \\
\text { evelopment Preference }
\end{gathered}
$$

WACM10

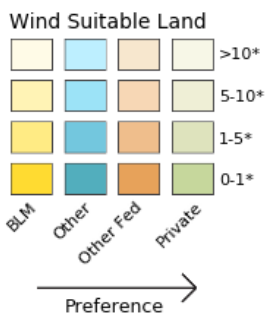

+ Capacity builds are allocated proportionally to land ownership

*Distance from substation(miles)

REF LO-NG ST-DRT ST-MT ST-URT WC-MT

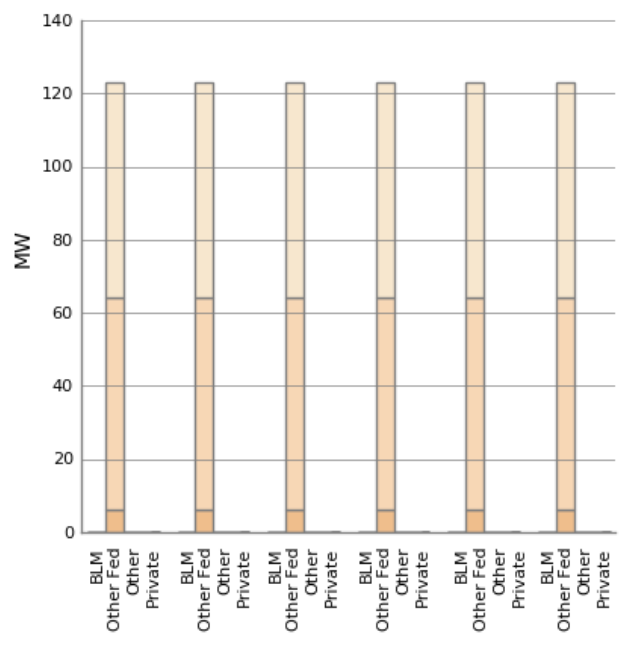

Wind BLM

Development Preference

WACM10

Wind Suitable Land

$\square \square \square \square>10$ *

$\square \square \square \square$ 5-10*

$\square \square \square \square 1-5 *$

$\square \square \square-\square-1^{*}$

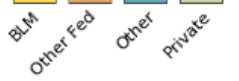

Preference $>$

*Distance from substation(miles)

REF LO-NG ST-DRT ST-MT ST-URT WC-MT

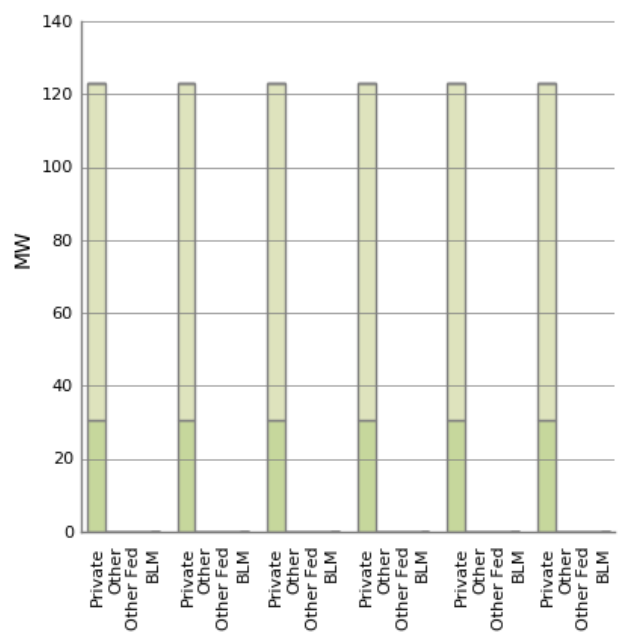

Wind Private Development Preference

WACM10

Wind Suitable Land

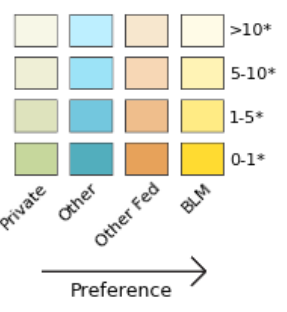

*Distance from substation(miles)

REF LO-NG ST-DRT ST-MT ST-URT WC-MT

This report is available at no cost from the National Renewable Energy Laboratory at www.nrel.gov/publications. 


\section{Solar Resource Regions}

\section{Colorado Solar Resource Regions}

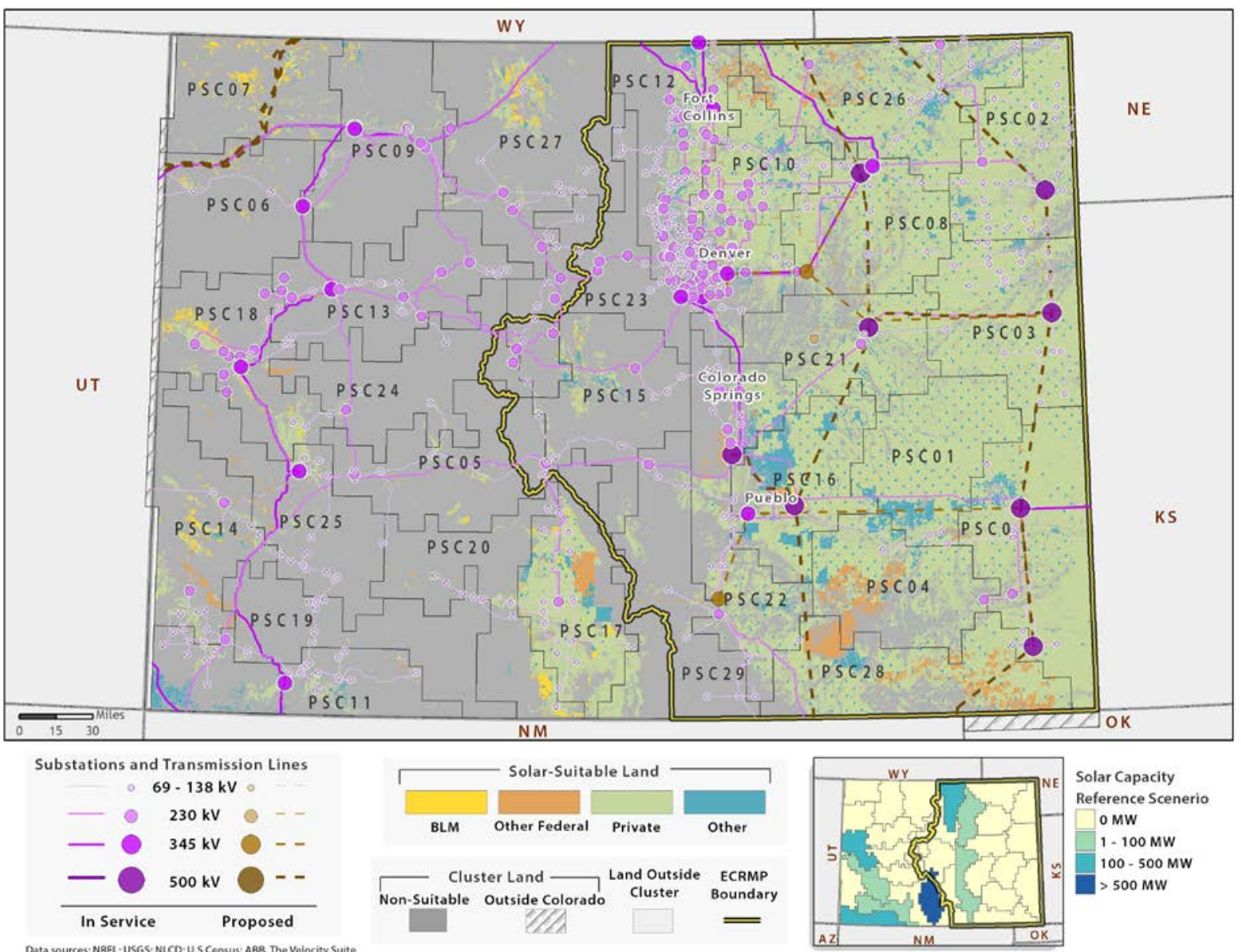

\begin{tabular}{c|cc|cc|cc|cc}
\hline \hline \multicolumn{8}{c}{ Colorado-Solar-Suitable Land: Area and MW Potential } \\
\hline $\begin{array}{c}\text { Distance to } \\
\text { Transmission }\end{array}$ & \multicolumn{2}{|c|}{$\mathbf{0 - 1}$ Miles } & \multicolumn{2}{c}{$\mathbf{1 - 5}$ Miles } & \multicolumn{2}{c}{$\mathbf{5 - 1 0}$ Miles } & \multicolumn{2}{c}{$>$ 10 Miles } \\
\hline BLM & 542 & 155 & 53,225 & 15,251 & 111,854 & 32,050 & 259,125 & 74,248 \\
Federal & 936 & 268 & 65,781 & 18,848 & 212,993 & 61,030 & 605,166 & 173,400 \\
Other & 18,784 & 5,382 & 321,219 & 92,040 & 489,051 & 140,129 & $1,050,674$ & 301,053 \\
Private & 311,631 & 89,293 & $5,025,581$ & $1,439,995$ & $5,892,545$ & $1,688,408$ & $9,035,090$ & $2,588,851$ \\
\hline \hline
\end{tabular}

\begin{tabular}{cccccc}
\hline \hline \multicolumn{7}{l}{ Colorado - Modeled Solar Capacity } & & & \\
\hline Ref & LO-NG & SC-DRT & SC-MT & SC-URT & WC-MT \\
1,280 & 1,658 & 2,749 & 110 & 3,479 & 1,280 \\
\hline \hline
\end{tabular}




\section{ECRMP Solar Resource Regions}

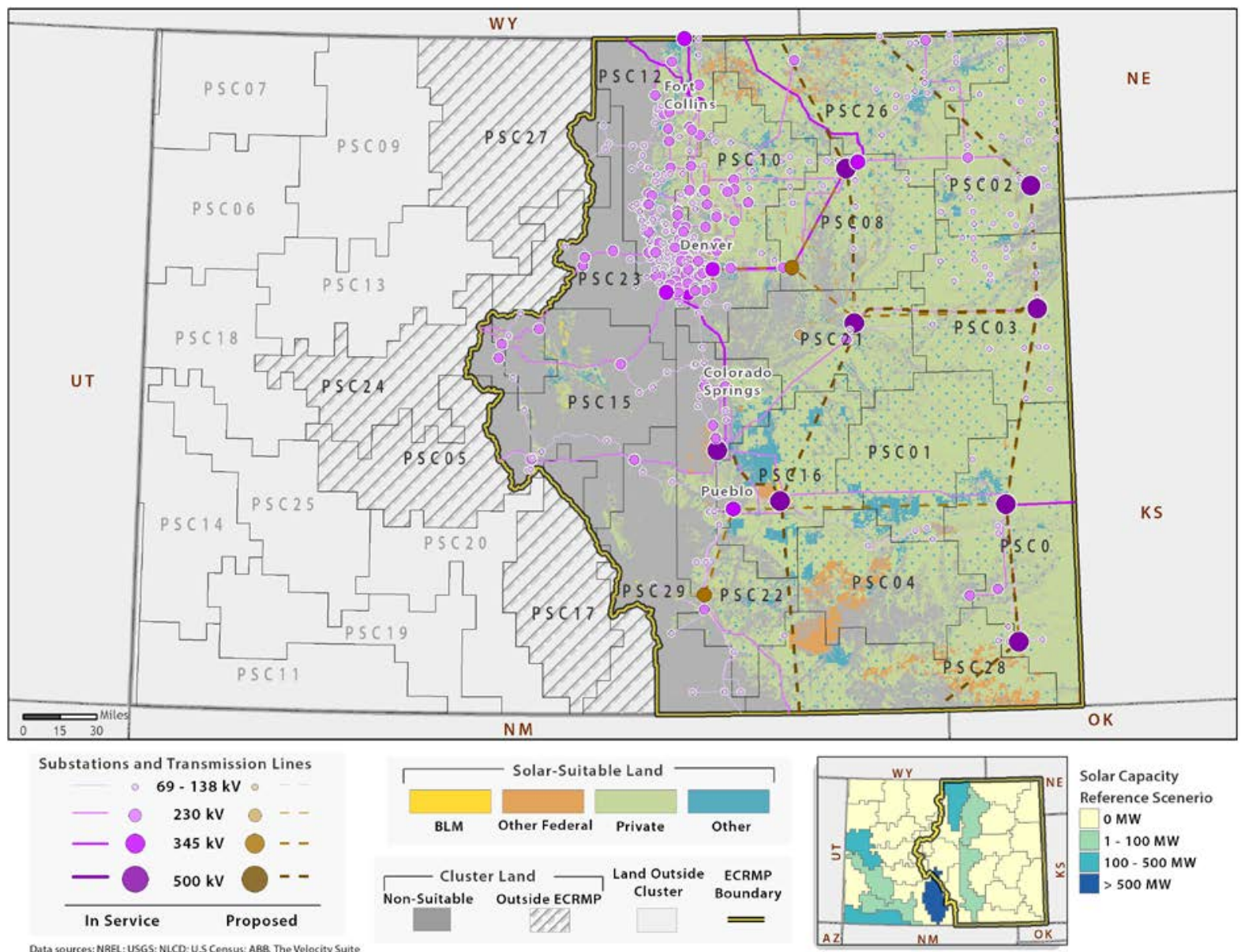

\begin{tabular}{c|cc|cc|cc|cc}
\hline \hline \multicolumn{8}{c}{ ECRMP-Solar-Suitable Land: Area and MW Potential } \\
\hline Distance to & \multicolumn{2}{|c|}{$\mathbf{0 - 1}$ Miles } & \multicolumn{2}{c}{$\mathbf{1 - 5}$ Miles } & \multicolumn{2}{c}{$\mathbf{5 - 1 0}$ Miles } & \multicolumn{2}{c}{$>$ 10 Miles } \\
Transmission & Acres & MW & Acres & MW & Acres & MW & Acres & MW \\
\hline BLM & 43 & 12 & 3,296 & 945 & 12,376 & 3,546 & 24,173 & 6,926 \\
Federal & 731 & 209 & 47,607 & 13,641 & 117,043 & 33,537 & 549,218 & 157,369 \\
Other & 17,180 & 4,923 & 289,844 & 83,050 & 425,478 & 121,914 & 877,034 & 251,299 \\
Private & 264,183 & 75,697 & $4,292,574$ & $1,229,964$ & $5,237,288$ & $1,500,655$ & $8,428,131$ & $2,414,937$ \\
\hline \hline
\end{tabular}

\begin{tabular}{|c|c|c|c|c|c|}
\hline \multicolumn{6}{|c|}{ ECRMP - Modeled Solar Capacity } \\
\hline Ref & $L O-N G$ & $S C-D R T$ & SC-MT & SC-URT & WC-MT \\
\hline 988 & 902 & 415 & 109 & 228 & 977 \\
\hline
\end{tabular}




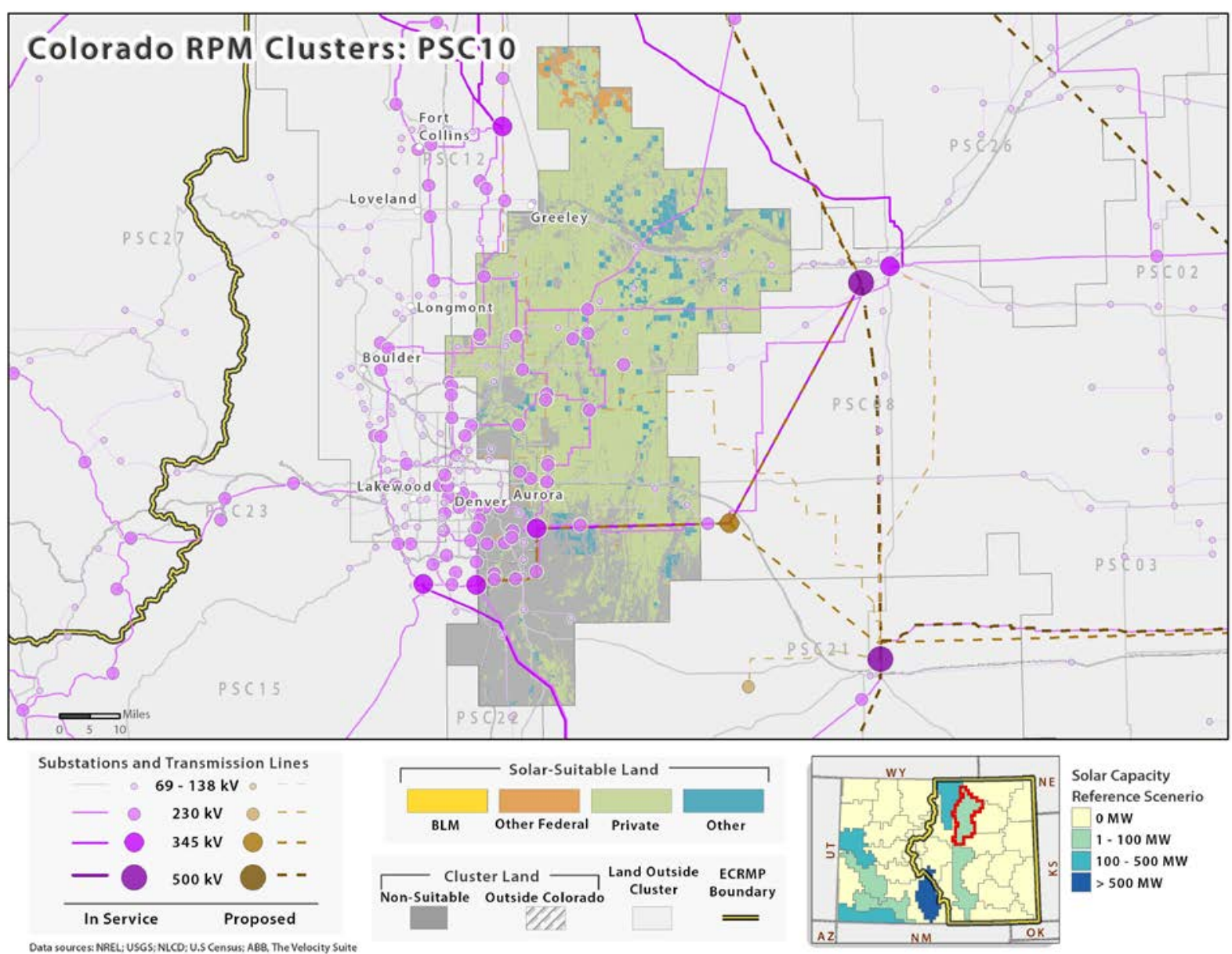

\begin{tabular}{c|cc|cc|cc|cc}
\hline \hline \multicolumn{10}{c}{ PSC10-Solar-Suitable Land: Area and MW Potential } \\
\hline $\begin{array}{c}\text { Distance to } \\
\text { Transmission }\end{array}$ & \multicolumn{2}{c|}{$\mathbf{0 - 1}$ Miles } & \multicolumn{2}{c}{$\mathbf{1 - 5}$ Miles } & \multicolumn{2}{c}{$\mathbf{5 - 1 0}$ Miles } & \multicolumn{2}{c}{$>$ 10 Miles } \\
\hline Acres & MW & Acres & MW & Acres & MW & Acres & MW \\
\hline BLM & 13 & 4 & 80 & 23 & 226 & 65 & 0 & 0 \\
Federal & 84 & 24 & 2,264 & 649 & 5,716 & 1,638 & 18,386 & 5,268 \\
Other & 2,021 & 579 & 41,812 & 11,981 & 41,398 & 11,862 & 10,240 & 2,934 \\
Private & 57,509 & 16,478 & 701,083 & 200,883 & 397,722 & 113,960 & 172,623 & 49,462 \\
\hline \hline
\end{tabular}

\begin{tabular}{cccccc}
\hline \hline \multicolumn{7}{l}{ PSC10 } & Modeled Solar Capacity \\
\hline Ref & LO-NG & SC-DRT & SC-MT & SC-URT & WC-MT \\
3 & 3 & 3 & 3 & 3 & 3 \\
\hline \hline
\end{tabular}




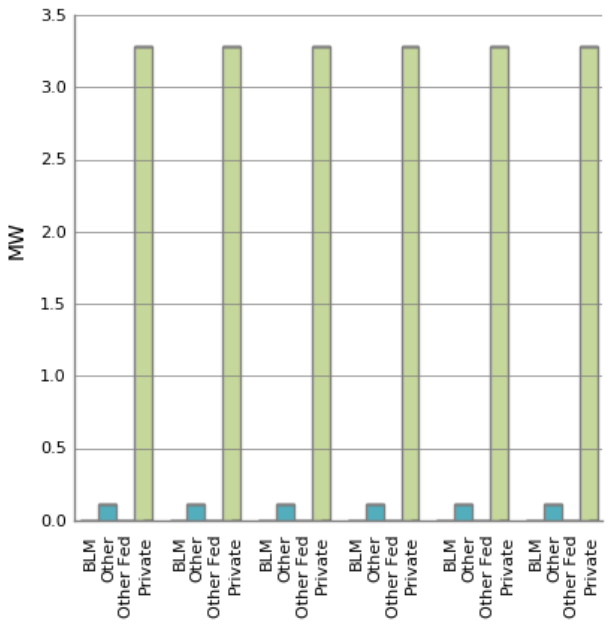

REF LO-NG ST-DRT ST-MT ST-URT WC-MT

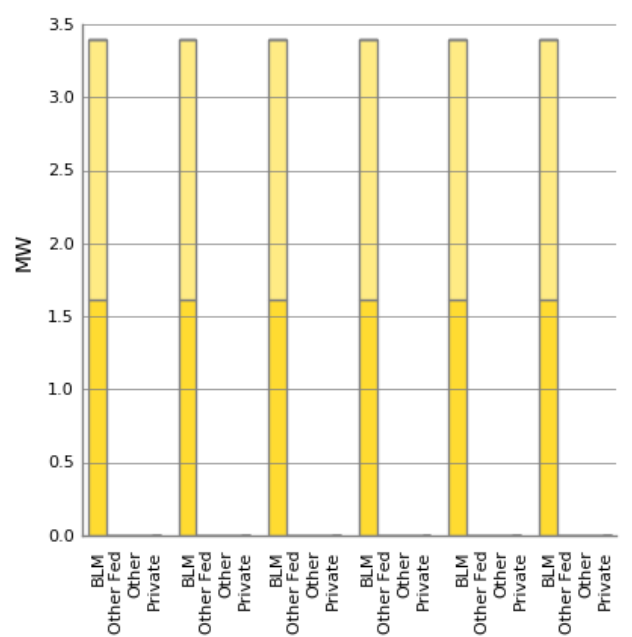

REF LO-NG ST-DRT ST-MT ST-URT WC-MT

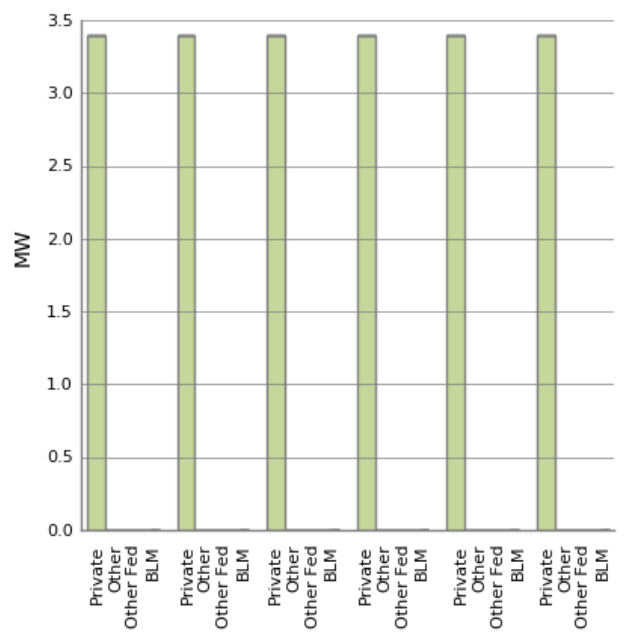

REF LO-NG ST-DRT ST-MT ST-URT WC-MT
Solar

Proportional+

Development Preference

PSC10

Solar Suitable Land

$\square \square \square>10 *$

$\square \square \square-10 *$

$\square+\square \square D_{1-5 *}$

$\square \square \square \square-0-1 *$

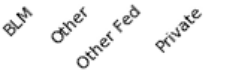

$\longrightarrow$ Preference $>$

+ Capacity builds are allocated proportionally to land ownership

*Distance from substation(miles)

Solar BLM Development Preference

PSC10

Solar Suitable Land

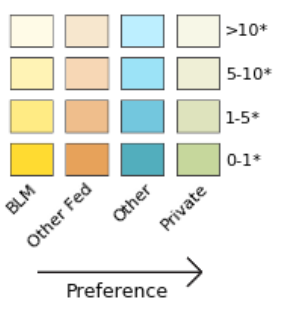

*Distance from substation(miles)

Development Preference

PSC10

Solar Suitable Land

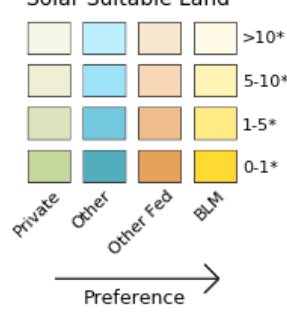

*Distance from substation(miles) 

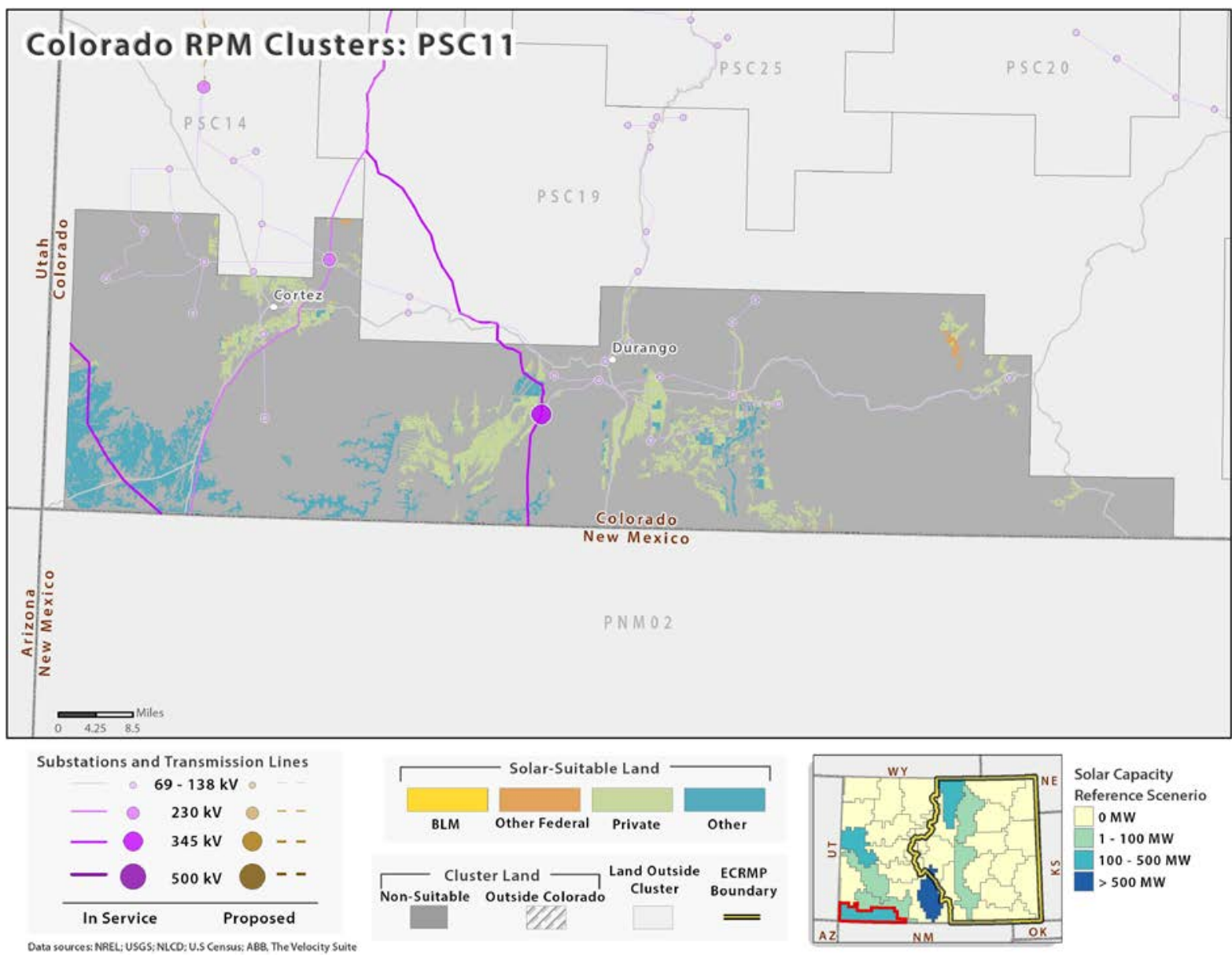

\begin{tabular}{|c|c|c|c|c|c|c|c|c|}
\hline \multicolumn{9}{|c|}{ PSC11-Solar-Suitable Land: Area and MW Potential } \\
\hline \multirow{2}{*}{$\begin{array}{l}\text { Distance to } \\
\text { Transmission }\end{array}$} & \multicolumn{2}{|c|}{ 0-1 Miles } & \multicolumn{2}{|c|}{ 1-5 Miles } & \multicolumn{2}{|c|}{ 5-10 Miles } & \multicolumn{2}{|c|}{$>10$ Miles } \\
\hline & Acres & MW & Acres & MW & Acres & MW & Acres & MW \\
\hline BLM & 0 & 0 & 322 & 41 & 3 & 0 & 1 & 0 \\
\hline Federal & 0 & 0 & 328 & 42 & 1,795 & 227 & 424 & 54 \\
\hline Other & 16 & 2 & 7,983 & 1,010 & 14,595 & 1,847 & 88,349 & 11,183 \\
\hline Private & 3,756 & 475 & 60,879 & 7,706 & 26,243 & 3,322 & 24,923 & 3,155 \\
\hline
\end{tabular}

\begin{tabular}{cccccc}
\hline \hline \multicolumn{7}{l}{ PSC11 } & Modeled Solar Capacity \\
\hline Ref & LO-NG & SC-DRT & SC-MT & SC-URT & WC-MT \\
0 & 109 & 405 & 0 & 549 & 0 \\
\hline \hline
\end{tabular}




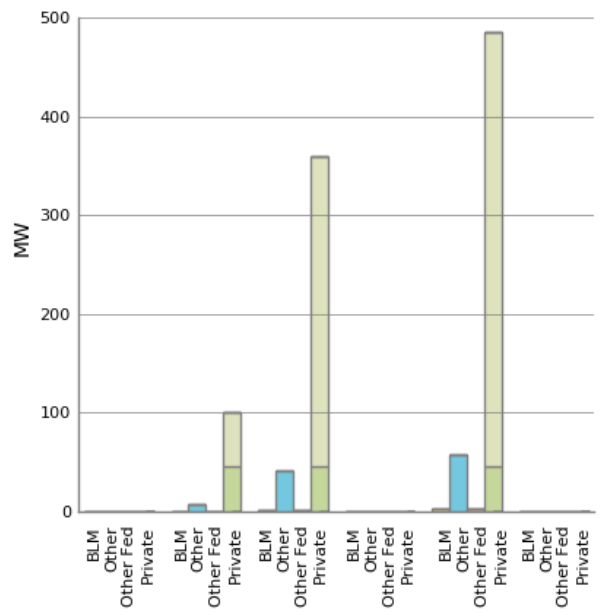

REF LO-NG ST-DRT ST-MT ST-URT WC-MT

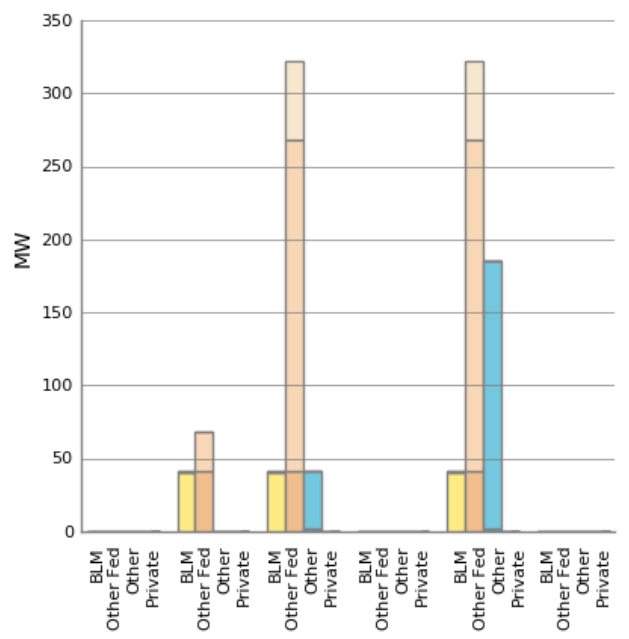

REF LO-NG ST-DRT ST-MT ST-URT WC-MT

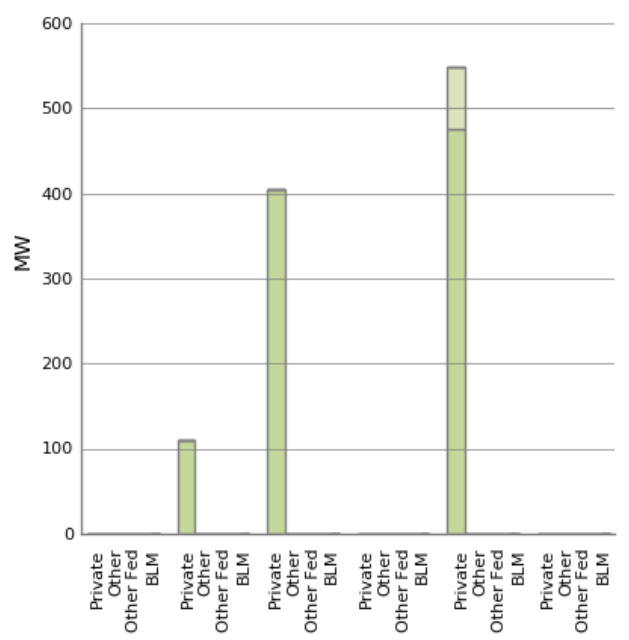

REF LO-NG ST-DRT ST-MT ST-URT WC-MT

\section{Solar
Proportional} Development Preference

PSC11

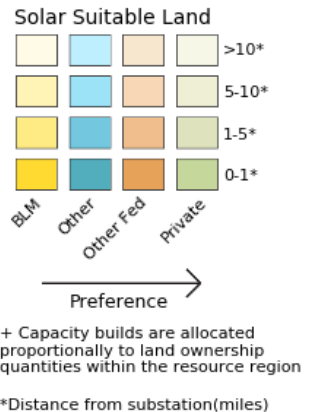

*Distance from substation(miles)

Solar BLM Development Preference

PSC11

Solar Suitable Land $\square \square \square \square>10 *$ $\square \square \square \square-10$ $\square \square \square \square(-5 *$ $\square \square \square \square 0-1^{*}$

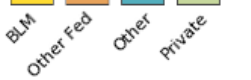
$\underset{\text { Preference }}{>}$

*Distance from substation(miles)

Solar Private Development Preference

PSC11

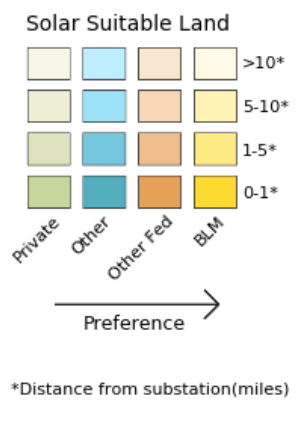




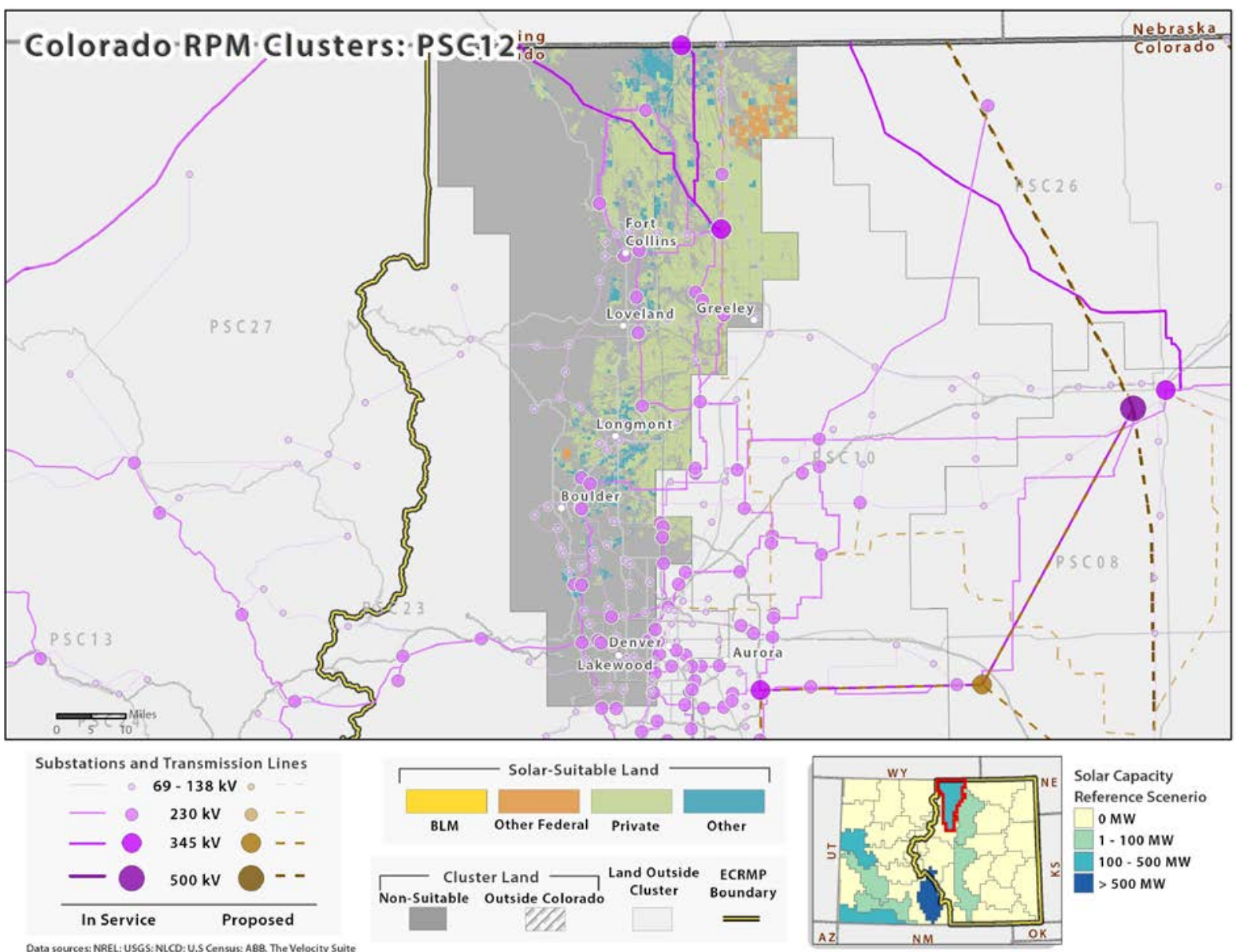

\begin{tabular}{c|cc|cc|cc|cc}
\hline \hline \multicolumn{10}{c}{ PSC12-Solar-Suitable Land: Area and MW Potential } \\
\hline Distance to & \multicolumn{2}{c|}{$\mathbf{0 - 1}$ Miles } & \multicolumn{2}{c}{$\mathbf{1 - 5}$ Miles } & \multicolumn{2}{c}{$\mathbf{5 - 1 0}$ Miles } & \multicolumn{2}{c}{$>$ >10 Miles } \\
Transmission & Acres & MW & Acres & MW & Acres & MW & Acres & MW \\
\hline BLM & 0 & 0 & 1 & 0 & 43 & 12 & 0 & 0 \\
Federal & 4 & 1 & 2,313 & 663 & 15,170 & 4,347 & 3,212 & 920 \\
Other & 3,128 & 896 & 53,761 & 15,404 & 12,438 & 3,564 & 1,782 & 511 \\
Private & 28,706 & 8,225 & 346,056 & 99,156 & 124,534 & 35,683 & 13,002 & 3,725 \\
\hline \hline
\end{tabular}

\begin{tabular}{cccccc}
\hline \hline \multicolumn{7}{l}{ PSC12 } & Modeled Solar Capacity \\
\hline Ref & LO-NG & SC-DRT & SC-MT & SC-URT & WC-MT \\
148 & 200 & 44 & 6 & 18 & 147 \\
\hline \hline
\end{tabular}



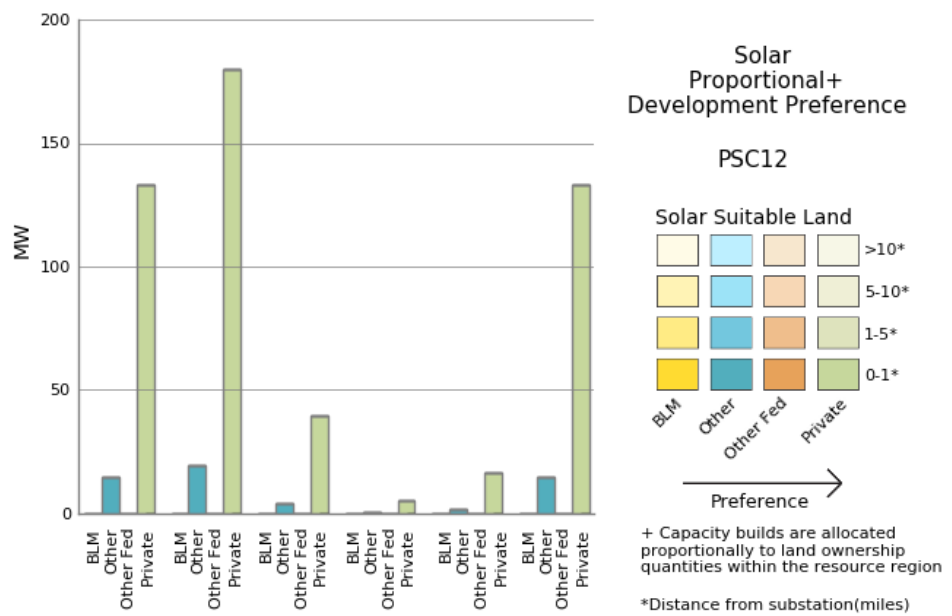

REF LO-NG ST-DRT ST-MT ST-URT WC-MT
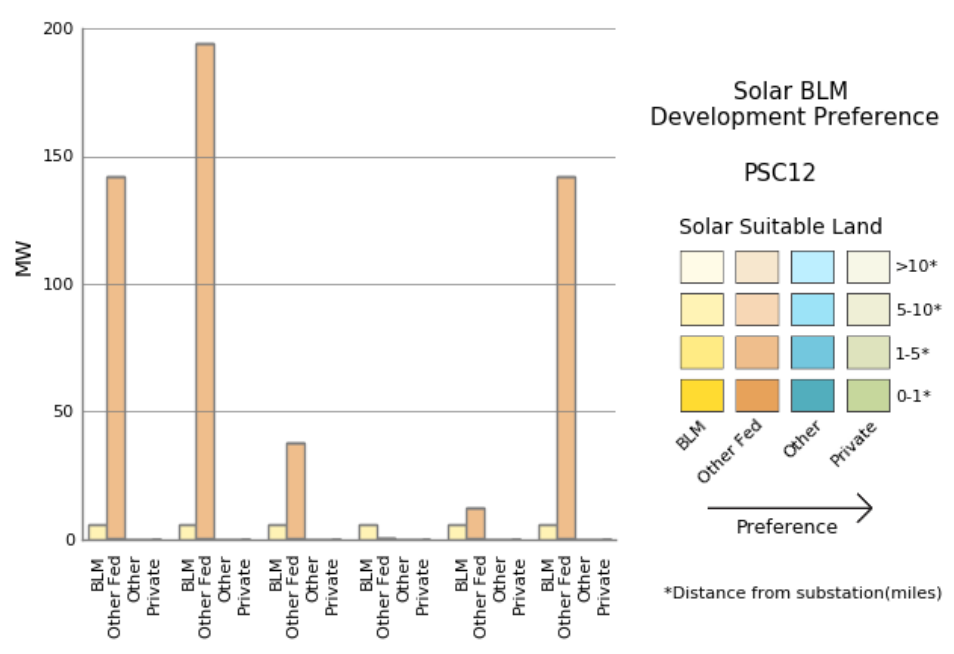

$\mathrm{PSC12}$

Solar Suitable Land $\square \square \square \square>10 *$ $\square \square \square \square-10 *$ $\square \square \square \square 1-5^{*}$ $\square \square \square \square-\square^{*}$

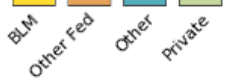
$\underset{\text { Preference }}{\longrightarrow}$ *Distance from substation(miles) REF LO-NG ST-DRT ST-MT ST-URT WC-MT

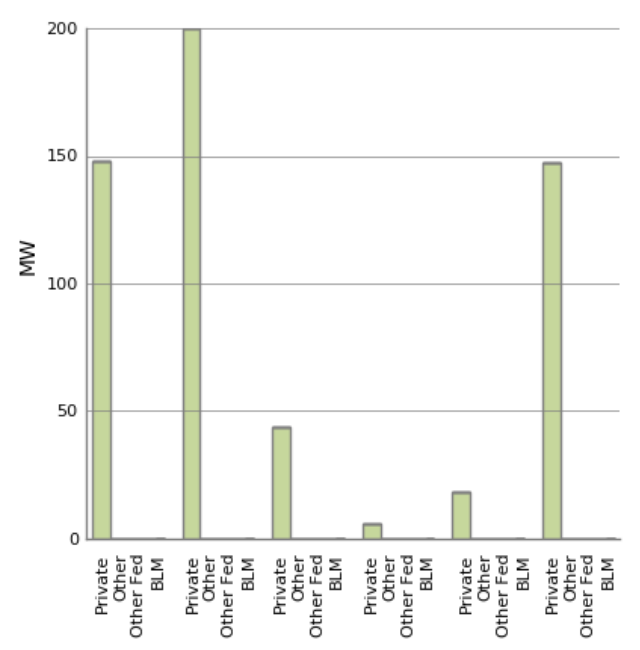

$$
\begin{gathered}
\text { Solar Private } \\
\text { Development Preference } \\
\text { PSC12 }
\end{gathered}
$$

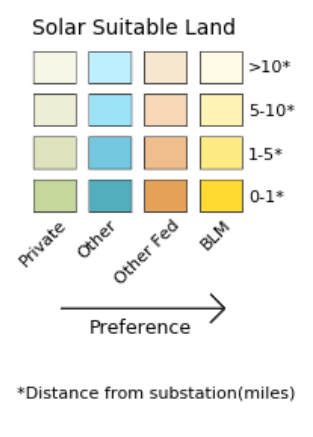

REF LO-NG ST-DRT ST-MT ST-URT WC-MT 


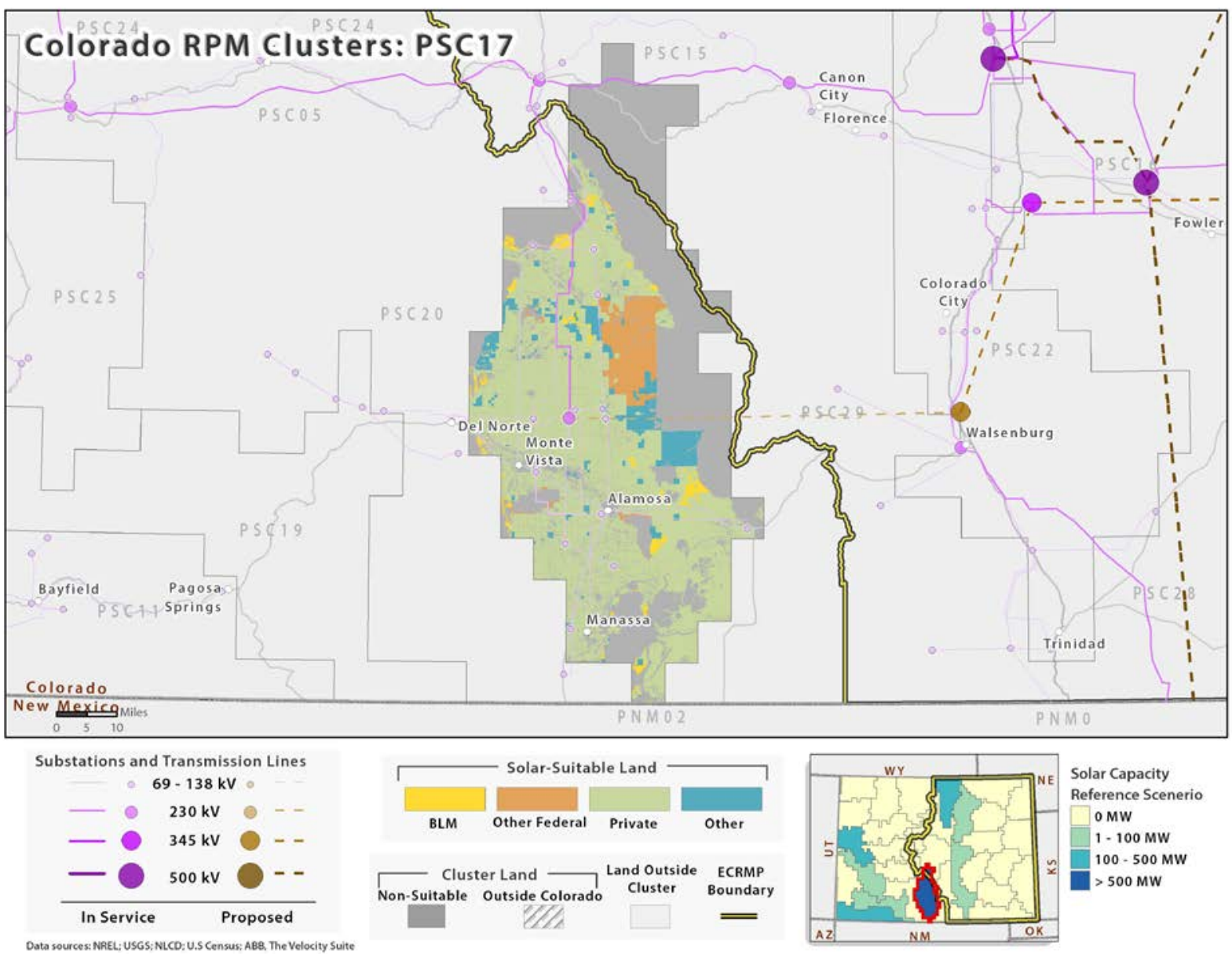

\begin{tabular}{c|cc|cc|cc|cc}
\hline \hline \multicolumn{10}{c}{ PSC17-Solar-Suitable Land: Area and MW Potential } \\
\hline Distance to & \multicolumn{2}{|c|}{$\mathbf{0 - 1}$ Miles } & \multicolumn{2}{|c}{$\mathbf{1 - 5}$ Miles } & \multicolumn{2}{c}{$\mathbf{5 - 1 0}$ Miles } & \multicolumn{2}{c}{$>$ 10 Miles } \\
Transmission & Acres & MW & Acres & MW & Acres & MW & Acres & MW \\
\hline BLM & 86 & 25 & 9,934 & 2,846 & 16,833 & 4,823 & 10,998 & 3,151 \\
Federal & 151 & 43 & 9,417 & 2,698 & 56,086 & 16,070 & 19,218 & 5,507 \\
Other & 684 & 196 & 16,657 & 4,773 & 36,869 & 10,564 & 37,076 & 10,623 \\
Private & 23,994 & 6,875 & 376,762 & 107,955 & 370,048 & 106,031 & 185,197 & 53,065 \\
\hline \hline
\end{tabular}

\begin{tabular}{cccccc}
\hline \hline \multicolumn{7}{l}{ PSC17 } & Modeled Solar Capacity \\
\hline Ref & LO-NG & SC-DRT & SC-MT & SC-URT & WC-MT \\
825 & 443 & 267 & 92 & 149 & 814 \\
\hline \hline
\end{tabular}



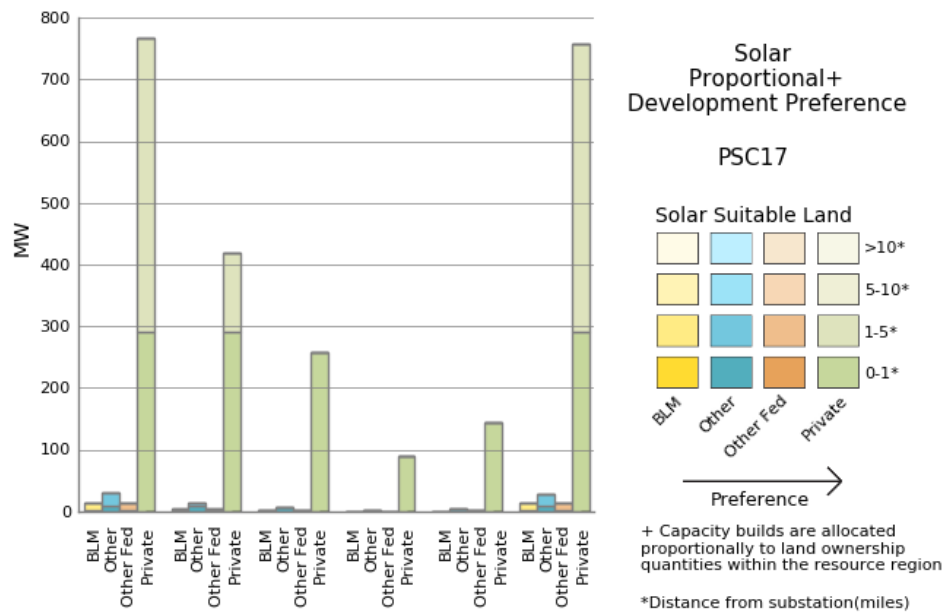

REF LO-NG ST-DRT ST-MT ST-URT WC-MT

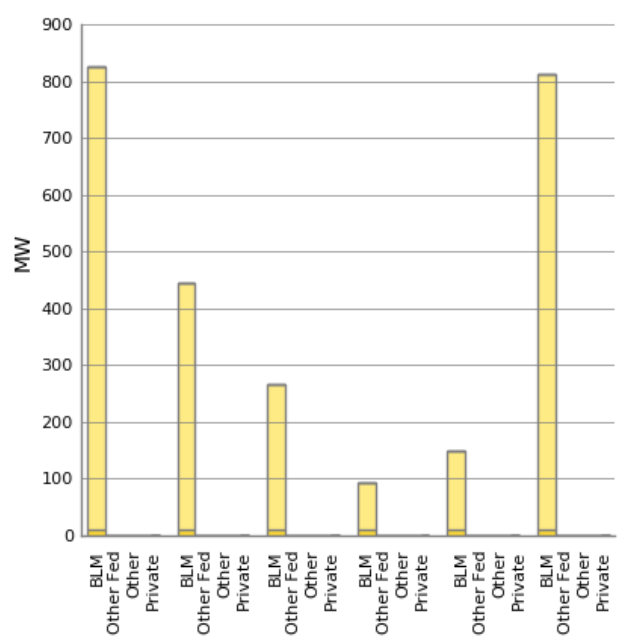

Solar BLM Development Preference

PSC17

Solar Suitable Land $\square \square \square \square>10 *$ $\square \square \square-10 *$ $\square \square \square \square 1-5^{*}$ $\square \square \square \square-1 *$

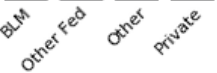
$\underset{\text { Preference }}{>}$

REF LO-NG ST-DRT ST-MT ST-URT WC-MT

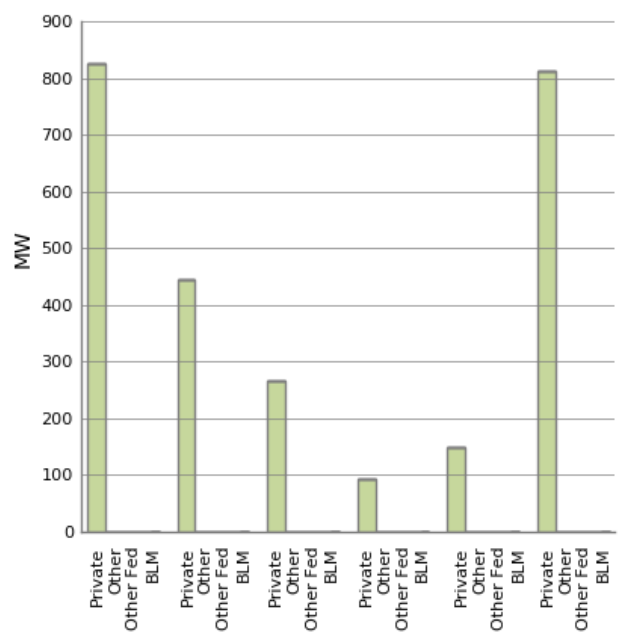

Solar Private Development Preference

PSC17

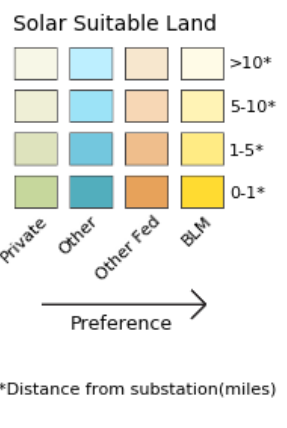

REF LO-NG ST-DRT ST-MT ST-URT WC-MT 


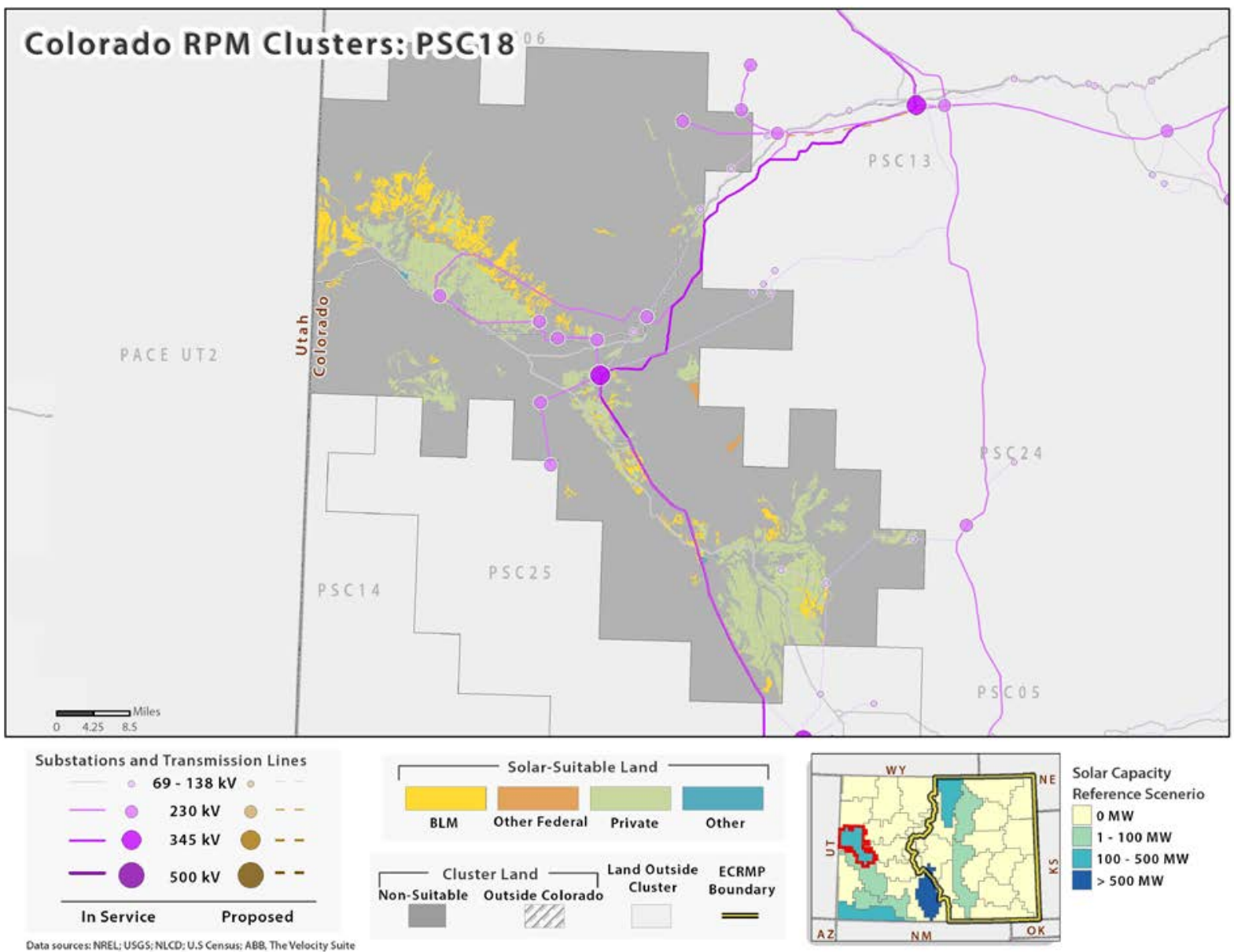

\begin{tabular}{c|cc|cc|cc|cc}
\hline \hline \multicolumn{10}{c}{ PSC18-Solar-Suitable Land: Area and MW Potential } \\
\hline Distance to & \multicolumn{2}{|c|}{$\mathbf{0 - 1}$ Miles } & \multicolumn{2}{c|}{$\mathbf{1 - 5}$ Miles } & \multicolumn{2}{c}{5 -10 Miles } & \multicolumn{2}{c}{$>$ 10 Miles } \\
Transmission & Acres & MW & Acres & MW & Acres & MW & Acres & MW \\
\hline BLM & 209 & 26 & 10,584 & 1,340 & 21,103 & 2,671 & 30,816 & 3,901 \\
Federal & 31 & 4 & 78 & 10 & 1,281 & 162 & 1,271 & 161 \\
Other & 31 & 4 & 328 & 42 & 446 & 56 & 0 & 0 \\
Private & 5,902 & 747 & 72,518 & 9,179 & 75,541 & 9,562 & 15,161 & 1,919 \\
\hline \hline
\end{tabular}

\begin{tabular}{cccccc}
\hline \hline \multicolumn{7}{l}{ PSC18 } & Modeled Solar Capacity \\
\hline Ref & LO-NG & SC-DRT & SC-MT & SC-URT & WC-MT \\
289 & 644 & 0 & 0 & 0 & 300 \\
\hline \hline
\end{tabular}




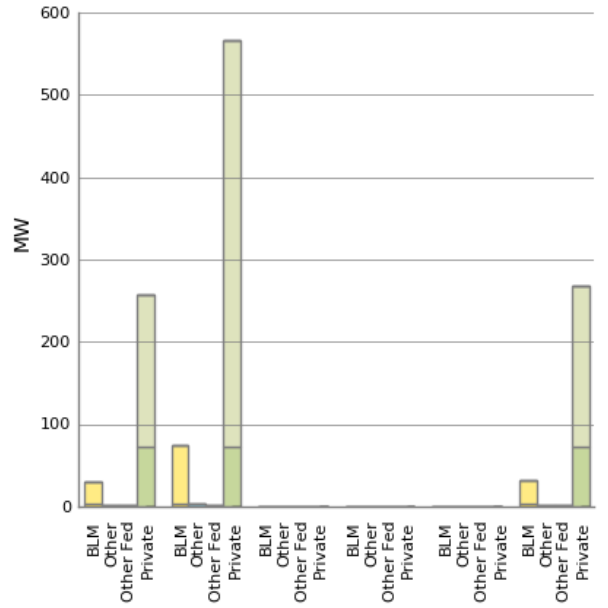

REF LO-NG ST-DRT ST-MT ST-URT WC-MT

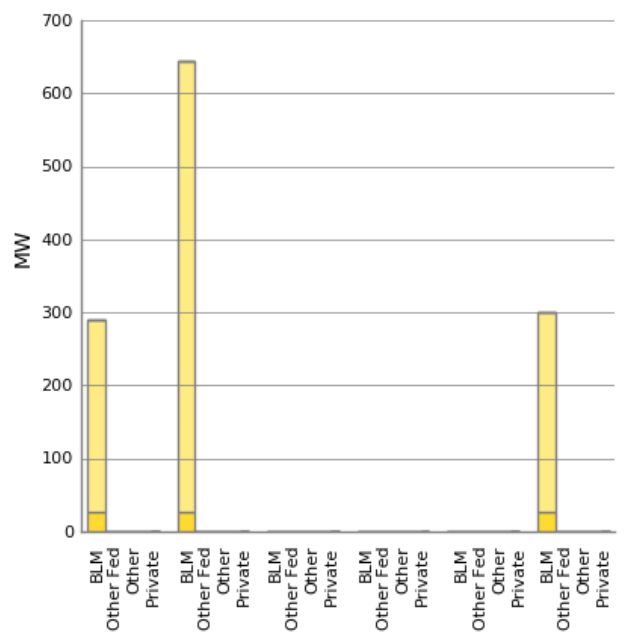

REF LO-NG ST-DRT ST-MT ST-URT WC-MT

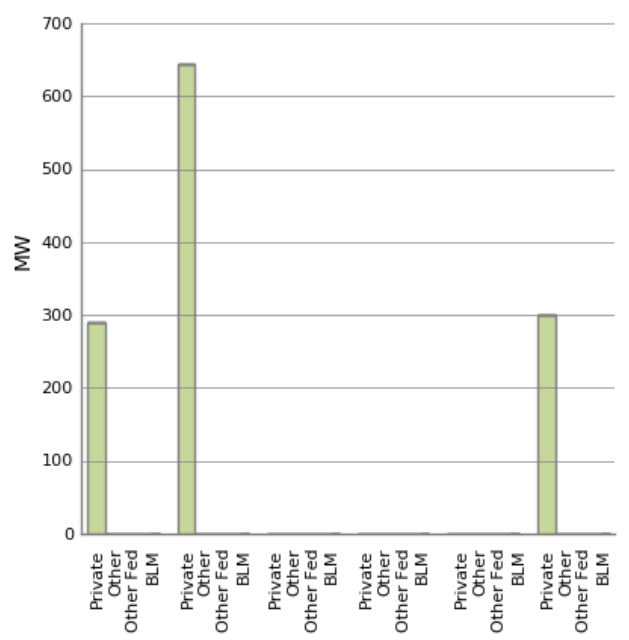

REF LO-NG ST-DRT ST-MT ST-URT WC-MT
Solar

Proportional+

Development Preference

PSC18

Solar Suitable Land

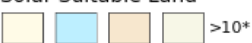

$\square \square \square \square-10 *$

$\square \square \square \square 1-5 *$

$\square \square \square \square 0-\square^{*}$

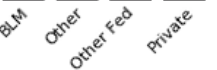

Preference $>$

Capacity builds are allocated proportionally to land ownership

*Distance from substation(miles)

Development Preference

PSC18

Solar Suitable Land

$\square \square \square \square>10 *$

$\square \square \square-\square-10^{*}$

$\square \square \square \square$ (-5*

$\square \square \square \square 0-1 *$

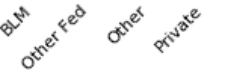

$\underset{\text { Preference }}{>}$

*Distance from substation(miles)

Solar Private Development Preference

PSC18

Solar Suitable Land
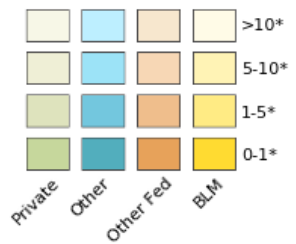

Preference $>$

*Distance from substation(miles)

This report is available at no cost from the National Renewable Energy Laboratory at www.nrel.gov/publications. 

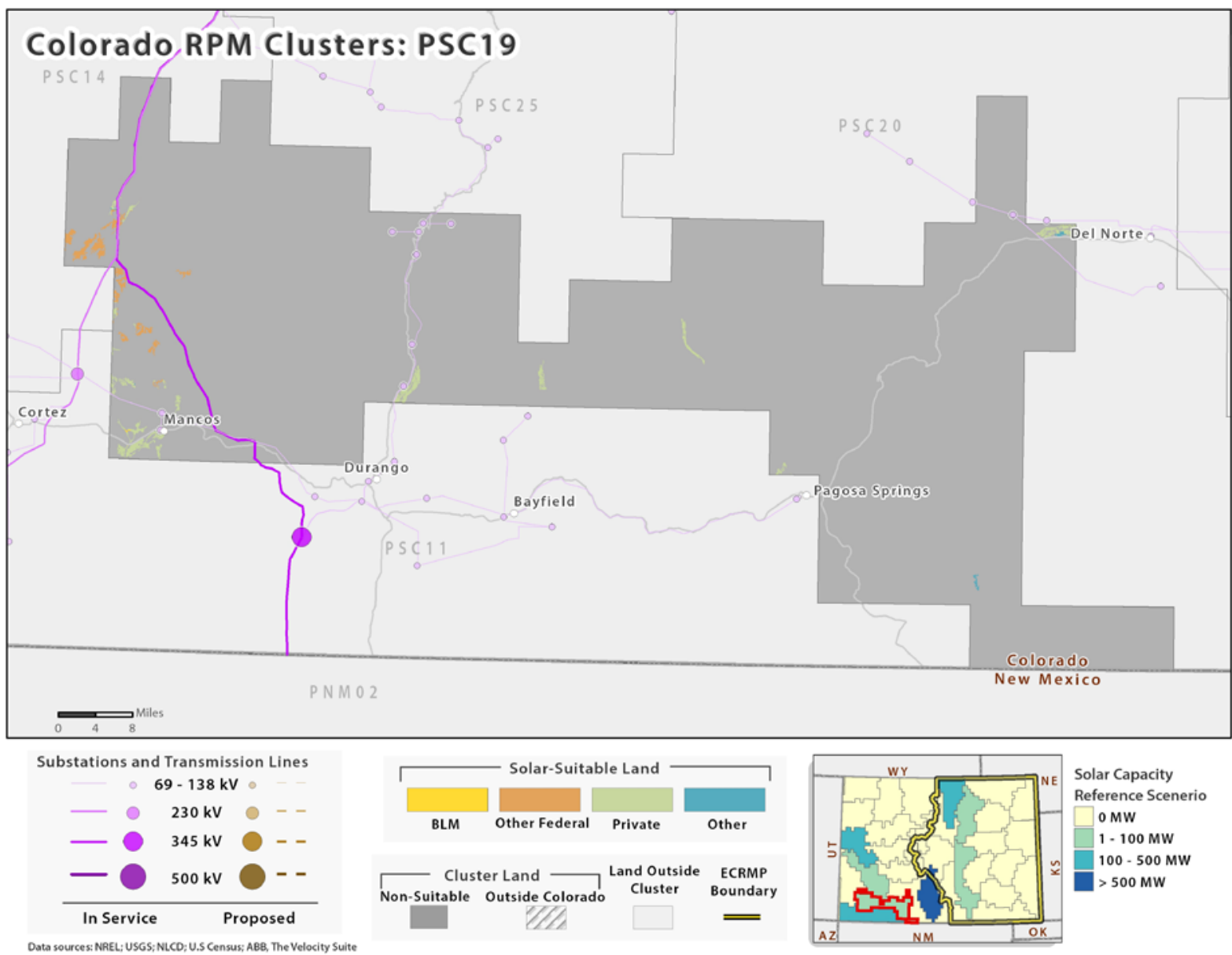

Data sources NRELL:USGS: NLCD: U.S Census; AEB, The Velocity Suite

\begin{tabular}{c|cc|cc|cc|cc}
\hline \hline \multicolumn{1}{c}{ PSC19-Solar-Suitable Land: Area and MW Potential } \\
\hline $\begin{array}{c}\text { Distance to } \\
\text { Transmission }\end{array}$ & \multicolumn{2}{c|}{-1 Miles } & \multicolumn{2}{c|}{$\mathbf{1 - 5}$ Miles } & \multicolumn{2}{c}{$\mathbf{5 - 1 0}$ Miles } & \multicolumn{2}{c}{$>$ 10 Miles } \\
Acres & MW & Acres & MW & Acres & MW & Acres & MW \\
\hline BLM & 0 & 0 & 58 & 17 & 0 & 0 & 0 & 0 \\
Federal & 0 & 0 & 145 & 42 & 3,679 & 1,054 & 3,308 & 948 \\
Other & 0 & 0 & 221 & 63 & 0 & 0 & 289 & 83 \\
Private & 1,038 & 297 & 8,229 & 2,358 & 737 & 211 & 1,618 & 464 \\
\hline \hline
\end{tabular}

\begin{tabular}{cccccc}
\hline \hline \multicolumn{1}{l}{ PSC19 } & Modeled Solar Capacity \\
\hline Ref & LO-NG & SC-DRT & SC-MT & SC-URT & WC-MT \\
2 & 2 & 0 & 0 & 2 & 2 \\
\hline \hline
\end{tabular}



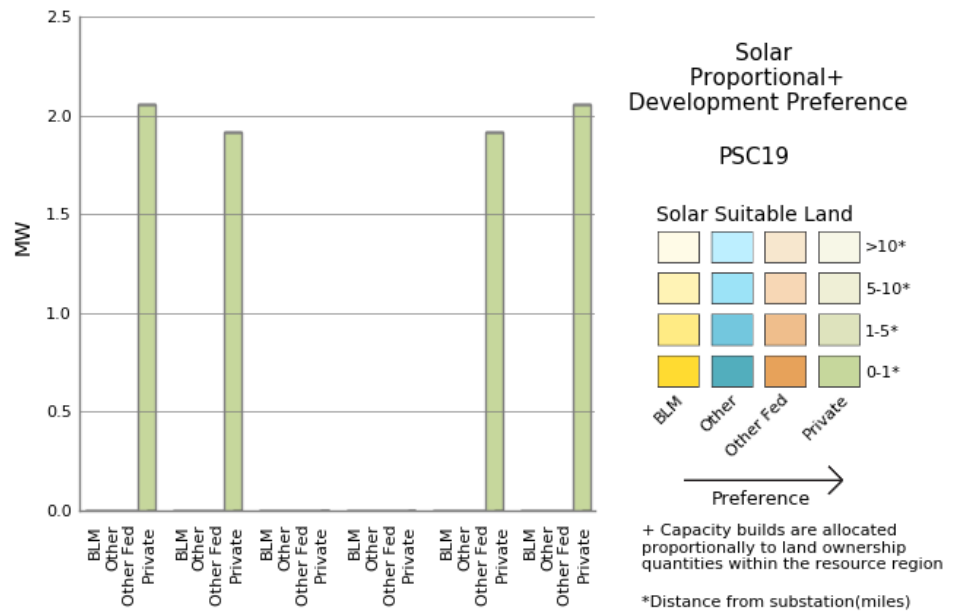

REF LO-NG ST-DRT ST-MT ST-URT WC-MT

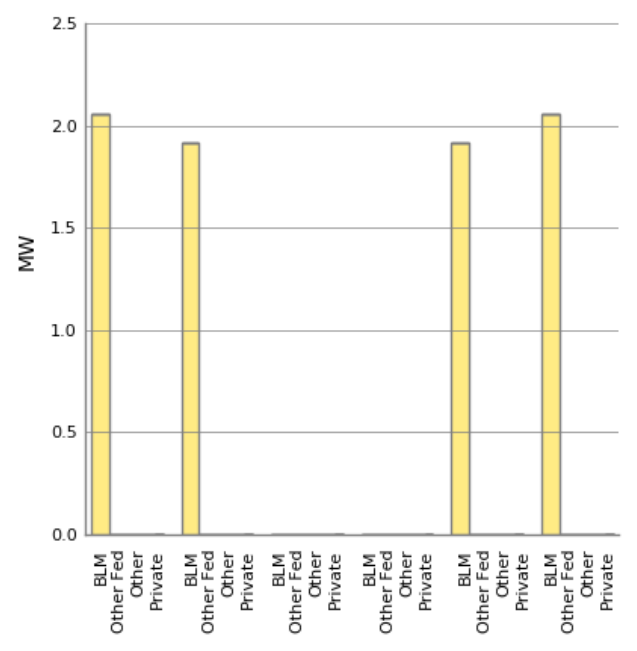

Solar BLM
Development Preference

PSC19

Solar Suitable Land

$\square \square \square \square>10 *$

$\square \square \square \square-10^{*}$

$\square \square \square \square 1-5^{*}$

$\square \square \square \square 0-1 *$

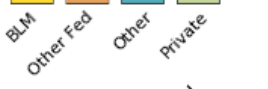

$\underset{\text { Preference }}{>}$

REF LO-NG ST-DRT ST-MT ST-URT WC-MT

*Distance from substation(miles)

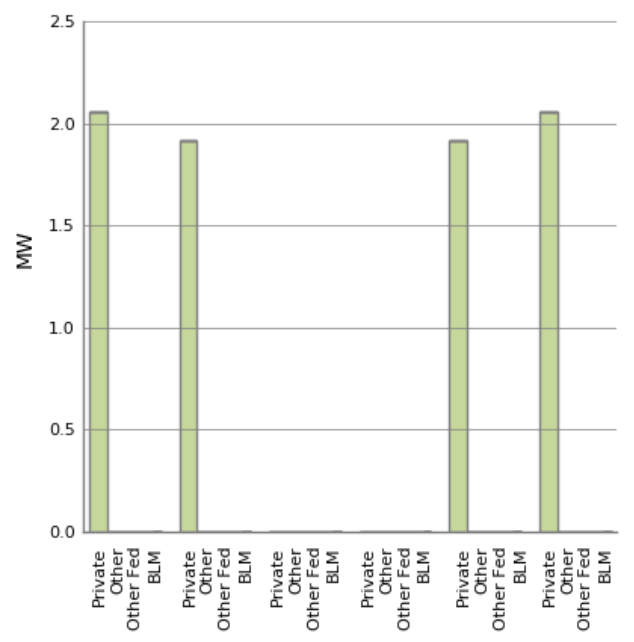

Solar Private

Development Preference

PSC19

Solar Suitable Land

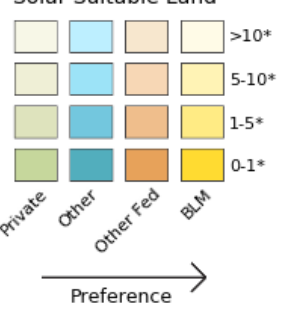

*Distance from substation(miles)

REF LO-NG ST-DRT ST-MT ST-URT WC-MT 


\section{PSC21 Solar Resource Region}

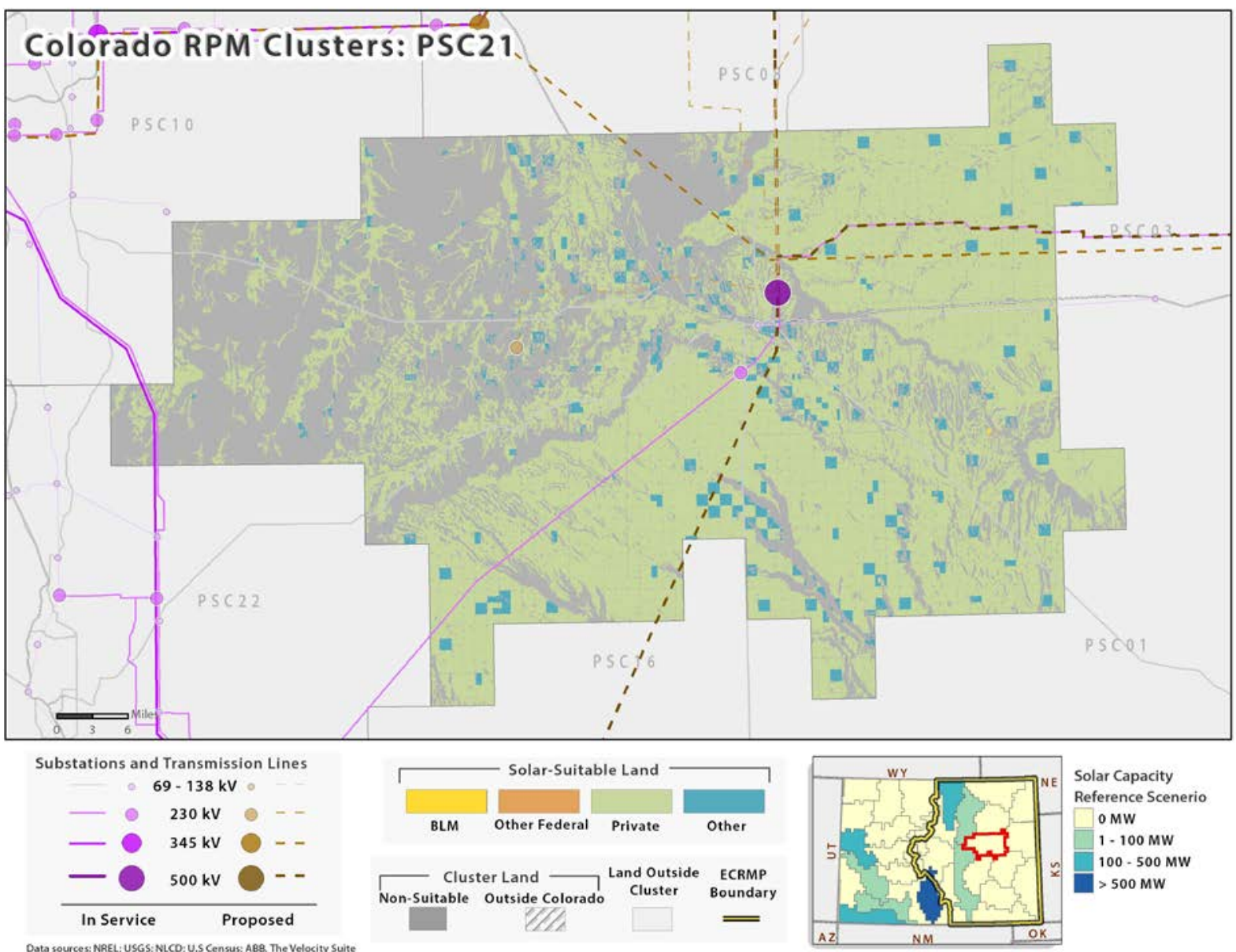

\begin{tabular}{c|cc|cc|cc|cc}
\hline \hline \multicolumn{10}{c}{ PSC21-Solar-Suitable Land: Area and MW Potential } \\
\hline Distance to & \multicolumn{2}{|c|}{$\mathbf{0 - 1}$ Miles } & \multicolumn{2}{c|}{$\mathbf{1 - 5}$ Miles } & \multicolumn{2}{c}{$\mathbf{5 - 1 0}$ Miles } & \multicolumn{2}{c}{$>$ 10 Miles } \\
Transmission & Acres & MW & Acres & MW & Acres & MW & Acres & MW \\
\hline BLM & 0 & 0 & 0 & 0 & 0 & 0 & 96 & 12 \\
Federal & 0 & 0 & 0 & 0 & 0 & 0 & 0 & 0 \\
Other & 470 & 60 & 7,842 & 993 & 14,026 & 1,776 & 42,102 & 5,329 \\
Private & 3,880 & 491 & 70,100 & 8,873 & 212,291 & 26,872 & 775,946 & 98,221 \\
\hline \hline
\end{tabular}

\begin{tabular}{cccccc}
\hline \hline \multicolumn{7}{l}{ PSC21 } & Modeled Solar Capacity \\
\hline Ref & LO-NG & SC-DRT & SC-MT & SC-URT & WC-MT \\
0 & 202 & 93 & 0 & 50 & 0 \\
\hline \hline
\end{tabular}



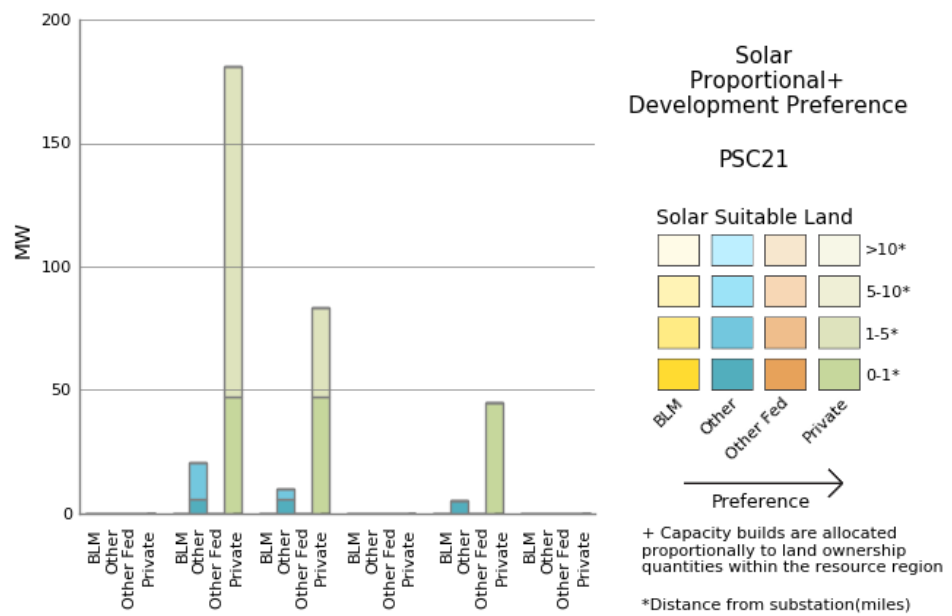

REF LO-NG ST-DRT ST-MT ST-URT WC-MT
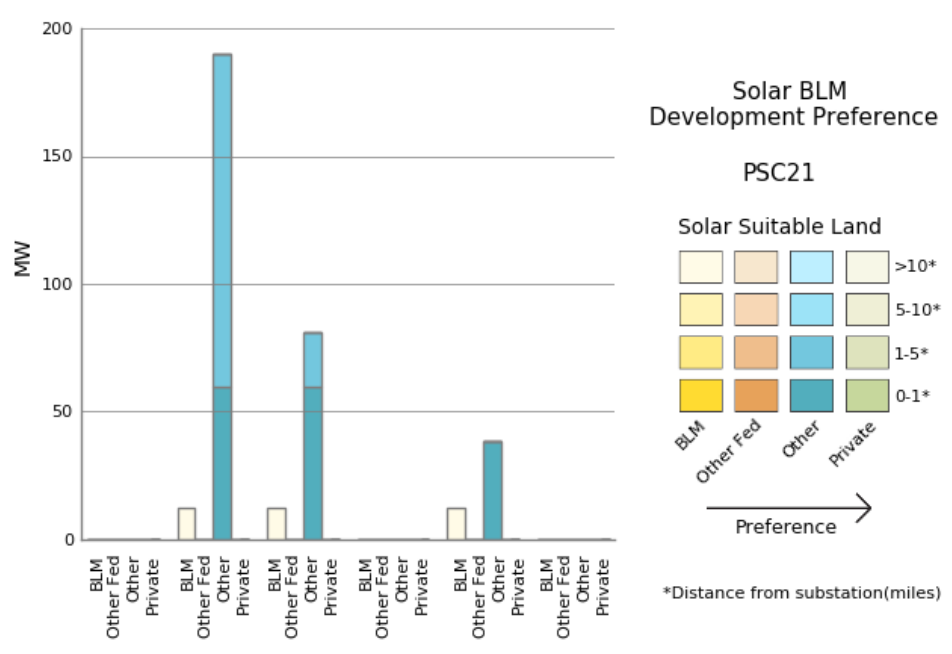

PSC21

Solar Suitable Land $\square \square \square \square>10 *$ $\square \square \square \square$ 5-10* $\square \square \square \square \square_{1-5 *}^{*}$ $\square \square \square \square \square^{0.1 *}$

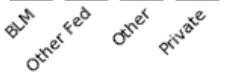
$\underset{\text { Preference }}{\longrightarrow}$

REF LO-NG ST-DRT ST-MT ST-URT WC-MT *Distance from substation(miles)

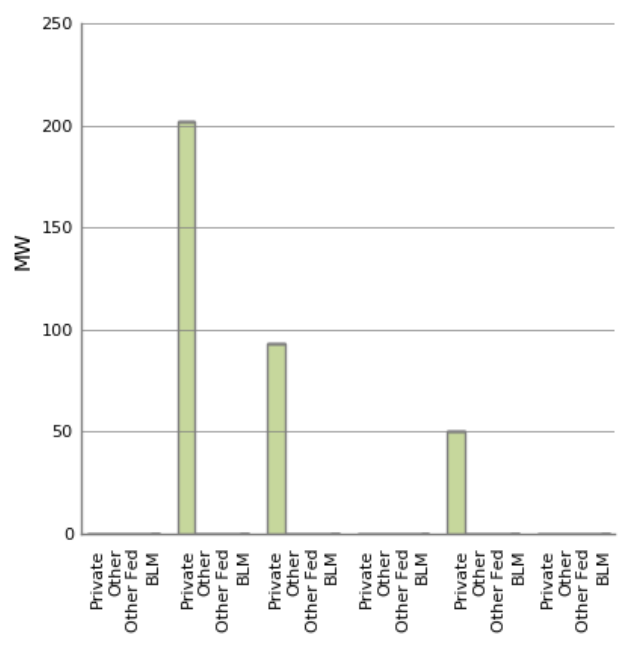

Solar Private Development Preference

\section{PSC21}

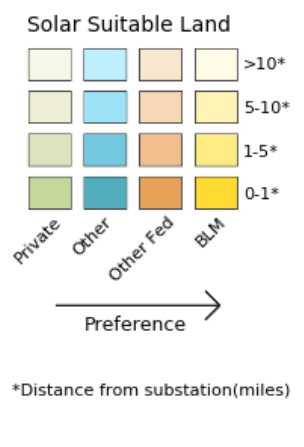

REF LO-NG ST-DRT ST-MT ST-URT WC-MT 


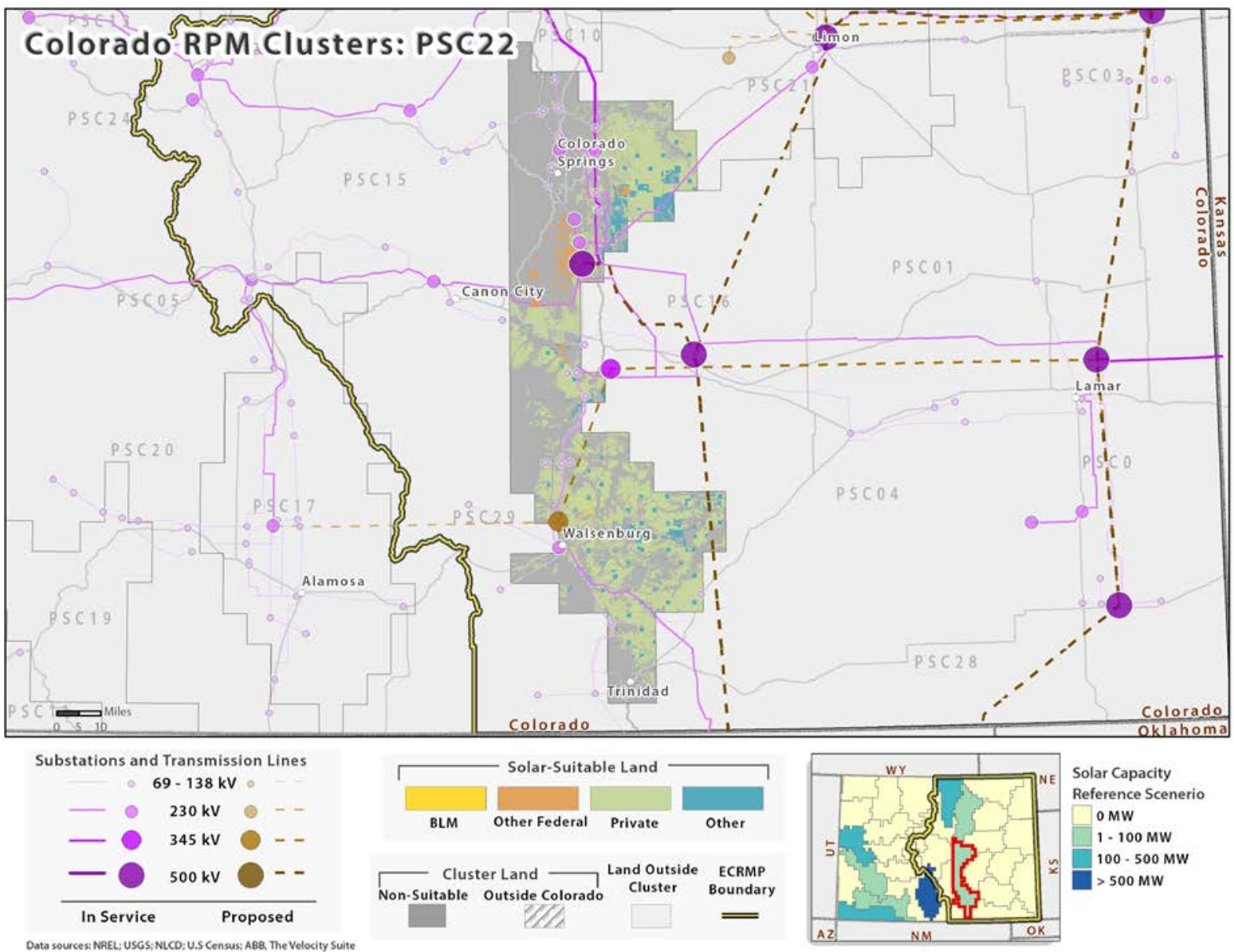

\begin{tabular}{c|cc|cc|cc|cc}
\hline \hline \multicolumn{10}{c}{ PSC22-Solar-Suitable Land: Area and MW Potential } \\
\hline Distance to & \multicolumn{2}{c|}{$\mathbf{0 - 1}$ Miles } & \multicolumn{2}{c}{$\mathbf{1 - 5}$ Miles } & \multicolumn{2}{c}{$\mathbf{5 - 1 0}$ Miles } & \multicolumn{2}{c}{$>$ 10 Miles } \\
Transmission & Acres & MW & Acres & MW & Acres & MW & Acres & MW \\
\hline BLM & 0 & 0 & 506 & 145 & 1,651 & 473 & 718 & 206 \\
Federal & 14 & 4 & 17,372 & 4,978 & 12,380 & 3,547 & 2,879 & 825 \\
Other & 613 & 176 & 17,010 & 4,874 & 26,880 & 7,702 & 55,287 & 15,842 \\
Private & 15,939 & 4,567 & 209,334 & 59,981 & 301,807 & 86,478 & 311,033 & 89,121 \\
\hline \hline
\end{tabular}

\begin{tabular}{cccccc}
\hline \hline \multicolumn{7}{l}{ PSC22 } & - Modeled Solar Capacity \\
\hline Ref & LO-NG & SC-DRT & SC-MT & SC-URT & WC-MT \\
8 & 34 & 8 & 8 & 8 & 8 \\
\hline \hline
\end{tabular}




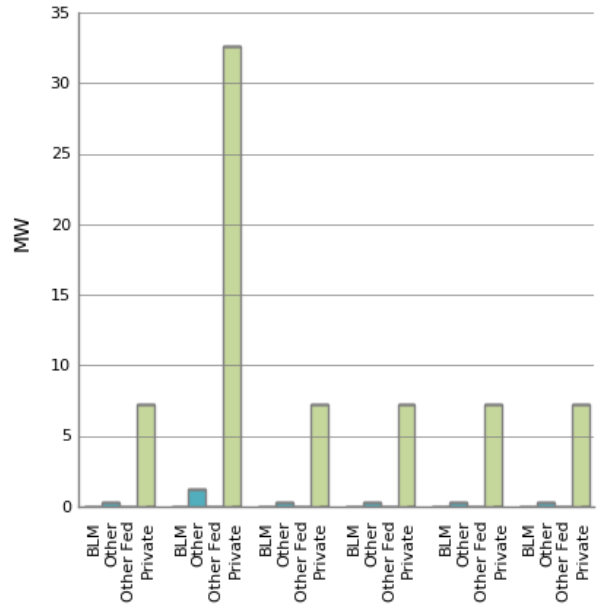

REF LO-NG ST-DRT ST-MT ST-URT WC-MT

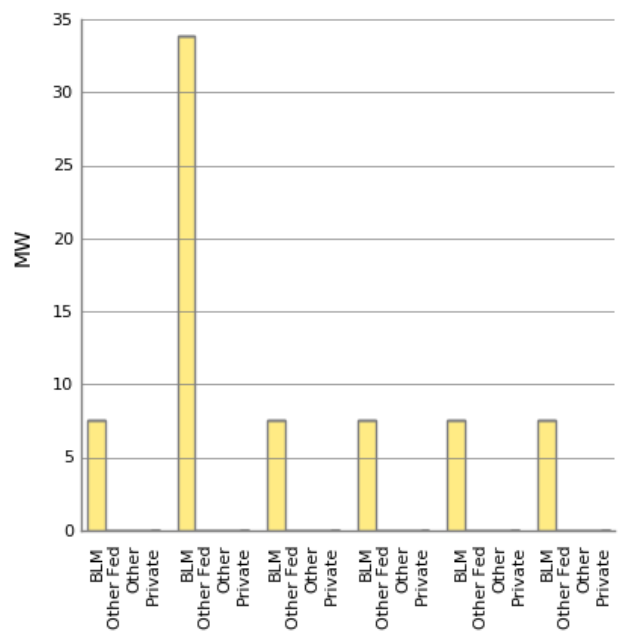

REF LO-NG ST-DRT ST-MT ST-URT WC-MT

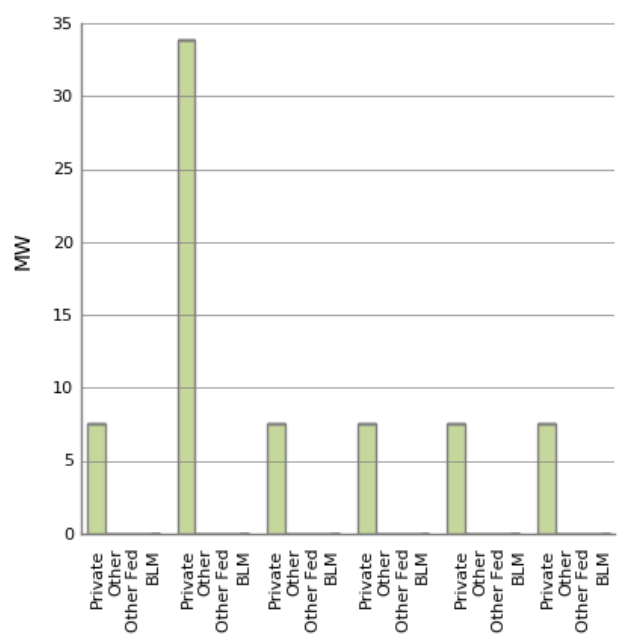

REF LO-NG ST-DRT ST-MT ST-URT WC-MT
Solar

Proportional+

Development Preference

PSC22

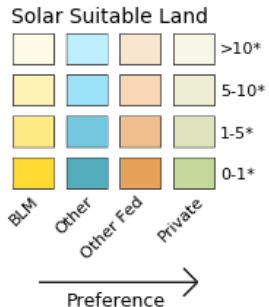

Capacity builds are allocated proportionally to land ownership

*Distance from substation(miles)

Solar BLM Development Preference

PSC22

Solar Suitable Land $\square \square \square \square>10 *$ $\square \square \square-\square-10^{*}$ $\square \square \square \square(-5 *$ $\square \square \square \square 0-1^{*}$

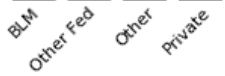
$\underset{\text { Preference }}{>}$

*Distance from substation(miles)

Solar Private Development Preference

PSC22

Solar Suitable Land

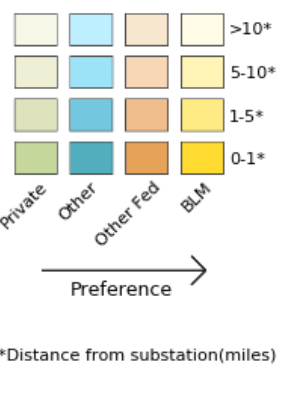




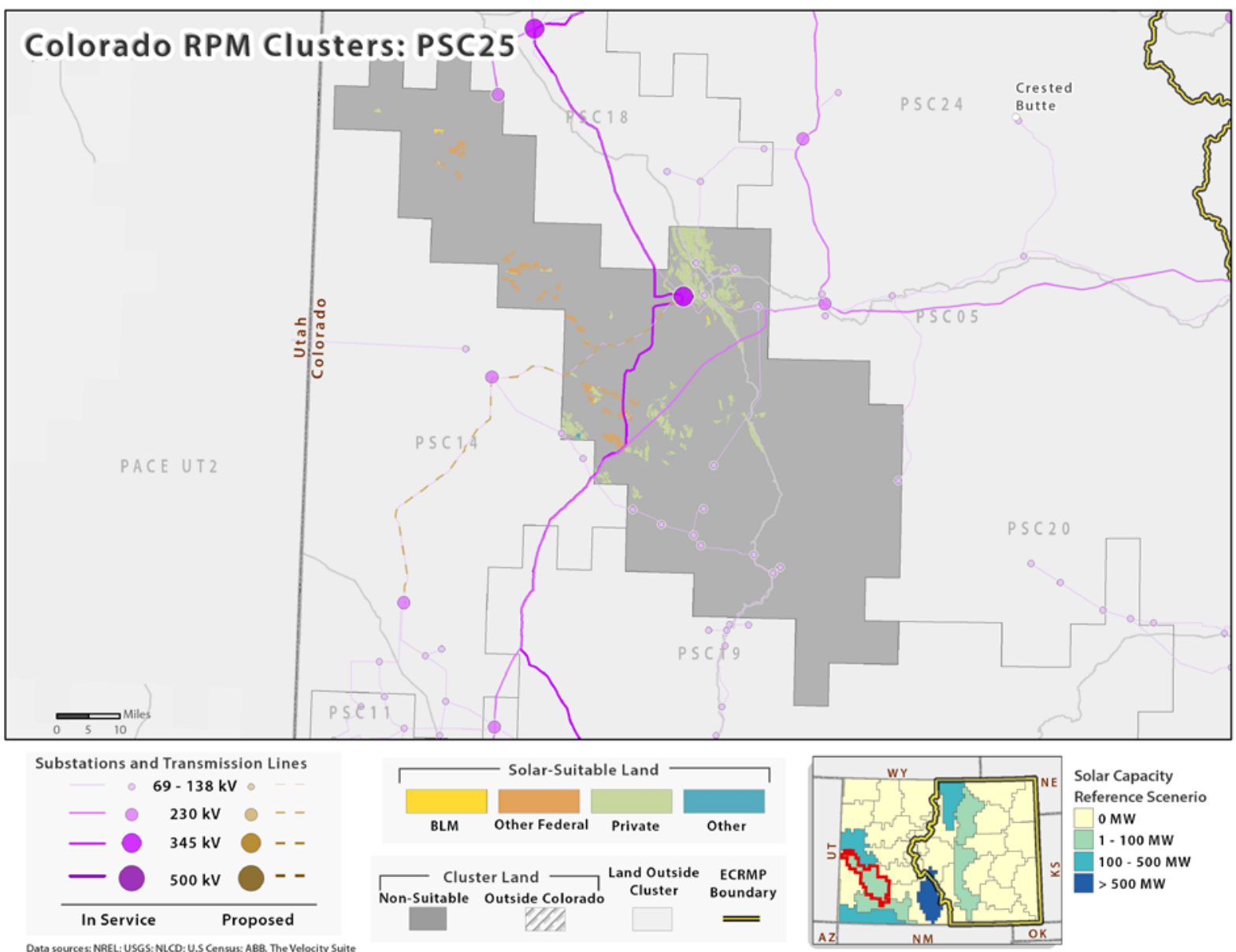

\begin{tabular}{c|cc|cc|cc|cc}
\hline \hline \multicolumn{8}{c}{ PSC25-Solar-Suitable Land: Area and MW Potential } \\
\hline Distance to & \multicolumn{2}{|c|}{$\mathbf{0 - 1}$ Miles } & \multicolumn{2}{c|}{$\mathbf{1 - 5}$ Miles } & \multicolumn{2}{c}{5 -10 Miles } & \multicolumn{2}{c}{$>$ 10 Miles } \\
Transmission & Acres & MW & Acres & MW & Acres & MW & Acres & MW \\
\hline BLM & 25 & 7 & 433 & 124 & 57 & 16 & 443 & 127 \\
Federal & 0 & 0 & 241 & 69 & 5,756 & 1,649 & 9,800 & 2,808 \\
Other & 0 & 0 & 338 & 97 & 75 & 21 & 0 & 0 \\
Private & 3,447 & 988 & 39,198 & 11,231 & 16,890 & 4,840 & 7,986 & 2,288 \\
\hline \hline
\end{tabular}

\begin{tabular}{cccccc}
\hline \hline \multicolumn{7}{l}{ PSC25- Modeled Solar Capacity } \\
\hline Ref & LO-NG & SC-DRT & SC-MT & SC-URT & WC-MT \\
1 & 1 & 1 & 1 & 1 & 1 \\
\hline \hline
\end{tabular}



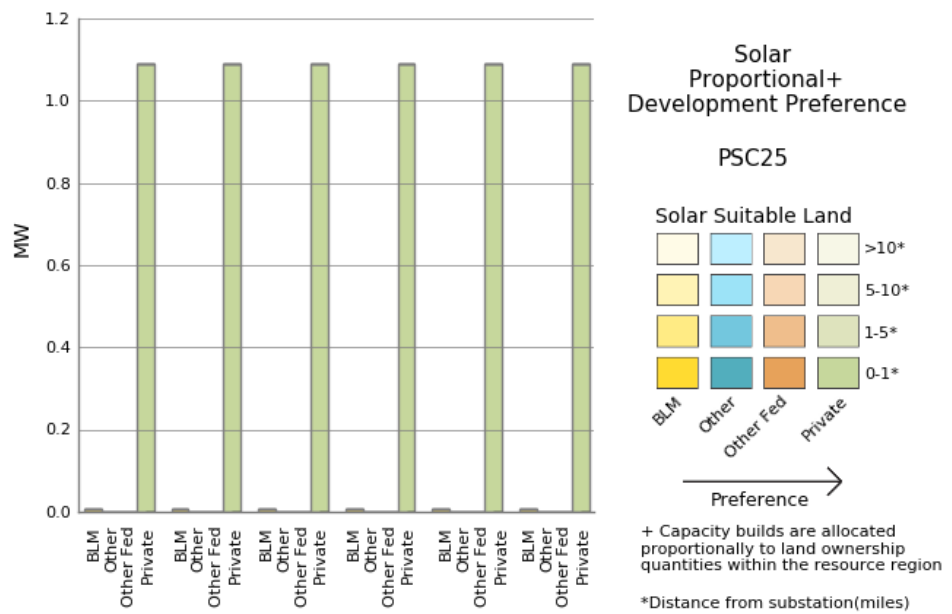

REF LO-NG ST-DRT ST-MT ST-URT WC-MT

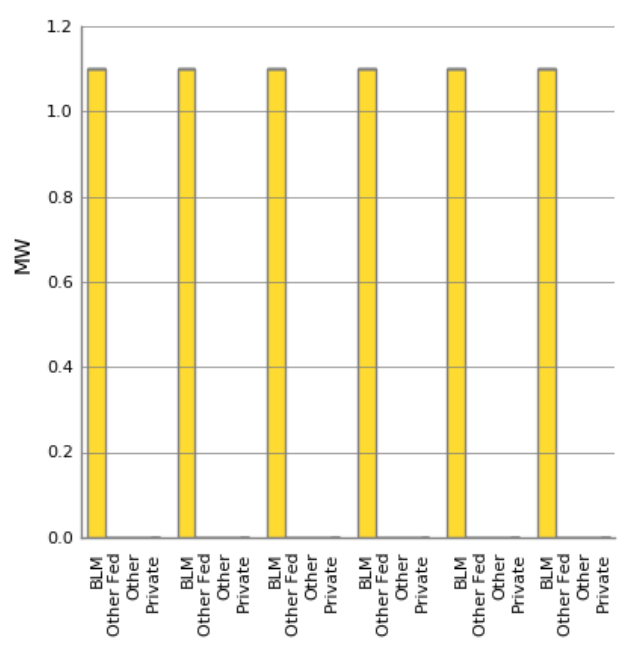

Solar BLM
Development Preference

PSC25

Solar Suitable Land

$\square \square \square \square>10 *$

$\square \square \square \square-10 *$

$\square \square \square \square 1-5^{*}$

$\square \square \square-\square-1^{*}$

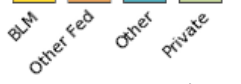

$\underset{\text { Preference }}{\longrightarrow}$

REF LO-NG ST-DRT ST-MT ST-URT WC-MT

*Distance from substation(miles)

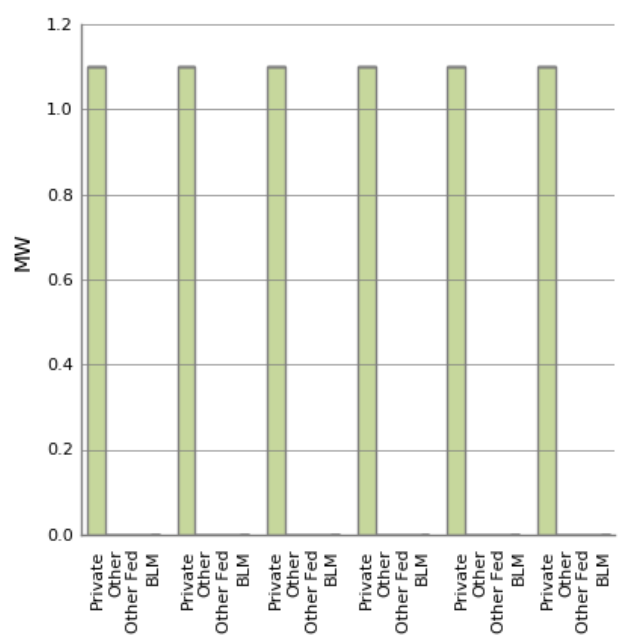

Solar Private Development Preference

PSC25

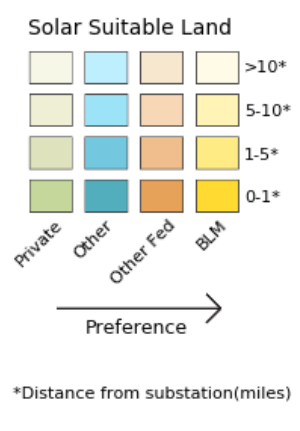

REF LO-NG ST-DRT ST-MT ST-URT WC-MT

This report is available at no cost from the National Renewable Energy Laboratory at www.nrel.gov/publications. 


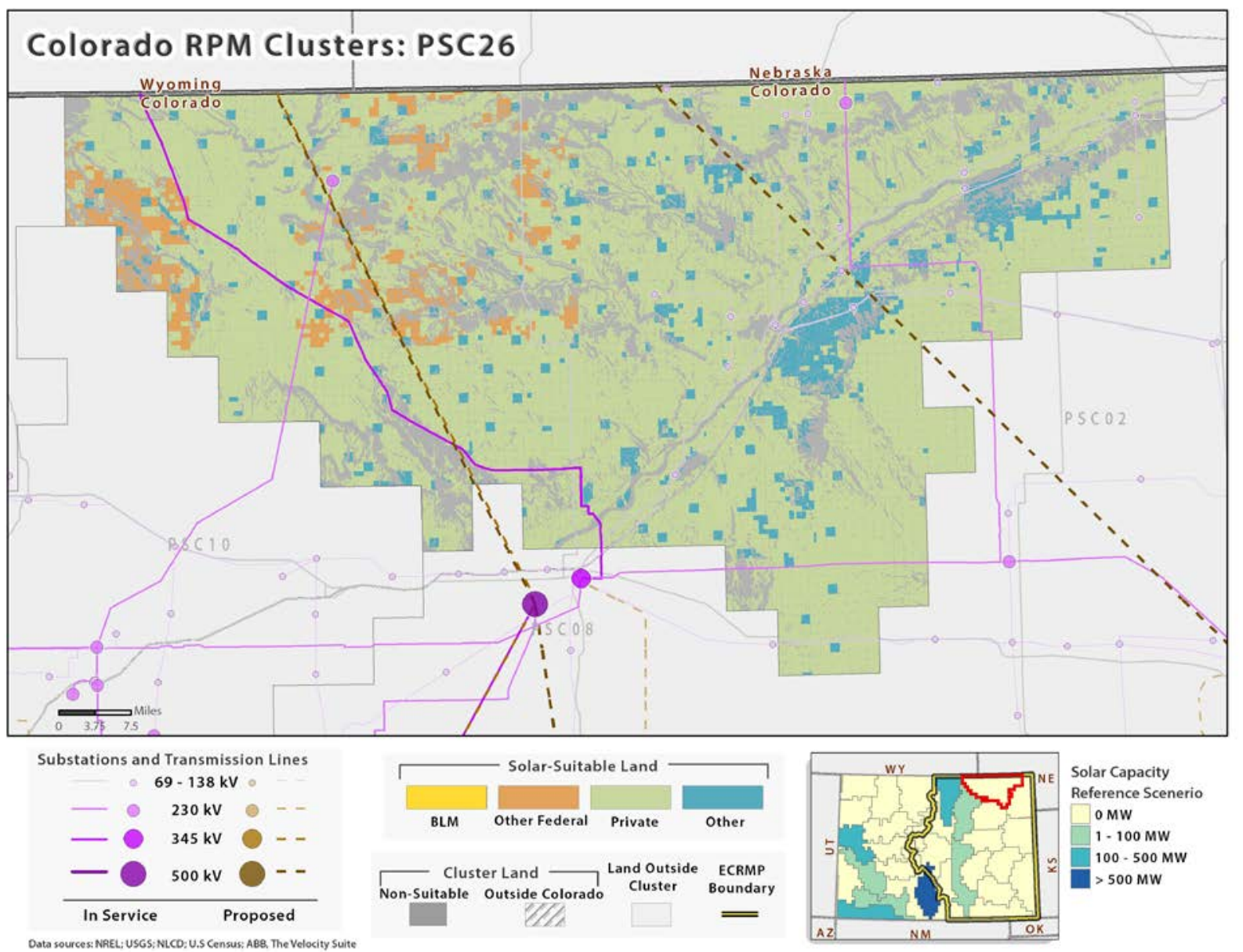

\begin{tabular}{c|cc|cc|cc|cc}
\hline \hline \multicolumn{10}{c}{ PSC26-Solar-Suitable Land: Area and MW Potential } \\
\hline $\begin{array}{c}\text { Distance to } \\
\text { Transmission }\end{array}$ & \multicolumn{2}{c|}{ A-1 Miles } & \multicolumn{2}{c|}{$\mathbf{1 - 5}$ Miles } & \multicolumn{2}{c}{$\mathbf{5 - 1 0}$ Miles } & \multicolumn{2}{c}{$>$ 10 Miles } \\
\hline BLM & 0 & 0 & 17 & 2 & 87 & 11 & 45 & 6 \\
Federal & 0 & 0 & 1,445 & 183 & 12,119 & 1,534 & 92,805 & 11,747 \\
Other & 3,081 & 390 & 62,334 & 7,890 & 68,247 & 8,639 & 48,961 & 6,198 \\
Private & 29,382 & 3,719 & 458,014 & 57,977 & 670,581 & 84,884 & 772,551 & 97,791 \\
\hline \hline
\end{tabular}

\begin{tabular}{cccccc}
\hline \hline \multicolumn{7}{l}{ PSC26- } & Modeled Solar Capacity \\
\hline Ref & LO-NG & SC-DRT & SC-MT & SC-URT & WC-MT \\
4 & 19 & 0 & 0 & 0 & 4 \\
\hline \hline
\end{tabular}




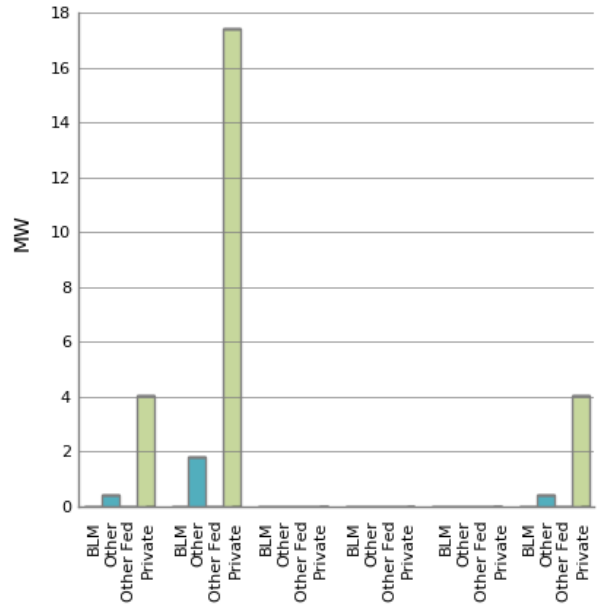

REF LO-NG ST-DRT ST-MT ST-URT WC-MT

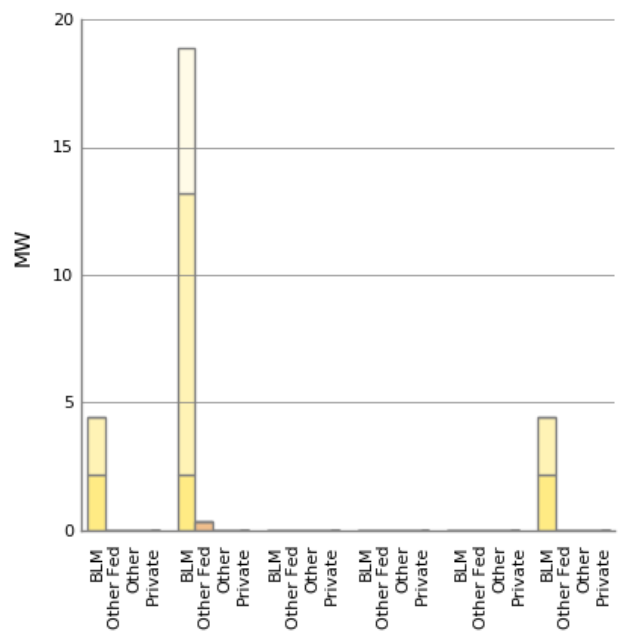

REF LO-NG ST-DRT ST-MT ST-URT WC-MT

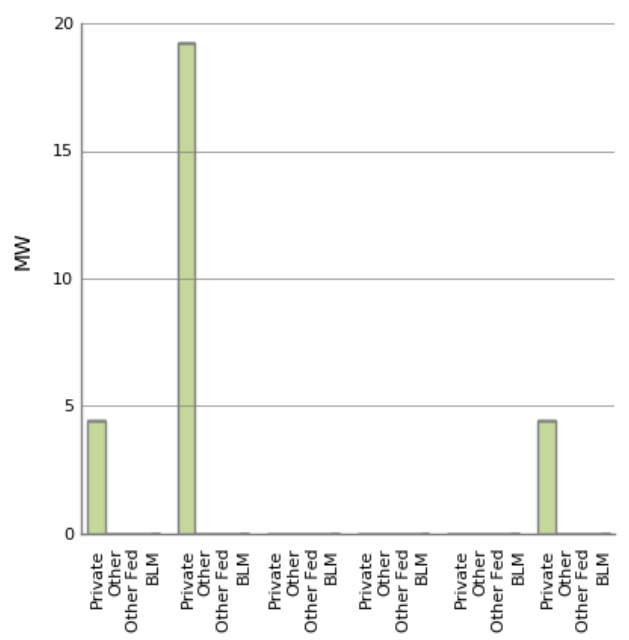

REF LO-NG ST-DRT ST-MT ST-URT WC-MT
Solar
Proportional+ Development Preference

PSC26

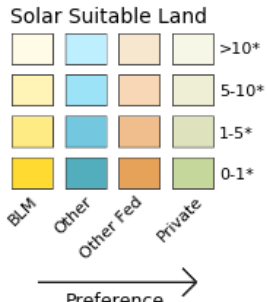

Capacity builds are allocated proportionally to land ownership *Distance from substation(miles) Development Preference

PSC26

Solar Suitable Land $\square \square \square \square>10 *$ $\square \square \square \square-10^{*}$ $\square \square \square \square(-5 *$ $\square \square \square \square 0-1^{*}$

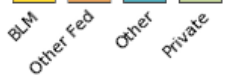

$\underset{\text { Preference }}{>}$

*Distance from substation(miles)

Solar Private Development Preference

PSC26

Solar Suitable Land

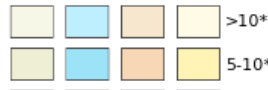

$\square \square \square \square$ 1-5*
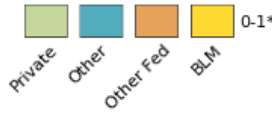

Preference $>$

*Distance from substation(miles) 